A \102 572ᄅ07

MEFEREMEE

NBS

PUBLICATIONS

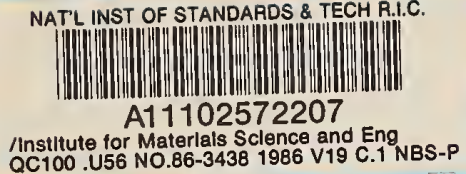

Institute for Materials Science and Engineering

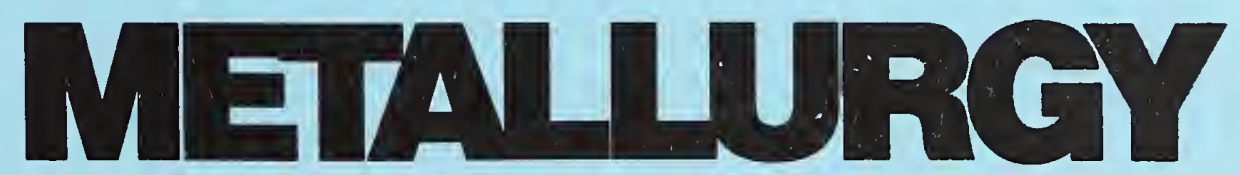

NBSIR $86-3438$

U.S. Department of Commerce National Bureau of Standards

\section{- $\mathrm{CC}$ \\ 100 \\ .1156 \\ 86-3438

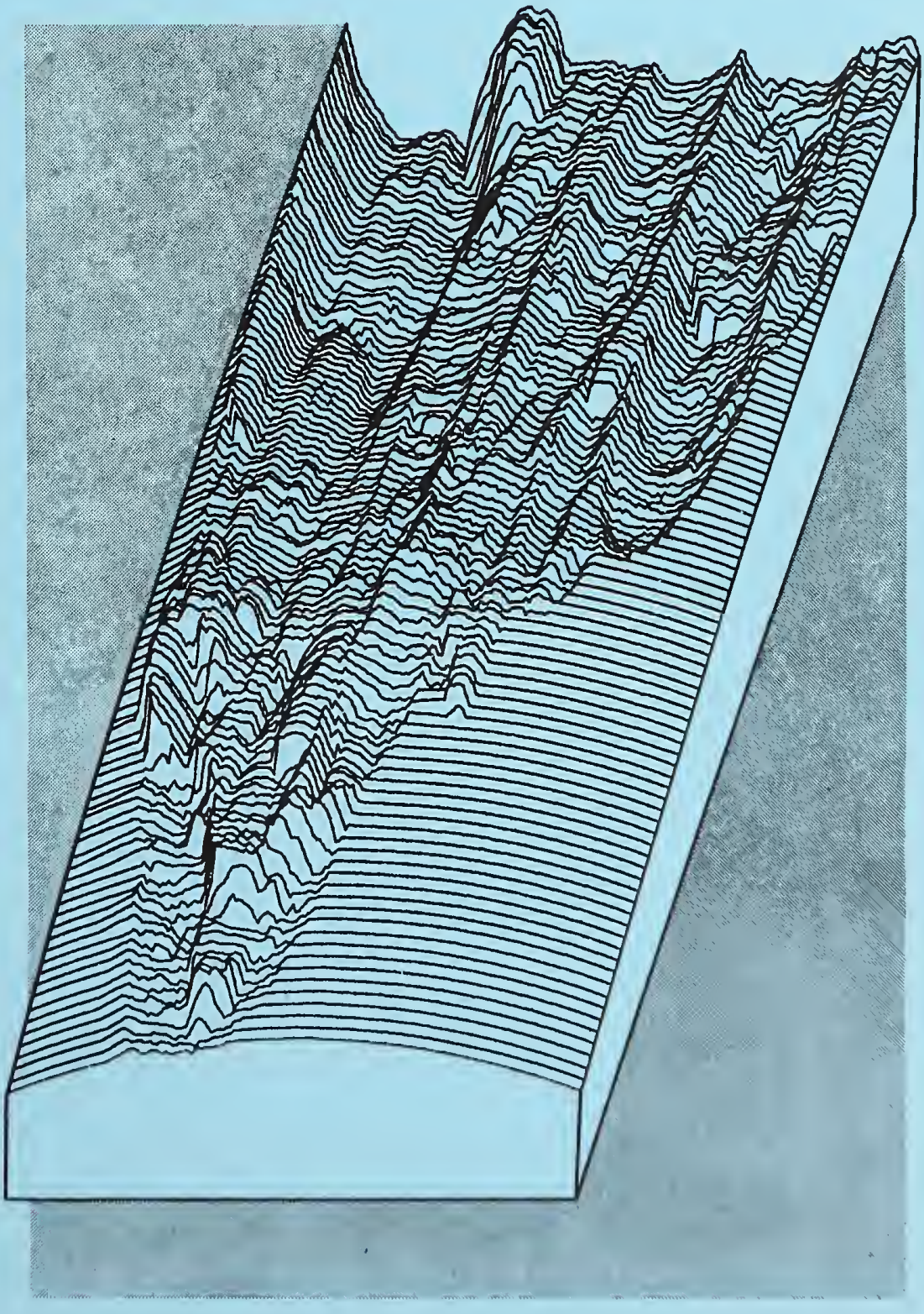

\title{
Technical Activities 1986
}


Topography of a severely worn, galled steel surface acquired and plotted with a computerized surface profiling system.

Computer graphics by $\mathrm{E}$. Whitenton 
E.N. Pugh, Chief

J.G. Early, Deputy 


\section{METALLURGY DIVISION}

\section{CHIEF}

E. Neville Pugh

Phone: (301) 975-5960

\section{DEPUTY CHIEF}

James G. Early

Phone: (301) 975-5961

\section{GROUP LEADERS}

Structure Characterization

Masao Kuriyama

Phone: (301) 975-5974

Metallurgical Processing

John R. Manning

Phone: (301) 975-6157

Wear and Mechanical Properties

Arthur W. Ruff

Phone: (301) 975-6010

Chemical Metallurgy

John B. Clark

Phone: (301) 975-6040

Corrosion

U. Bertocci (Acting)

Phone: (301) 975-6017

Electrodeposition

David S. Lashmore

Phone: (301) 975-6405

Nondestructive Characterization

Haydn N. G. Wadley

Phone: (301) 975-6140 


\section{ABSTRACT}

This report summarizes the FY 1986 activities of the Metallurgy Division of the National Bureau of Standards. The research centers upon the structure-processing-properties relations of metals and alloys and on the methods of their measurement. The activities also include the generation and evaluation of critical materials data. Efforts comprise studies of synchrotron radiation research for materials characterization, metallurgical processing, wear and mechanical properties, chemical metallurgy, corrosion and protection of metals, electrodeposition, nondestructive characterization and magnetic materials.

The work described also includes three cooperative programs with American professional societies and industry: the American Society for Metals (ASM) - NBS Alloy Phase Diagram Program, the National Association of Corrosion Engineers (NACE) - NBS Corrosion Data Program, and the American Iron and Steel Institute (AISI) - NBS Steel Sensor Program.

Work in support of other government agencies includes a major program to assist the Nuclear Regulatory Commission in addressing the critical national problem of disposing of high level nuclear waste in geologic repositories. Another example described is the use of advanced electrodeposition technique to assist the Bureau of Engraving and Printing in the development of wear resistant chromium coatings for currency printing plates.

The scientific publications, committee participation, and other professional interactions of the 86 full-time and part-time permanent members of the Metallurgy Division and its 70 guest researchers are identified. 
$\pi$

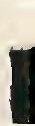

,

,

,

,



,





,

,

,

,

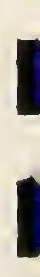

I

; 
TABLE OF CONTENTS

$\underline{\text { PAGE }}$

OVERVIEW . . . . . . . . . . . . . . . . . . . . . . . . 1

METALLURGY DIVISION

ORGANIZATIONAL CHART . . . . . . . . . . . . . . . . . . 5

RESEARCH STAFF . . . . . . . . . . . . . . . . 6

TECHNICAL ACTIVITIES

Structure Characterization . . . . . . . . . . 13

Metallurgical Processing . . . . . . . . . . 19

Wear and Mechanical Properties . . . . . . . . . 29

Chemical Metallurgy . . . . . . . . . . . . 37

Corrosion and Protection of Metals . . . . . . . . . 43

Electrodeposition . . . . . . . . . . . . 49

Nondestructive Characterization ... . . . . . . . 59

Magnetic Properties .. . . . . . . . . . 71

OUTPUTS/INTERACTIONS

Recent Publications .............. 73

Industrial and Academic Interactions . . . . . . . . 85

Technical/Professional Committee

Leadership Activities . . . . . . . . . . . . . 93

APPENDIX

Organizational Chart

National Bureau of Standards. . . . . . . . . . . . . Al

Organizational Chart

Institute for Materials Science and Engineering . . . . . A2 
?

,

,

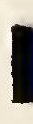

,

I



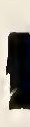

,

,

,

,

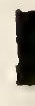

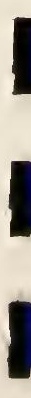


E. Neville Pugh, Chief

James G. Early, Deputy Chief

June Toms, Secretary

In keeping with the Bureau's traditional role, the Metallurgy Division continues to generate measurement methods, critical materials data and standards to support U.S. industry, government and universities. The Division's research programs support our measurement activities and, in addition, are moving increasingly to address the science base underlying both traditional and new materials technologies, a trend which is leading to more direct interaction with industry. Our involvement with other government agencies also continues to grow and, in particular, the Division is providing technical assistance in several critical areas, each closely related to our specific research expertise. These diverse activities are summarized here and described in more detail in the narratives of the Division's seven groups.

The area of measurement was highlighted by activities of the Structure Characterization Group at the National Synchrotron Light Source at Brookhaven. FY86 was the first full year of operation of the IMSE beamlines and a number of experiments were conducted, including the implementation of a tunable $x$-ray image magnifier to study the microstructures of several hightechnology materials, and measurement of near edge and extended fine structure using Raman EXAFS. Another significant development during FY85 was the initiation of a cooperative program between the Corrosion and Nondestructive Evaluation Groups to measure and analyze acoustic emission $(A E)$ during the propagation of stress corrosion cracks in austenitic stainless steels; in addition to providing mechanistic insight into the stress corrosion process, the $A E$ technique is a potentially valuable method of monitoring critical structures for the occurrence of this dangerous type of failure.

Data programs continued to be an important component of the Division's activities in FY86. In the Alloy Phase Diagram Data Program, set up cooperatively with the American Society for Metals (ASM) to provide critically evaluated phase diagrams, the year was highlighted by the completion of digitization of over 1500 binary diagrams for the new ASM book which updates Hansen's classical compilation. In addition, the task of entering graphical and numerical information for binary systems into a computerized on-line database is well underway, and a meeting to obtain input from potential users proved highly successful. The evaluation of ternary Albased $(\mathrm{Al}-\mathrm{Cu}-\mathrm{X})$ systems has been initiated, and software used in the binary program has been extended to ternary applications. The focus of activities in the National Association of Corrosion Engineers (NACE)-NBS Corrosion Data Center has been in two areas: completion of the computer-encoding of NACE's 
Corrosion Data Survey-Metals, resulting in the issue of a floppy disc package, and the acquisition of industrial corrosion databases. The Wear and Mechanical Properties Group organized a workshop at NBS to evaluate needs in the tribology data and information area; a report containing specific recommendations was prepared, and some of the efforts are now underway.

As indicated above, our research programs are moving increasingly to address the science underlying materials processing, and are leading to more direct interaction with industry. The work on process sensors being carried out in the Nondestructive Characterization Group is a prime example of this trend. In a collaborative effort with the American Iron and Steel Institute, a program in which ultrasonic time of flight tomography is being used to measure internal temperature distribution in hot steel bodies has continued to make significant progress and is now being extended from solid to partially solidified material. In FY86, a similar program has been initiated with the Aluminum Association to investigate the use of an eddy current approach in the measurement of internal temperatures during the extrusion of aluminum. Another major activity centers on the production of powders by means of high pressure inert gas atomization, an important method for the production of rapidly solidified materials. This activity, centered in the Metallurgical Processing Group, has already led to considerable interaction with various industrial laboratories, and discussions are in progress to build a cooperative program around the full scale atomizer which has been assembled in the group. The immediate challenge is to reproducibly produce powders of the desired size (and hence properties), and the thrust of the proposed consortium is the development of sensors and an automated process control system.

Metal matrix composites represent another important emerging technology in which we have mounted a significant effort. The performance of such composites is critically dependent on the mechanical properties of the interface between the matrix and the reinforcing phase, and our studies have focussed on this factor, particularly in composites consisting of SiC fibers in an Al alloy matrix. Several groups have interacted in this effort. Our approach is unusual in that the alloy is electrodeposited onto the fiber, and thus the Electrodeposition Group is playing a lead role. In addition to investigating the properties of electrodeposited Al alloys, their activities include modeling of the alloy deposition process on moving fibers, and studies of the feasibility of producing compositionally graded alloys to minimize interfacial stresses. In other groups, the interfaces are being characterized by means of ultrasonic (Nondestructive Characterization) and microhardness (Wear and Mechanical Properties) techniques; thermodynamic modeling of stresses generated by interdiffusion at the interface are being conducted in the Metallurgical Processing Group.

A broad range of activities involving other government agencies was conducted in FY86, some in support of our basic research programs and others which provide technical support to the agencies in areas of our expertise. The former is exemplified by studies in the Metallurgical Processing Group of quasicrystals and rapid solidification under Defense Advanced Research Projects Agency support. An example of the latter is the effort in the Corrosion Group to assist the Nuclear Regulatory Commission in the critical national problem of developing geologic repositories for high level nuclear waste. Pitting and stress corrosion cracking are major processes which 
threaten the integrity of the metallic waste containers, and these phenomena have been central to the research interests of the Corrosion Group for some years. Another example of our research expertise providing direct assistance has been in the application of advanced electrodeposition techniques to the development of wear-resistant chromium coatings for the Bureau of Engraving and Printing to be used in currency printing plates.

Our staff and their areas of expertise are given in the following pages. There were 86 full-time and part-time permanent people. In addition, there were 70 guest researchers and research associates in residence during the past year who collaborated with Division scientists. 
I

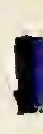

,

,

,

,

,

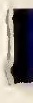

I

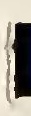

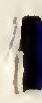

I

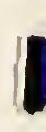

I

I

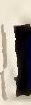

,

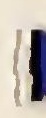

1 


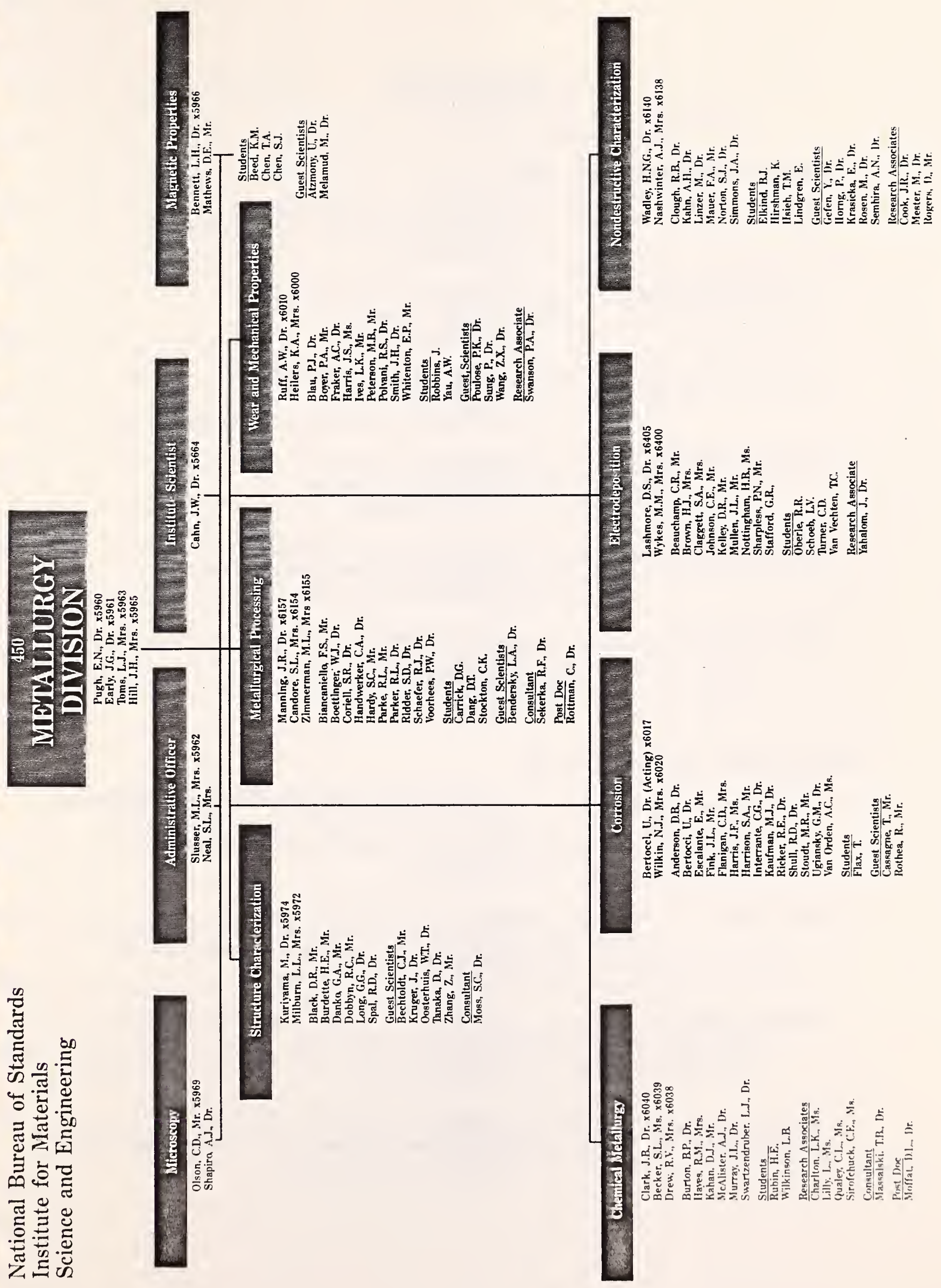




\section{RESEARCH STAFF}

\section{Structure Characterization Group}

Black, David R.

Burdette, Harold E.

Dobbyn, Ronald C.

Kuriyama, Masao

Long, Gabrielle G.

Spal, Richard D.
- Inelastic x-ray scattering

- Energy dispersive $x$-ray diffraction

o X-ray optics

o X-ray optics engineering

o Crystal growth

o Instrumentation

o X-ray dynamic imaging

o X-ray optics

- Synchrotron radiation instrumentation

- Scattering physics

- Solid state physics

- Crystallography

- X-ray scattering physics

- X-ray absorption spectroscopy

- Disordered materials

- X-ray imaging

o X-ray optics

- Instrumentation

\section{Metallurgical Processing Group}

Biancaniello, Francis S.

Boettinger, William J.

Coriell, Sam R.

Handwerker, Carol A.
- Special alloy and quasicrystal preparation

- Melt-spinning rapid solidification

- Inert gas atomization and metal powder processing

- Rapid solidification

- Alloy microstructural characterization

- Relation of alloy microstructures to processing conditions

- Modeling of solidification processes

- Interface stability

- Convection and alloy segregation during solidification

- Interface studies

- Diffusion-induced grain boundary migration

o Liquid film migration 

Hardy, Stephen C.
- Alloy coarsening
- Surface tension measurements
- Interface segregation
Manning, John R.
- Metallurgical processing
- Diffusion kinetics
- Interface migration
Parker, Robert L.
- Ultrasonic measurement of solid/liquid interface, interface kinetics
- Applications to alloys, casting, metallography, rapid solidification
Ridder, Stephen D.
- Microparticle rapid solidification
- Solidification dynamics
- Inert gas atomization
Rottman, Craig A.
o Structure and properties of interfaces
- Phase transformations
- Statistical mechanics
Schaefer, Robert J.
- Quasicrystals
- Electron beam rapid solidification
- Convection and interface effects during solidification
Voorhees, Peter W.
- Coarsening phenomena
- Elastic effects during phase transformations
- Anisotropic interface effects

\section{Wear and Mechanical Properties Group}
Blau, Peter J.
- Friction and wear transitions
- Wear microstructure relations
- Microindentation and scratch hardness
Fraker, Anna C.
- Titanium alloys
- Corrosion processes
- Transmission electron microscopy
- Surgical implant metals
Harris, Jonice S.
- Scanning electron microscopy
- Fatigue properties measurements
o Wear and friction properties
Ives, Lewis $\mathrm{K}$.
o Wear of metals
- Transmission electron microscopy
- Erosion of metals 
Peterson, Marshall B.

Polvani, Robert S.

Ruff, Arthur W.

Smith, John H.
- Wear of metals

- Solid film lubricants

- Mechanical behavior

- Mechanical behavior

- High temperature strengthening mechanisms

- Microindentation measurements

- Dimensional instability behavior

o Wear and friction

- Microstructure effects

- Mechanical behavior

o Microscopy

- Mechanical properties of materials

- Fracture of materials

- Structural integrity analysis

\section{Chemical Metallurgy Group}

Burton, Benjamin P.

Kahan, Daniel J。

McAlister, Archie J.

Murray, Joanne L.

Swartzendruber, Lydon J.
- Thermodynamic modeling of alloy phase diagrams

- Order-disorder and phase separation in alloy systems

- Associate editor, BAPD

- Computer database development

- Ab-initio calculation of phase diagrams

- Evaluation of binary alloy phase diagrams

- Prepare computer graphics for phase diagrams

- Respond to technical inquiries

- Differential thermal analysis

- Equilibrium phase diagrams

- Enthalpy and kinetics of metastable phase transformations

- Evaluation of binary and higher order phase diagram data

- Thermodynamic modeling of alloy phase diagrams

- Data evaluation for Ti and A1-based alloy systems

- Editor, Bulletin of Alloy Phase Diagrams and Constitution of Binary Alloys

- Computer database development for alloy phase diagrams

- Magnetic methods, NDE

- Gamma-ray resonance spectroscopy

- Iron binary phase diagrams 


\section{Corrosion Group}

Anderson, David B.

Bertocci, Ugo

Escalante, Edward

Harrison, Steve

Interrante, Charles G.

Kaufman, Michael J.

Ricker, Richard E.

Shu11, Robert D.

Stoudt, Mark R.

Ugiansky, Gilbert M.

Van Orden, Ann C.
- Industrial corrosion testing

- Corrosion data evaluation

- Corrosion database development

- Electrochemical measurements

- Computer modeling

- Passivity and pitting

- Underground corrosion

- Corrosion in concrete

- Corrosion rate measurements

- Computer systems programming

- Software engineering

- Laboratory automation

- Hydrogen embrittlement

- Nuclear waste disposal

- Environmental testing

- Physical Metallurgy

- Electron Microscopy

- Stress Corrosion Cracking

- Environmental induced fracture

- Corrosion and electrochemistry

- Scanning and transmission electron microscopy

o X-ray and neutron diffraction

- Rapid solidification

- Differential thermal analysis

- Scanning electron microscopy

- Physical metallurgy

- Corrosion testing

- Environmentally induced fracture

- Management of computer database for corrosion data

- Corrosion data evaluation and dissemination

- Localized corrosion

- Slow strain rate stress corrosion testing

- Marine corrosion

- Localized corrosion

- Dealloying 
Electrodeposition Group

Beauchamp, Carlos R.

Brown, Henrietta J.

Claggett, Sandra W.

Johnson, Christian E.

Kelley, David R.

Lashmore, David S.

Mullen, Jasper L.

Stafford, Gery R.
- Computer simulation of electrodeposition processes

- Electrochemical measurements of kinetic parameters

- Corrosion measurements of electrodeposited coatings

- Coating thickness SRM development

- Simultaneous thickness electropotential (STEP) SRM development

- Scanning electron microscopy

- Metallographic specimen preparation

o Ultra-black coatings

- Electroless deposition processes

- Metallic glass alloy deposition

o Microhardness SRM research

- Microhardness SRM development

o Dye penetrant SRM development

- Precious metal electrodeposition

- Electrochemical mechanisms of coating processes

- Pulsed alloy deposition

- Composition modulated alloy deposition

- Properties and structure of electrodeposited coatings

- Amorphous alloys

- Development of automated hardness testing

- Electrochemical measurements for determining metal corrosion

- Analytical spectroscopy

- Electrocatalysis

- Electrochemical transients

- Electrodeposition

- Molten salt electrochemistry

\section{Nondestructive Characterization Group}

Clough, Roger B.

Kahn, Arnold H.
- Acoustic emission

- Mechanical properties

o Surface modification

- Eddy current modeling

- Electromagnetic theory

- Solid state physics 
- Electromagnetic theory

- Solid state physics

Linzer, Melvin

- Ultrasonic imaging

- Acoustic emission

- Ultrasonic scattering

Mauer, Floyd A.

- Ultrasonic tomography

- X-ray diffraction

- Ultrasound-microstructure relations

Norton, Stephen J.

- Ultrasonic imaging

- Inverse modeling

- Dimensional resonance tomography

Simmons, John A.

- Dislocation theory

- Acoustic emission

- Inverse modeling

Wadley, Haydn N.G.

- Dislocations and fracture

- Acoustic emission

- Ultrasonics

\section{Microscopy}

Olson, Craig D.

- Scanning electron microscopy

o X-ray microanalysis

- Thermal wave microscopy

Shapiro, Alexander J.

- Analytical electromicroscopy

o X-ray microanalysis

- Image analysis

Magnetic Properties

Bennett, Lawrence $\mathrm{H}$.

- Magnetic measurements

- Alloy phase stability

- Hyperfine fields 
: 
ADVANCED MICROSTRUCTURE CHARACTERIZATION AND SYNCHROTRON RADIATION RESEARCH FOR MATERIALS SCIENCE Gabrielle Long and Masao Kuriyama

The emergence of nontraditional materials and intensive materials engineering necessitates new approaches to materials characterization and quality control. Often the properties of these new high technology materials depend critically on subtle differences in chemistry and microstructure. The objectives of these tasks are to address this challenge through the development of $x$-ray measurement methods and standards for the advanced microstructure characterization of metallurgical microstructures and other high technology materials, and to perform these measurements in real time. The research has included structural determination of disordered materials and ultra-thin films, the nondestructive evaluation of imperfections and strains in materials, the microstructure characterization of high technology single crystals, ultrasensitive trace element detection, and even the study of structural features in human teeth.

These tasks are directly related to the synchrotron radiation program in the Institute for Materials Science and Engineering (IMSE), which was initiated in FY80. The Office of Nondestructive Evaluation in IMSE contributed to the support of this effort in the areas of data processing and image detector development for real time observations. The IMSE synchrotron radiation program is the materials science part of the joint effort between the Naval Research Laboratory (NRL) and the National Bureau of Standards (NBS) to establish and operate a synchrotron radiation facility for NRL and NBS scientists at the National Synchrotron Light Source (NSLS), Brookhaven, NY. In FY86, NBS completed the first year of experimental operations and instrument evaluation at the IMSE $x$-ray beamline at NSLS.

\section{FY86 Significant Accomplishments}

- This was the first full year of operation of the IMSE synchrotron radiation beamlines for scientists from NBS, NRL, and from government, industry and universities.

- A tunable $\mathrm{x}$-ray image magnifier, covering the energy range 8-30 keV was constructed, tested, and implemented for the real time observation of microstructures.

- Detailed microstructural measurements were carried out, as a function of incident photon energy, on several high technology materials of high current interest.

- Near edge and extended fine structure measured using $x$-ray Raman EXAFS were analyzed.

- Near neighbor environments for atoms in icosahedral phase aluminummanganese were calculated.

- Progress was made on the construction of an innovative $x$-ray camera based on a CCD sensor. 
Operation of the NBS/IMSE X-23A Beamline at NSLS

Subtask 1

R. Dobbyn, D. Black, R. Spal, H. Burdette, G. Long and M. Kuriyama

The Structure Characterization and Synchrotron Radiation Group at NBS has completed the first year of experimental operations and instrument evaluation on the IMSE $\mathrm{x}$-ray beamline at the NSLS in Brookhaven, NY. The beamline offers materials scientists from NBS, NRL and other government laboratories, as well as from industry and from universities, a research tool combining the highest brightness, lowest emittance source of $\mathrm{x}$-rays in the world with high resolution $x$-ray optics for characterizing the microstructures of materials. It enables researchers to conduct real-time in-situ measurements on a micrometer scale.

The $\mathrm{x}$-ray storage ring at NSLS was operated for most of this year at an energy of $2.5 \mathrm{GeV}$ with electron currents starting as high as $160 \mathrm{~mA}$ and decaying to 30-40 mA before reinjection. Beam lifetimes were often 4 to 5 hours and occasionally as good as 7 hours. There were two shutdowns, each of approximately one month duration, for repairs and replacement of critical instrumentation in the ring. At present, the source is operating at the design energy and about one-third the design current, with the excellent brightness and low emittance that was predicted.

Scientists from the group used this time to perform energy dependent $x$-ray topography research on high technology single crystals and to commission new instrumentation and perform first experiments using these enhanced capabilities. A tunable x-ray image magnifier for providing magnified diffraction and microradiographic images was installed. This new magnifier is tunable over the energy range $8-30 \mathrm{keV}$ and can be used to extend the spatial resolution of two-dimensional $x$-ray detectors (such as video or film) by one to two orders of magnitude with the goal being submicrometer resolution.

Since the beamline can receive white radiation as well as monochromatic $x$-rays, scientists from the this group used the opportunity to install instrumentation for energy dispersive $x$-ray diffraction. The probe volume $\left(0.1 \times 1.0 \times 1.0 \mathrm{~mm}^{3}\right)$ is more than two orders of magnitude smaller than that achieved in the laboratory and the data acquisition time is reduced by at least a factor of 30. Diffraction peaks up to $60 \mathrm{keV}$ are seen. Experiments have been performed on a cylindrical sample with a known strain distribution. The radial and tangential components were measured and found to agree well with theory.

Scientists from this group, in collaboration with a scientist from the Analytical Chemistry Division, have established a high-sensitivity trace element detection capability using the high brightness, energy tunability and polarization of synchrotron radiation together with grazing incidence reflection techniques. In the synchrotron radiation experiment, scattered radiation can be greatly reduced by effective utilization of polarization, thereby substantially increasing the fraction of fluorescence signal and bringing about a significant reduction in the minimum detectability limit. 
The tuning capabilities of the monochromator were expanded to include a scanning feature applicable to performing absorption spectroscopy and Extended X-ray Absorption Fine Structure (EXAFS) experiments. Measurements have been made on iron-chromium alloys and their oxides, icosahedral phase aluminum-manganese, and thin film yttria and zironia.

$X$-ray Image Magnification Using Hard Radiation

Subtask 2

R. C. Dobbyn, D. R. Black, and M. Kuriyama

A tunable $\mathrm{x}$-ray image magnifier, has been implemented for the real time observation of microstructures at the IMSE x-ray beamline at NSLS. Early results on magnified diffraction topographs of VLSI devices on silicon and magnified microradiographs of crack specimens have demonstrated the real time applicability of this method.

High resolution, image-magnified $x$-ray microradiographs of dental specimens [1] have been obtained over a range of $x$-ray energies from 8 to 19 $\mathrm{keV}$. Earlier work, [2] using $8 \mathrm{keV} x$-rays and $22 \mathrm{x}$ image magnification showed detailed structural features such as prism lines, lines of Retzins and cross-striations with some images as small as one micrometer. The present magnification technique was used with varying photon energies to enhance the structural details and to enable quantitative image analysis. Microradiographs of tooth specimens up to $1 \mathrm{~mm}$ thick were obtained, as well as a microradiograph of a tooth specimen immersed in a demineralizing solution cell. This research was performed in collaboration with scientists from the Health Foundation Research Unit (American Dental Association) at NBS.

[1] S. Takagi, L. C. Chow, W. E. Brown, R. C. Dobbyn, M. Kuriyama, Nucl. Instr. Meth. in Physics Res. 222: 256-258 (1984).

[2] S. Takagi, L. C. Chow, W. E. Brown, R. C. Dobbyn, M. Kuriyama, J. Dental Res. 64: 866-869 (1985).

\section{X-Ray Topographic Examination of LiNbO 3 Single Crystals} Subtask 3

G. G. Long and M. Kuriyama

Single crystal lithium niobate $\left(\mathrm{LiNbO}_{3}\right)$ is currently the nonphoto-refractive, electrooptic material of choice for optical switching and modulation technology. The prominance of lithium niobate technology has very recently been enhanced by the announcement of laser action in doped samples. In this work, which was performed in collaboration with a scientist from the Ceramics Division, only measurements of undoped material was involved.

High sensitivity monochromatic ( $8 \mathrm{keV}$ ) $\mathrm{x}$-ray topography was carried out on two $z$-cut $(0001)$ crystals from $z$-grown boules, two y-cut (0110) crystals from y-grown boules and one z-cut crystal from a boule grown in the $y-$ direction. The major type of defect observed was a filamentary structure which appeared with different density in various crystal samples. For example, the density of filaments was quite different for the two $z$-cut 
samples, where the defect-free volume was much greater in the (optically) good sample. Data from the y-cut crystals showed that the defectfree volume may be even greater than that in the better $z$-cut crystal. In addition to the filamentary defects mentioned above, there was also evidence of periodic striations in topographs from some of the crystals.

Energy Dependent X-Ray Topography of Bi $12 \underline{\text { SiO }}_{20}$ Single Crystals Subtask 4

G. G. Long and M. Kuriyama

Single crystals of bismuth silicate $\left(\mathrm{Bi}_{12} \mathrm{SiO}_{20}\right)$ are of primary importance in spatial light modulator technology. The property of greatest interest is its photorefraction. Much effort has been devoted to the growth of good crystals, but it has thus far been difficult to obtain detailed information on crystal quality. In this work, performed in collaboration with a scientist from the Ceramics Division, high sensitivity monochromatic topography was used to examine the nature of both bulk and surface crystal structure, and to observe defects not detectable by traditional optical inspection. Three samples were studied, all from the same boule grown in the $\langle 001\rangle$ direction. Under a polarizing microscope, they each appeared to be nearly free of birefringent strain. Two important properties of the samples were apparent: there are significant surface imperfections, and there is a segmented appearance to the diffracted image. Crystal growth bands are evident in the four outer segments, and fringes are seen in the central segment. Since the (100) and (110) crystal faces grow at different rates, this introduces characteristic stresses. Sharp boundary lines are clearly visible between each of the segments. Each crystal topograph contains information on a slice in the thermal history of the growth of the crystal. The nature of the fringes in the central region were studied using reflection topography at ten different $x$-ray energies. No change in the moire was seen even in the neighborhood of the Bil III edge. Real time depth profiling of these crystals was carried out based on References 1 and 2 .

[1] M. Kuriyama and G. G. Cohen, Z. F. Naturf. 37a, 465 (1982). [2] M. Kuriyama and G. G. Long, in Applications of X-Ray Topographic Methods to Materials Science, ed. by S. Weissmann, Plenum, NY 97109 (1984).

Perfection of Copper Single Crystals

Subtask 5

D. R. Black, G. G. Long, and M. Kuriyama

In the study of interfaces in metals and alloys, the crystal perfection of substrate materials often affects the structure and microstructure of films deposited on the substrates and these effects obscure the nature of interfaces. It is a serious problem to find a way to hold ductile substrate crystals without introducing deformation during cleaning of the substrate surface and deposition of films in a vacuum chamber. Disks of copper, $0.5 \mathrm{~mm}$ to $1 \mathrm{~mm}$ thick, were prepared from a boule grown by the Czochralski method $[1,2]$. They were annealed in a hydrogen furnace at 
$1000^{\circ} \mathrm{C}$ for a week. A diffusion zone approximately 15 micrometers thick was created between the oxygen free copper mounting plate and the single crystal. The monochromator system at X23-A was operated to create a large $(2 \mathrm{~cm} \mathrm{X} 2.5 \mathrm{~cm}$ ) parallel beam. Topographs were taken with the beam operated at 7,8 and $9 \mathrm{keV}$, using (111) asymmetric diffraction in transmission. Anomalous transmission was evident, where the same quality of crystal perfection was in evidence as before the diffusion bonding. This experiment confirms that diffusion bonding may be used for metal crystal mounting without causing deterioration in crystal quality.

[1] M. Kuriyama, J. Early, H. Burdette, J. Appl. Cryst. 7535 (1974).

[2] W. Boettinger, H. Burdette, M. Kuriyama, Phil. Mag. $\underline{34} 119$ (1976).

X-Ray Raman EXAFS of Low Z Elements Using Hard Radiation

Subtask 6

D. R. Black, G. G. Long and M. Kuriyama

Using a double crystal $\mathrm{x}$-ray spectrometer, $\mathrm{K}$-x-ray Raman edges in the inelastically scattered spectrum of $8 \mathrm{keV}$ radiation from lithium, boron, carbon and nitrogen have been observed. Recent experiments have concentrated on boron nitride and polycrystalline graphite as standard samples with known structure. Good resolution carbon spectra, showing the characteristic pre-edge peaks and fine structure, were obtained. The fine structure above the edge can be analyzed in a fashion similar to that of EXAFS data to extract near neighbor atomic distances. The initial step in the Raman data analysis was a deconvolution of the data to remove the instrument profile. The standard method for performing this deconvolution is difficult to apply to this data. To solve this problem other deconvolution techniques have been investigated. In particular, the Root Projection Deconvolution algorithm developed at NBS for the analysis of acoustic emission waveforms has been applied. Preliminary results are very encouraging. The problems of amplified high frequency noise and truncation errors are substantially reduced. A first application to data from boron nitride indicate that the deconvolved data is suitable for further analysis.

Local Atomic Environments in Icosahedral Aluminum-Manganese Alloys Subtask 7

M. Kuriyama, G. G. Long, and R. D. Spal

As part of this subtask, the topological properties of the atomic scale structure description of the icosahedral phase developed earlier [1, 2, 3] were investigated. In a periodic crystal, the local environment of an atom is described most easily by its point symmetry within the space group to which the structure of the crystal belongs. The Wigner-Seitz (W-S) cells about the atom give additional information in this case. For icosahedral crystals, for which there is as yet no appropriate crystallographic description, the $W-S$ cell may be the only way to study the local environment. Applying the $W-S$ constructs, it was found that: $i$ ) there is a broad distribution of Mn site $W-S$ cell topologies and an even broader one of Al site topologies. The volumes span those appropriate to $M n$ and 
Al and they tend to fall into two well-defined groups with $20 \%$ characteristic of $\mathrm{Mn}$; $\mathrm{ii})$ No sites were found to be or $\left(0,0,12, \mathrm{v}_{6}\right), \mathrm{v}_{6}=0,2$, 3 or 4. Cells with these topologies are the building blocks of the FrankKasper structures. iii) The radial distribution function (RDF) shows nearest neighbors lying between 0.25 and $0.3 \mathrm{~nm}$ in a bimodal distribution, and narrow peaks were observed beyond $0.6 \mathrm{~nm}$, implying long range positional correlations characteristic of a crystal and inconsistent with a glass. iv) The coordination number is between 12 and 12.5 for $\mathrm{Mn}$, compared to 10 in crystalline $\mathrm{MnAl}_{6}$.

In the other part of this subtask [4], an infinite class of quasiperiodic lattices, whose diffraction patterns have icosahedral symmetry, was derived. This class of lattices is composed of incommensurately modulated sublattices with displacive modulations. The sublattice reference lattices, as well as the sublattice displacement fields, belong to the space group $\mathrm{R} 3 \mathrm{~m}$, and are equivalent under the icosahedral point group. The relative positions of the reference lattices and displacement fields are described by a three dimensional vector $a_{2}$. As a varies continuously, the quasilattice changes discontinuously, but its diffraction pattern remains the same. The amplitude of the displacement field is described by a function $u$ belonging to an infinite class of periodic, discontinuous functions. As $u$ varies continuously, the quasilattice and its diffraction pattern change continuously. For general $u$, the quasilattice has infinitely many nearest neighbor configurations, unlike icosahedral quasilattices constructed by the projection and grid methods. A special u reproduces a three dimensional generalization of the Penrose tiling.

[1] M. Kuriyama, G.G. Long, L. Bendersky, Phy. Rev. Lett. $\underline{55}, 849$ (1985).

[2] G. G. Long, M. Kuriyama, Acta Cryst. A42, 156 (1986).

[3] M. Kuriyama, G. G. Long, Acta Cryst. A $\overline{42}, 164$ (1986).

[4] R. D. Spal, Phys. Rev. Lett. 56, 1823 (1986).

Construction of an X-Ray Camera Using a CCD Sensor

Subtask 8

R. D. Spal and M. Kuriyama

An X-ray camera based on a CCD sensor is under construction. It promises to deliver better sensitivity and/or resolution than current $x$-ray cameras. Four printed circuit boards were designed for the camera. The CCD mounts on the first board, which also serves mechanically as one wall of a thermoelectrically cooled, vacuum sealed enclosure. This board also contains a buffer amplifier for the CCD output. The second board has the high speed drivers for the three parallel and serial CCD gates. The third board contains the analog circuits to convert the buffered, clocked CCD output into an RS170 video signal. The fourth board has the digital circuits to control the second and third boards. Due to the high frequency $(7 \mathrm{MHz})$, high slew rate $(3000 \mathrm{~V} / \mu \mathrm{sec})$, and high peak current (1 amp) required to drive the CCD gates, it is anticipated that the current design will undergo several revisions before a satisfactory printed circuit board layout is found. Computer aided design software has been developed to facilitate the process of revising and producing the boards. 
The objective of this task is to develop measurements and processing models to allow prediction and control of the effect that processing history has on alloys. Alloy properties depend on the microstructures and composition distributions that are developed in the alloy during its solidification and subsequent solid state processing. Proper control of processing conditions allows tailoring of alloys to produce microstructures, compositions and properties needed for particular applications. The NBS work develops overall predictive guidelines relating these conditions to final alloy results. These guidelines then can be applied by industrial alloy designers to their particular problems, thus providing increased reliability, cost savings and higher performance in final products.

The NBS effort emphasizes three major areas of work: (1) rapid solidification, which allows production of advanced alloys unobtainable by conventional means, (2) improved understanding and control of conventional solidification processes to produce economical high quality materials, and (3) kinetic processes in solids, especially those connected with reactions at interfaces, which significantly alter alloy microstructures, composition distributions, and properties even after solidification has occurred.

As an unexpected result of the investigations of rapidly solidified alloys which provide extended solid solubility, a dramatically new class of materials, called quasicrystals, was recently discovered at NBS when very high levels of Mn were added to Al. In addition, as part of the NBS study of solid state processes and alloy interfaces, mechanisms for another unexpected phenomenon, diffusion-induced grain boundary migration, have been determined. These results, while important in themselves, also had wider implications, such as indicating the large effect that coherency strains can have on many interface processes, including those in metal matrix composites. The quasicrystal discoveries even have changed our basic ways of thinking about possible crystal structures and how they are formed. This work is now being pursued further to investigate additional practical and scientific consequences. In an application of previous work on controlled solidification having similar broad implications, calculations of interface instability and associated segregation effects have been extended to the higher solidification velocities typical of continuous casting of thin steel sheet. This extension was done as part of the new Congressionally-mandated NBS steel research program.

In addition to working with the steel industry on problems concerning continuous casting, staff members have interacted with many other industrial groups, for example, collaborating with industrial scientists in producing special rapidly solidified alloys. Much of the current work also is supported by other government agencies. Interface studies for application to metal matrix composites and studies of stress effects on alloy coarsening are being funded by the Office of Naval Research. Studies of coarsening in liquid-solid mixtures and of convection and interface stability during directional solidification are being sponsored by the National Aeronautics and Space Administration. Powder processing of rapidly solidified Al-Fe alloys is supported by the Naval Air Development Center. Major studies on quasicrystals and rapid solidification were funded during the past year by the Defense Advanced Research Projects Agency. 
- Mechanisms were determined by which fine dispersoids can be produced in rapidly solidified $\mathrm{Al}-\mathrm{Ni}-\mathrm{Fe}$ alloys, which are of industrial interest because of their intermediate high temperature strength. High solidification rates in these alloys produce discrete beads of liquid rich in $\mathrm{Fe}$ and $\mathrm{Ni}$ within an $\mathrm{Al}$ alloy matrix. Subsequent freezing of these beads produces uniformly distributed intermetallic phase dispersoids, which provide the desired hardening and alloy strength.

- Experiments on nucleation of quasicrystals in submicron atomized droplets showed nucleation rates so high that microquasicrystalline structures almost indistinguishable from those of a metallic glass were formed.

- The special nucleation and growth behaviors of quasicrystal alloys were analyzed. These studies not only yielded information on processing paths for production of these extraordinary 5-fold and 10-fold symmetry alloys but also provided general insights into the growth of complex crystal phases and the structure of supercooled liquids from which quasicrystals can be formed.

- For iron-carbon-sulfur ternary alloys, limiting conditions of solidification velocity, temperature gradient, and alloy composition were calculated for the onset of cellular growth. In addition, cell spacings, which provide the scale of expected alloy segregation in these steel materials, were determined for this onset condition in the high velocity ranges typical of thin sheet continuous casting of steel.

- Electron microscopy results on microstructures formed near interfaces in single phase $\mathrm{Cu}-\mathrm{CuZn}$ systems showed that surprisingly high dislocation densities were generated by diffusion across these interfaces. This implies that large elastic energies are being developed in the interfacial region. Significant changes in equilibrium compositions near these interfaces are calculated to result from these effects.

\section{Rapid Solidification}

Subtask 1

W. J. Boettinger, R. J. Schaefer, S. D. Ridder, S. R. Coriell, J. G. Early, F. S. Biancaniello, and J. W. Cahn

Rapid solidification and subsequent thermomechanical consolidation permits a new approach to alloy design. Application of predictive modelling and microstructural control to these processes can permit the tailoring of microstructure to meet specific alloy property requirements. To promote the development of this new design strategy into a mature element of the field of metallurgy, research has been performed in three areas: (a) an exploration of new metallic metastable phases with unique structure and properties, with emphasis during the past year on quasicrystal alloys; (b) mechanisms of microstructure formation; and (c) improvements in processing techniques used for the production of rapidly solidified alloy particulate. 
Quasicrystalline intermetallic phases, which were initially discovered during rapid solidification studies at the National Bureau of Standards, have symmetries which are not allowed by classical crystallography. Since the initial announcement of the NBS discovery of quasicrystalline Al-Mn in November 1984, these materials have attracted intensive study in many laboratories. Rapid progress has been made at NBS in understanding both the crystallography and the kinetics of formation of these materials.

The symmetries of the quasicrystalline phases are icosahedral, with six 5fold axes, or decagonal, with one 10-fold axis. The lattices of crystals with these symmetries must be quasiperiodic in three dimensions, but they can be described as periodic lattices of higher dimension which are projected into three dimensions. Such a formulation is being used for the analysis of $\mathrm{x}$-ray, electron, and neutron diffraction data and has had considerable success in describing the positions and intensities of the diffraction peaks. Understanding of the atomic configuration which can decorate such lattices is being gained through the analysis of data from EXAFS, NMR, Mossbauer spectroscopy and other techniques. In several cases, these experiments have been carried out at other laboratories using samples provided by NBS. In addition, NBS guest scientists D. Shechtman and L. Bendersky from the Technion and Johns Hopkins University, who originally identified these materials, are continuing to work at NBS on these problems. These studies have led to the conclusion that many quasicrystals contain local atomic groups which are the same as those in crystals of similar compositions, but these groups are packed together differently.

In addition to their unique crystallography, quasicrystals have unusual nucleation and growth behavior which is providing insight into more general studies of the structure of supercooled liquids and the growth of complex crystal phases. In Al-Mn quasicrystalline alloys it is found that the quasicrystals replace the equilibrium phases because of their much higher nucleation rate in the supercooled liquid. For alloys atomized into submicron droplets, it was found that in the smallest drops, which would have had the highest cooling rates, the nucleation rate was so high that it produced a microquasicrystalline structure, almost indistinguishable from that of a metallic glass (fig. 1). Such high rates of nucleation give support to current theories of icosahedral clustering in supercooled liquids. Electron beam surface melting experiments also demonstrated that the icosahedral phase of AI-Mn serves as a potent nucleation substrate for the somewhat more stable decagonal phase, with the result that the decagonal phase replaces the icosahedral phase unless the cooling rate following the initial solidification is sufficiently high.

\section{Mechanisms of Microstructure Formation}

Systematic research has been continued to discover the mechanisms and thus the conditions which produce the wide variety of microstructures possible in rapidly solidified materials. For example, experiments on $\mathrm{Al}-\mathrm{Fe}-\mathrm{Ni}$ alloys were focused on the formation of small $30 \mathrm{~nm}$ diameter particles of intermetallic phases (dispersoids) within a matrix phase. 
Rapidly solidified alloys containing fine dispersions of intermetallic phases constitute a technologically important class of materials. After consolidation into bulk samples these materials can exhibit unique mechanical properties and elevated temperature capability. Dispersoids form by two mechanisms in these samples: directly from the melt and by precipitation from the solid state. In the Al-Fe-Ni system precipitates formed in the solid state have a disk morphology and are therefore distinguishable from those formed by solidification. Using the electron beam melting and resolidification technique, the microstructures obtained by rapid solidification at controlled rates between 0.25 and $500 \mathrm{~cm} / \mathrm{s}$ were obtained in Al-3.7 wt\% $\mathrm{Ni}-1.5 \mathrm{wt} \% \mathrm{Fe}$, an alloy currently being considered by Alcoa as a material with intermediate high temperature strength. This hypereutectic alloy, which in its cast form exhibits coarse primary intermetallics of $\mathrm{Al}_{9}(\mathrm{Fe}, \mathrm{Ni})$, solidifies as a fine coupled eutectic for solidification velocities below $2.5 \mathrm{~cm} / \mathrm{s}$. Above this rate a cellular structure of $a-A l$ forms with continuous sheets of the intermetallic phase coating the cell walls. The eutectic and cell spacings are shown in figure 2. These sheets likely form by solidification of the $\mathrm{Fe}$ - and $\mathrm{Ni}-\mathrm{rich}$ intercellular liquid as shown in the left of figure 3. At higher solidification rate these deep intercellular liquid regions become unstable and discrete "beads" of liquid, which subsequently freeze as $\mathrm{Al}_{9}(\mathrm{Fe}, \mathrm{Ni})$, are left by the cellular interface, as shown in the right of figure 3 . This process which provides a desirably uniform distribution of dispersoids occurs for solidification rates above $\sim 100 \mathrm{~cm} / \mathrm{s}$.

\section{Powder Processing}

Inert gas atomization is an important method for the production of rapidly solidified alloy powders. A full scale atomizer is nearing completion and fundamental studies into the mechanism of powder formation and process control have been initiated. A detailed flow study of high energy helium jets was performed to determine the optimum geometry of the exit nozzle used to deliver molten metal to the higher energy jets. An additional high pressure-high flow system was built that duplicates the flow capability of the atomizer and allows us to take high speed photographs of the atomization of water under varying flow conditions. In addition, aspiration tests were run to determine optimum helium jet velocity. This study showed that optimum particle disruption occurs at a jet delivery pressure of $11.7 \mathrm{mPa}(1700 \mathrm{psi})$ for helium gas. These flow conditions were then duplicated in a small $(1 \mathrm{Kg})$ batch atomization of Sn-95 wt\% Sb, with much of the powder produced being in the $10 \mu \mathrm{m}$ to $50 \mu \mathrm{m}$ diameter range. Commercial alloy powders in this size range provide improved product properties after consolidation. Studies to determine the optimum conditions for consolidation of commercial Al-8 wt\% Fe rapidly solidified powder with minimum microstructural coarsening have been conducted.

In the area of electrohydrodynamic (EHD) atomization, which produces sma11 amounts of very fine powder $(<1 \mu \mathrm{m})$, system modifications included a change to a wire feed-electron beam melting source and new vacuum plumbing. This combination increased the upper temperature limit for alloys which can be processed into the $4000^{\circ} \mathrm{C}$ range as well as providing better process control. 
Controlled Solidification

Subtask 2

S. R. Coriell, R. L. Parker, R. J. Schaefer, and J. R. Manning

In this research, the fluid flow, solute segregation, and interface morphologies which occur during solidification are being studied and techniques for monitoring solidification velocities are being developed. Numerical calculations in collaboration with G. B. McFadden, R. F. Boisvert, and R. G. Rehm of the NBS Center for Applied Mathematics and R. F. Sekerka of Carnegie-Mellon University have modelled double-diffusive convection and interface stability during alloy solidification. Algorithms have been developed to calculate both two- and three-dimensional cell shapes that occur during directional solidification. These predictive models can be used to guide alloy designers in choosing processing conditions that will provide optimum properties of the solidified materials, for example, in providing homogeneous material needed for electronic applications and in predicting the type of alloy segregation expected during continuous casting of steel. Ultrasonic techniques have been developed to measure interface position, velocity, and morphology during solidification of metals and semiconductors, including aerospace alloys. This work, undertaken in collaboration with N. C. Peterson of the Polytechnic University of New York, is directed toward the monitoring of casting, solidification, and crystal growth processes to provide real-time feedback and control, thus aiding in providing a uniform product and increasing productivity.

Convection and Interface Morphology during Directional Solidification

Solute segregation in directionally solidified materials is caused by fluid flow in the melt and by nonplanar interface morphologies. One of the goals of this work is to determine the role of buoyancy-driven fluid flow on solute segregation during directional solidification. Avoidance or minimization of segregation can be extremely important in high performance materials. In this work, directional solidification vertically upwards at velocity, V, was considered for a binary alloy which upon freezing rejects a solute which is lighter than the solvent, for example, lead containing small amounts of tin. Numerical results were obtained using finite differences in a two-dimensional time-dependent model that assumes a planar crystal-melt interface. Calculations were carried out for Schmidt numbers (ratio of kinematic viscosity and solute diffusivity, D) of 81 (typical of metals), 10 (typical of semiconductors) and unity. A detailed study of flow transitions for Schmidt number of unity shows that multiple steadystates, time-periodic states, and quasi-periodic states occur as the solute concentration increases. The multiple steady-states indicate that the flow field and the resulting solute segregation depend on initial conditions, and hence on how the final processing conditions are attained. Steady flows cause lateral solute segregation, while time-periodic flows cause both lateral and longitudinal segregation. The period of the time periodic flows is roughly given by the time for the crystal to grow a distance $D / V$.

Thin sheet continuous casting of steel alloys produces solidification conditions that differ significantly from those encountered during conventional ingot casting. Notably, the rates at which the solid-liquid 
interface advances during these continuous casting processes are much faster than those in conventional processes. During solidification, the shape of the solid-liquid interface may vary from smooth to cellular to dendritic. The processing conditions for the transition between planar and non-planar solidification for particular steel alloys and the characteristic wavelength of the microsegregation are being determined by linear morphological stability theory, which is being extended to multicomponent systems. The processing conditions (solidification velocity, temperature gradient in the liquid, and alloy composition) for the onset of cellular growth and the cell spacings at the onset have been calculated for the iron-carbon-sulfur ternary system with the assumption of constant liquidus slopes and constant distribution coefficients. In general, the distribution coefficient (ratio of solute concentration in the melt and in the solid at the solid-liquid interface) will depend on the concentration of all the other solutes in the alloy, and there may be coupling in the diffusion processes at the interface. The linear morphological stability theory will be extended to these more complex cases.

Ultrasonic Measurements of Solidification and Crystal Growth in Metals and Semiconductors

The velocity of sound and the density have values that are sufficiently different for liquid as compared to solid phases of metals, alloys and semiconductors to permit the use of pulse-echo ultrasonic techniques to locate the solid/liquid interface during solidification, crystal growth and melting. This technique has application to process control in any casting, crystal growth or solidification process whether fast or slow, high or low alloy, metal or semiconductor. This real-time ultrasonic metallography will be important to any materials processing industry in which opaque materials are solidified, since real-time measurements which allow feedback and control can provide both quality control and productivity improvement. Examples of such industries are steel, non-ferrous metals, and the electronics industry involving silicon crystal growth; all of which are multi-billion dollar industries in the U.S.

In addition to recently published NBS measurements on iron and steel, which showed quantitative pulse-echo observations of the melting and freezing of pure iron and 304-stainless steel, measurements also have been made of solidification in silicon. As in the steel measurements, combined induction and arc heating was used to obtain unidirectional heat flow. These new results on silicon, which show that silicon crystal growth can be monitored in real-time in situ with the pulse-echo technique, have elicited widespread interest in the crystal growth industry.

Digital signal processing techniques for this work have been improved to handle currently 100,000 pieces of data per second in the signal averaging mode. This capability is important to allow rapid, accurate determination of interface positions and eliminate spurious signals. Application of this technique to gallium arsenide crystal growth appears promising, as well as application for monitoring the processing of directionally solidified turbine blades (high nickel alloys) for aerospace applications. Work has started on developing the technique to provide in-situ real-time monitoring of rapid solidification processing. 
Solid State Processes and Alloy Interfaces

Subtask 3

J. R. Manning, C. A. Handwerker, S. C. Hardy, P. W. Voorhees, J. W. Cahn,

S. A. Hackney, and C. Rottman

Reactions at interfaces are important in a number of practical materials, including metal matrix composites, surface modified alloys, and alloys undergoing coarsening. Stresses produced near interfaces by diffusion reactions and lattice mismatches can strongly affect alloy properties. Determining how such stresses influence the alloy compositions, gradients, and reaction rates near these interfaces is an important aspect of the current work. In addition, volume fraction effects on alloy coarsening are being investigated in solid-liquid alloy systems where these stresses are absent. Of particular interest have been coherency strain effects which not only play an important role in diffusion-induced boundary migration effects but also are predicted to significantly affect compositions near interfaces in general, including those in composite materials.

\section{Thermodynamics and Kinetics of Reactions at Non-Equilibrium Interfaces}

Coherency strains and stresses are generated during interdiffusion at the interface in a binary solid solution diffusion couple when the lattice parameter is a function of composition. The change in lattice parameter produces a compressive stress on one side of the interface and a tensile stress on the other side, thus creating a stress discontinuity at the interface. Current work shows that inclusion of this stress discontinuity into the thermodynamic equations leads to a prediction that a chemical discontinuity also will exist at the interface. Calculations have been performed to assess the magnitude of this compositional discontinuity, starting with alloys of the same phase but of different initial compositions. Significant concentration steps, greater than 0.2 mole fraction, are predicted, as shown in figure 4 for $\mathrm{Cu}-\mathrm{Ni}$. Measurements of diffusion profiles perpendicular to grain boundaries and interfaces are being performed and the structure of the diffusion zone affected by these stresses is being assessed by TEM and field-ion microscopy. Temperature effects and misorientation effects on grain boundary structure also have been calculated.

Electron microscopy observations and thermodynamic calculations have been made of interfaces between $\mathrm{Cu}$ and $\mathrm{a}$-phase $\mathrm{Cu}-\mathrm{Zn}$. The observed $\langle 110\rangle$ dislocation patterns that develop during diffusion of $\mathrm{Zn}$ into the $\mathrm{Cu}$ side of the interface show surprisingly high dislocation densities, confirming that appreciable lattice stresses are being produced. Initial indications are that the defect density is even higher than would be expected from lattice parameter gradients alone. The additional defects perhaps are created by the net vacancy divergence which arises because $Z n$ diffuses across the interface faster than does $\mathrm{Cu}$ (Kirkendall effect). The resulting gradient in lattice sites produces plastic distortion and a significant extra work term. The effect of these extra terms on the analysis of multicomponent diffusion could be significant since stress effects from these sources have not usually been included in the thermodynamic equations. 
Diffusion-Induced Grain Boundary Migration

Grain boundaries in polycrystals, when exposed to a solute source, have been found unexpectedly to migrate and to form solid solutions in the regions swept by boundary motion. Examination of this diffusion-induced grain boundary migration (DIGM) in the $\mathrm{Cu}-\mathrm{Zn}$ system by transmission electron microscopy (TEM) has revealed the following general physical features: (a) a dislocation "wall" is formed at the original position of the grain boundary, (b) the region over which the grain boundary has migrated is alloyed with $\mathrm{Zn}$, (c) the grain boundary has a high density of defects having step character which show contrast behavior expected of extrinsic grain boundary dislocations produced by stress, and (d) the region in front of the migrating grain boundary is plastically deformed. Because of the large amounts of energy required to produce these dislocation arrays, none of the currently proposed mechanisms for DIGM can explain all of these recent electron microscopy results. However, the dislocation observations clearly indicate that stress effects are important at the moving interface and that stress relief occurs at the original grain boundary position. A possible mechanism map for DIGM has been derived which contains various diffusion and migration regimes where different driving forces can dominate. The features of this map are qualitatively consistent with the microstructural results obtained on the $\mathrm{Cu}-\mathrm{Zn}$ system.

\section{Alloy Coarsening}

Often commercial alloys obtain improved properties through the presence of coherent precipitates which engender long range stress fields. These elastic fields can have a profound effect on phase equilibria and phase transformation kinetics. In current work done in collaboration with W. C. Johnson of Carnegie-Mellon University, it has been shown that in such alloy systems these stresses produce a processing path dependence of the equilibrium phase diagram, so that the phase diagram is not a unique function of alloy composition, temperature, pressure and materials constants. An important result from the study of precipitate coarsening is that inverse coarsening, where small particles grow at the expense of large particles, instead of the usual case where the small particles shrink, can be obtained. Specific predictions are being generated concerning the kinetics and conditions for inverse coarsening. These results could be very important in aiding the development of stable precipitatestrengthened alloys.

Experiments have been conducted using small $\mathrm{Sn}$ crystals in $\mathrm{Sn}-\mathrm{Pb}$ eutectic liquid to provide the first experimental test of coarsening theory in a system in which all the materials parameters necessary for comparison to theory are known a priori. Detailed numerical calculations which account for the free-boundary nature of the coarsening problem have been performed to understand the morphology of the solid particles observed in these experiments involving high volume fraction of solid. The calculations are consistent with the experimental results. 


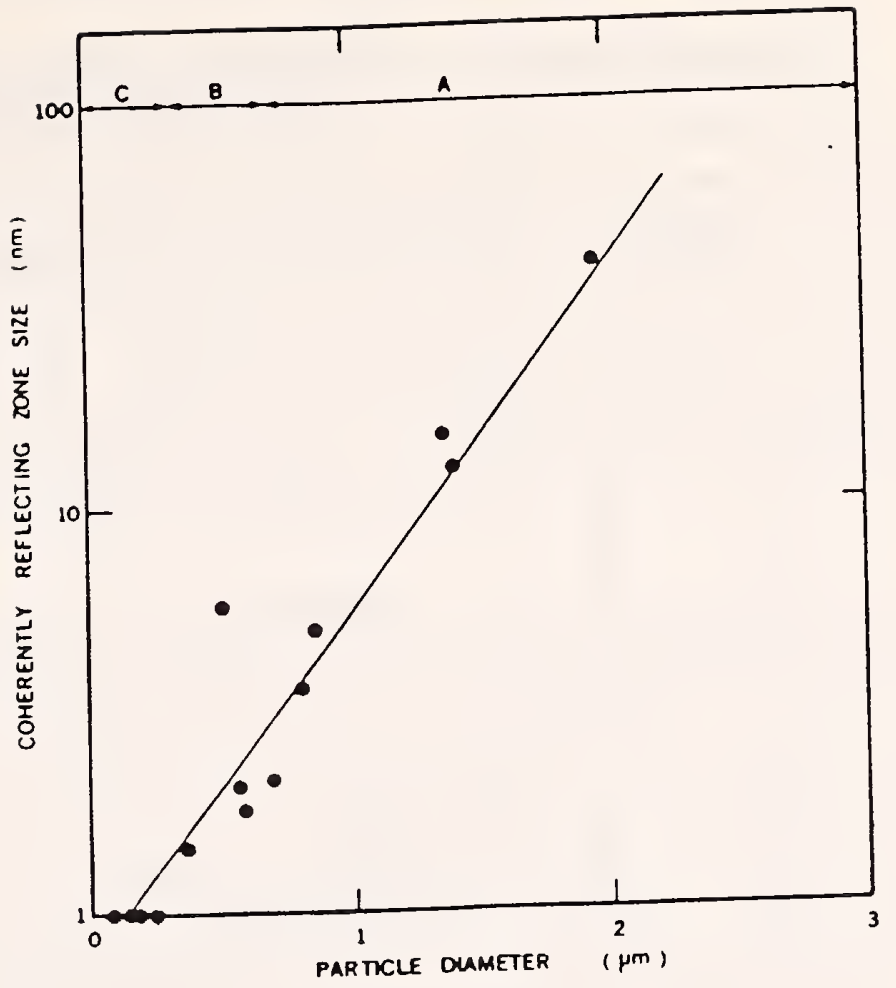

Fig. 1. Size of coherently reflecting zones plotted against particle diameter. The corresponding electron diffraction patterns consist of $(A)$ spotty rings, (B) continuous rings, and (C) broad glass-like rings.

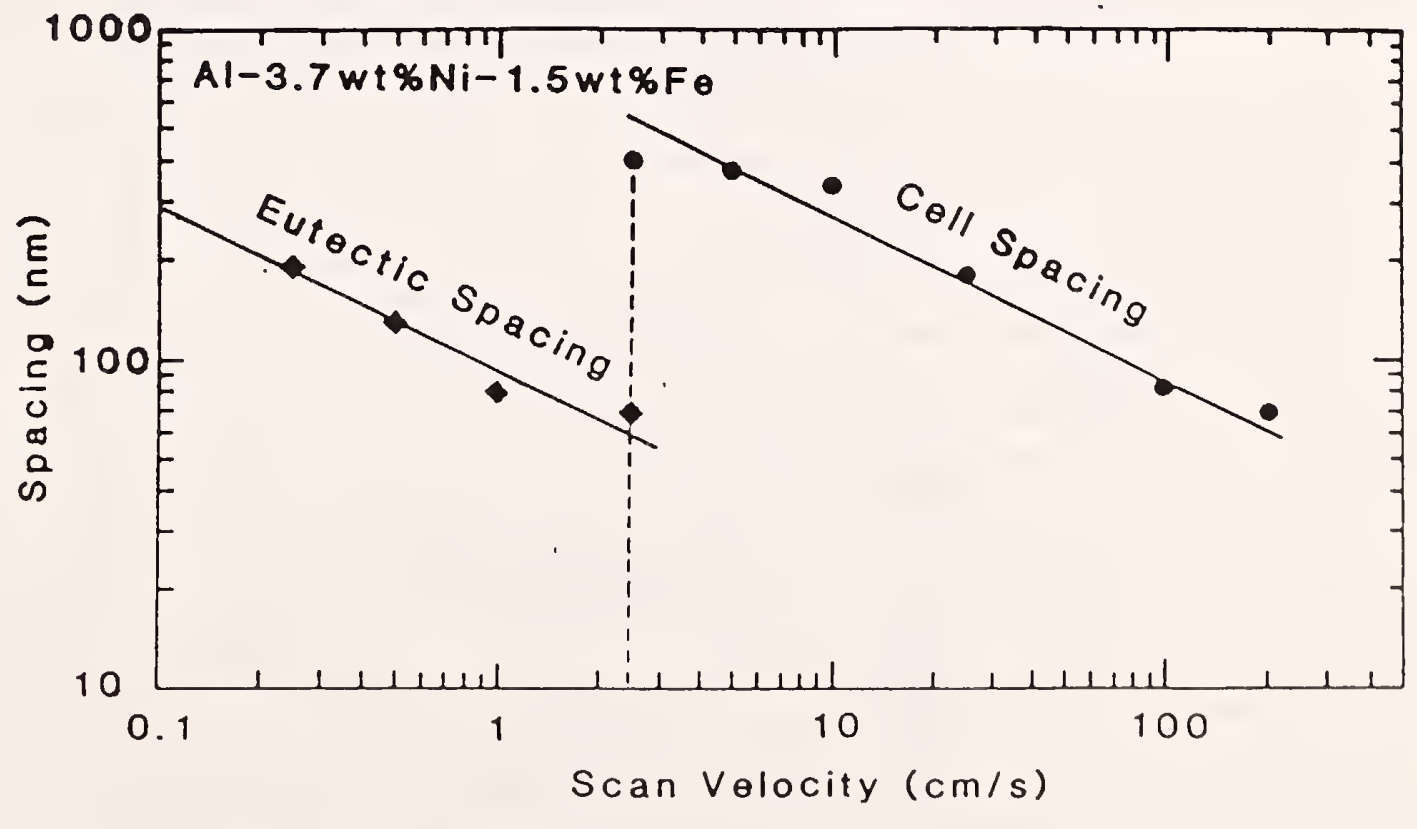

Fig. 2. The effect of solidification velocity on microstructure and the spacing of eutectic and cellular structures in Al-Fe-Ni alloys. 


\section{A MECHANISM FOR DISPERSOID}

\section{FORMATION BY RAPID SOLIDIFICATION}

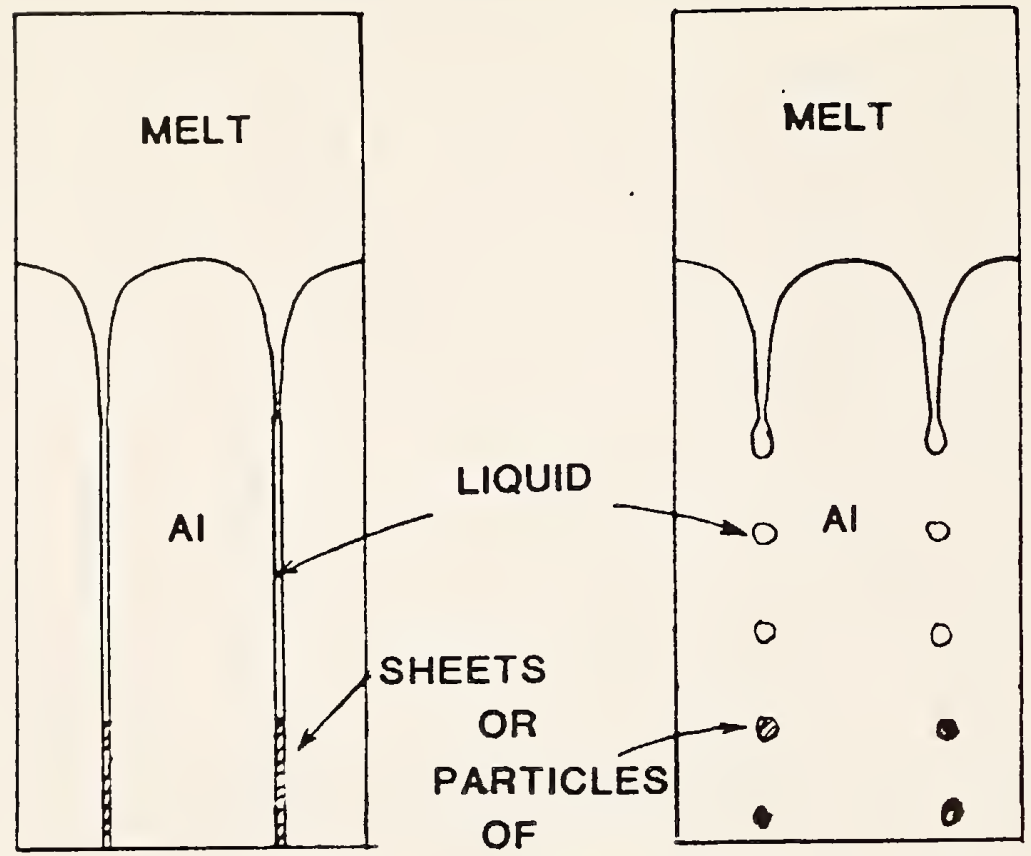

INTERMETALLIC

$50 \mathrm{~cm} / \mathrm{s}$

$500 \mathrm{~cm} / \mathrm{s}$

Fig. 3. Schematic représentation of different ways the intermetallic phase forms at cell walls. At intermediate solidification rates, continuous sheets of $\mathrm{Al}_{\mathrm{g}} \mathrm{FeNi}$ form on the cell walls. At high solidification rates, liquid pockets are formed at the liquid-solid interface and subsequently solidify to form the discrete particles of AlgFeNi.

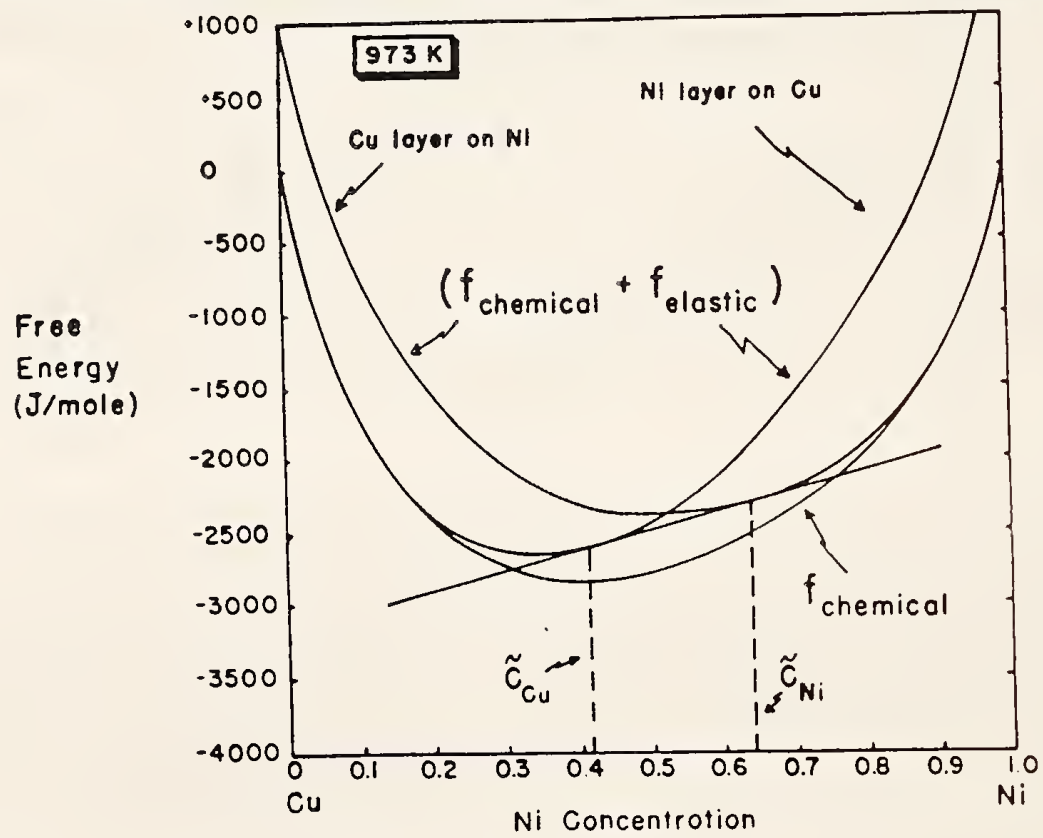

Fig. 4. Effect of elastic strain energy on alloy compositions near interface in single-phase $\mathrm{Cu}-\mathrm{Ni}$ alloy system. When diffusion occurs across the interface, the resulting gradients in composition and lattice parameter introduce elastic energy proportional to the square of the strain. The predicted equilibrium compositions on each side of the interface are the compositions $\widetilde{C}_{C}$ and $\widetilde{C}_{N i}$ where the common tangent to the free energy curves for the two stressed materials touches these curves. 
Research is carried out to improve measurement methods and to develop standards related to wear and mechanical properties of metals. A significant portion of the effort is directed towards an improved understanding of the physical mechanisms involved in wear, friction, and mechanical behavior. The methods used include wear and mechanical testing, optical and electron microscopy, microindentation measurements, metallography, surface analysis, and wear particle analysis. An additional activity in the task includes corrosion and fatigue behavior of alloys used in synthetic implants.

Wear and mechanical performance of industrial systems of all levels of complexity, including also a wide range of consumer products, is an important part of the nation's industrial effort. Costs associated with failure and inadequate performance in these areas have a significant economic effect. Greater use of stronger, more wear-resistant materials can improve productivity and our competitive position world-wide. This task is developing test methods suitable for evaluating new materials having improved mechanical and wear properties. This work leads to data on such materials that may be used by design engineers in applying new materials to use. One example of a currently important area is that of metallic coatings. There are no adequate standard methods for measuring the wear performance of coatings. In their absence, users have no basis for making choices among available coatings for better wear performance. One new area of emphasis in this task is that of wear data for commercially important alloys and coatings.

The work of the Group is supported in part by a number of other Federal agencies in recognition of the importance of adequate wear and mechanical behavior of machinery and mechanical systems. The Department of Transportation (DOT) supports our work in failure prevention for small pressurized containers that may contain toxic materials, or in the opposite extreme, breathing air for rescue personnel. In any case sudden fracture or slow leak failure can create unacceptable consequences. Our research on test methods and failure mechanisms has led to new U.S. regulations in this area. The Department of Energy (DOE) supports our work in galling wear of materials where new measurement methods for quantitatively assessing galling performance have been developed. New industrial valve materials and coatings have been examined in this work, and a new model for alloying effects on galling wear has been developed at NBS. The Office of Naval Research (ONR) supports a beginning effort to measure the dynamic mechanical properties of energetic (explosive) materials. A unique micromechanical testing approach developed in our laboratory has provided the first set of dynamic strength and fracture data on such materials in pure, crystalline form. The data will enable evaluation of a dislocation-based theory of "hot spot" formation preceding ignition of those substances.

Numerous activities in the Group also have significant involvement with private industry. We are funded by C. S. Draper Laboratory, Inc., Boston, MA, to conduct state-of-the-art creep measurements on highly stable materials used in gyroscope systems. We are conducting joint measurements with Deere and Company, Moline, IL, on galling wear properties of 
materials that may have future application in critical machine service. We have begun measurements jointly with Minnesota Mining and Manufacturing Company, Minneapolis, MN, on the micromechanical properties of magnetic recording discs. We are working with several implant manufacturing firms, including Howmedica, Inc., NJ, and DePuy Manufacturing Company, Inc., IN, to evaluate new materials for future prosthetic devices. In all of these cooperative activities, our measurement and metallurgical expertise is contributed to enable a more accurate understanding of material behavior in wear and mechanical properties. In addition, we contribute to the improved understanding of the fundamental mechanisms that are involved.

\section{FY 86 Significant Accomplishments}

- An analytical model has been developed for friction and wear break-in of sliding metals. The model also considers longer term transitions (sudden changes) that reflect change in the wear or friction mechanisms at work. Experimental work has produced data that is being used for testing and improving the model.

- Dynamic deformation and fracture properties have been obtained from small crystals of an energetic material, cyclotrimethylene trinitramine $(\mathrm{RDX})$, using instrumented microindentation. The results are a first indication of a loading rate dependence of onset of fracture in such materials. The behavior is being analyzed in terms of a dislocation-based model of hot spot formation.

- A workshop on tribology data and information was planned and held at NBS with leadership from this task. Approximately 40 individuals from both universities and private organizations participated over a four week period. Several foreign tribologists also participated. A report containing specific recommendations has been prepared, and some of the efforts are now underway. Funding for the work will come from DOE, other federal agencies, and the private sector.

- Studies of wear of chromium plating used in a currency printing process have led to the identification of the principal wear and corrosion process, and to the development of two laboratory wear tests that can be used to evaluate new plating methods and the inks involved in the process. The results and test methods will be utilized by the U.S. Bureau of Engraving and Printing.

Wear of Materials

Subtask 1

P. J. Blau, L. K. Ives, A. W. Ruff, M. Peterson, J. Harris, P. Boyer, and E. Whitenton

Friction and Wear Break-in

The previous year witnessed the development of an analytical framework for a model for the frictional running-in behavior of sliding metals. The model was based on an extensive survey of tribology literature and in-house experimental work performed on a series of ferrous and 
non-ferrous alloys over the last five years. The current year's research has extended the model to consider the case of longer term frictional transitions whose occurrence usually coincides with changes in the dominant modes of wear in the sliding contact zone. These transitions are frequently associated with such processes as nucleation and growth of sub-surface fatigue cracks, the formation of oxide films during sliding, debris compaction and accumulation, and the deposition of micrometer-thick lamellae of displaced and highly deformed material. Longer duration experiments complemented the development of transition terms for the model. These experiments were conducted on a reciprocating ball-on-flat tribometer to study the behavior of a tarnished $\mathrm{Cu}-5 \mathrm{wt} \% \mathrm{Sn}$ alloy and a specially heat-treated $\mathrm{Cu}-15 \mathrm{wt} \% \mathrm{Ag}$ alloy (fig. 1). The microstructure of the $\mathrm{Cu}-\mathrm{Ag}$ alloy was tailored to provide large $\mathrm{Cu}$ grains surrounded by a thin, continuous network of $\mathrm{Ag}-\mathrm{rich}$ constituent (eutectic). It was used in this condition to provide "built-in" microstructural markers for tracing the high near-surface strains associated with frictional shear damage. Characteristic running-in behavior of the $\mathrm{Cu}-\mathrm{Ag}$ alloy is shown in figure. 1. Plans for FY 87 are to test the validity of the model with further experiments and to incorporate functional relationships between test load and the incubation period preceding sudden friction transitions.

Wear Properties of Metal Coatings

Studies are being carried out on a series of $\mathrm{Ni}-\mathrm{Cu}$ composition modulated layered coatings on steel that were prepared by the Electrodeposition Group. Sliding wear experiments have been conducted under dry conditions in air using the new crossed cylinder tester that has recently been standardized by the ASTM committee G-2. A slow sliding speed of $1 \mathrm{~cm} / \mathrm{s}$ was selected to avoid surface heating. Both the load dependence and sliding distance dependence of wear rate were measured for three different coatings, and for the two base metals, $\mathrm{Ni}$ and $\mathrm{Cu}$. The counterface was 52100 bearing steel. The smallest layer spacing of $10 \mathrm{~nm}$ showed a much reduced wear rate over the coatings with spacings of $100 \mathrm{~nm}$ and $300 \mathrm{~nm}$, so long as the contact stress during wear was sufficiently low. For higher stresses the wear rate increased to that of the other coatings. These results appear to be consistent with the model of dislocation barriers at each internal interface between layers which offer resistance to the growth of plastic deformation beneath the wearing contact. This subsurface plastic deformation is the principal mechanism in the failure process that produces wear debris under the test conditions being used. Plans for next year include microscopic studies of the deformation associated with the wear zone so that direct evidence can be obtained for the barrier effect at the layer interfaces.

\section{Galling Wear}

A comprehensive investigation of the process and mechanism of galling of metals is being conducted partly under the sponsorship of DOE. Galling is a severe form of wear which occurs at sliding surfaces, leaving them markedly roughened as a result of plastic deformation, fracture, and transfer of metal from one surface to the other. The DOE has identified galling as a significant cause of failure of valves which are employed to control the flow of gasses and fluids in energy conversion systems. Roughening of the valve sealing faces by galling results in an increased 
rate of leakage. Galling may also lead to complete seizure of the valve. An important part of our program has been the study of the influence of various metallurgical parameters on galling severity. Twelve pure metals, six binary alloys, and numerous complex multiphase alloys have been studied. Among the pure metals it has been found that strength related properties such as hardness have little effect on galling severity. On the other hand, the mode of deformation has a strong influence. Hexagonal close packed metals that deform predominantly by basal slip have a much greater resistance to galling than body centered cubic and face centered cubic metals. Similarly, in the study of $\mathrm{Cu}-\mathrm{Al}$ and $\mathrm{Cu}-\mathrm{Ge}$ binary alloys, stacking fault energy which influences the mode of deformation was also found to affect galling severity. The galling behavior of several commercial steels having different heat treatments and surface treatments such as carburization has been of special interest. Figure 2 shows some results that were obtained for sliding couples of quench hardened AISI 1541 steel and case carburized AISI 8620 steel. Detailed studies by means of scanning electron microscopy of the initiation and subsequent propagation of damage have indicated that the mechanism of galling is what has been referred to as "prow" formation. An Industrial Research Associate from Deere and Company works with us on this project.

Wear of U.S. Currency Printing Plates

Wear of currency printing plates is a serious problem affecting both the quality of the impression and the unit cost. The objectives of this project which is sponsored by the Bureau of Engraving and Printing are:

1) determine the mechanisms responsible for the wear of printing plates,

2) develop a laboratory wear test for the evaluation of materials employed in the printing process, and 3) carry out laboratory wear tests to evaluate the wear performance of experimental electroplatings. The project is being conducted jointly with members of the Electrodeposition Group. Currency printing plates consist of a relatively soft electroformed sheet of nickel onto which a layer of hard chromium is electrodeposited. The wear life of the chrome plating depends on the properties of the plating itself, the ink employed, and the printing press operating parameters. Two laboratory wear tests have been developed to investigate the wear process. Based on results obtained with these tests and on the examination of actual worn plates it appears that the abrasive wear probably consists of direct loss from the chrome electroplate as well as loss by removal of the oxide film that forms on the surface of the chrome as a result of chemical reaction with the atmosphere and the ink. Our studies have indicated that increased wear life can be obtained with improved chrome plating materials. However, results have also shown that ink rheology and particle content coupled with the operating conditions of speed and load have a strong influence on wear rate.

\section{ASTM G-2 Committee on Wear and Erosion}

Several staff members continue to participate in the wear standardization work of this committee. Chairmanship is held of the Operations subcommittee, the Terminology subcommittee, and of the task group on solid particle jet erosion testing. Major contributions are also made in the task groups on galling wear, on crossed cylinder wear testing, and on friction measurements. We are also participating in the planning of 
several future symposia and workshops. There are about 80 members of the Committee from private industry, so there is ample opportunity for our staff to interact in an effective manner.

Mechanical Properties

Subtask 2

R. S. Polvani, J. H. Smith, P. Boyer, and E. Whitenton

\section{Dynamic Microindentation}

Industrial designers need data for dynamic mechanical properties of materials. A new and nondestructive approach to dynamical mechanical testing has been developed in this project. Derived from conventional hardness indentation testing, there are two important innovations. The indentation is described by a load-displacement curve, and is performed over a wide range of times, from hours to milliseconds.

In one project with ONR, we have studied the deformation behavior of an energetic material, $\mathrm{RDX}$, respecting the magnitude and duration of loading. We found a movable ductile-to-cleavage transition, which at fast impact rates occurs at undetectably small loads. The use of energetic materials, explosives and rocket propellants, require controlled ignition. Just why a mechanical impact causes ignition is still unclear. A theory we are investigating recognizes that impact deformation causes dislocation motion; and dislocation clustering causes ignition. Both the free motion and piling-up of dislocations at internal obstacles are key factors. The kinetic and/or self energies of dislocation strain fields are believed to cause "hot spot" formation and subsequent ignition. A major theoretical factor is the two competing deformation modes, plasticity and cleavage, and our mechanical studies will shed some light on these processes.

Recent modifications to the Dynamic Microindentation Instrument include a microscope for locating indentation sites, further reduction of the working applied load range to $0.01 \mathrm{~N}$, and use of an improved displacement gauge. The microscope provides the means to indent specific sample features to within $+/-3 \mu \mathrm{m}$. The improved displacement reduces systematic errors and increases signal sensitivity by a factor of $60 \mathrm{X}$, permitting greater precision of depth determination.

In another project composite materials are being studied to determine whether interfacial zones can be shown to contribute or detract from the overall performance of metal matrix composites. A schematic of one physical model we are developing is shown in figure 3. Assumptions implicit in this model are that all three zones occupy a significant fraction of the total system volume, and that interfaces form at the expense of matrix volume. Recent work by Arsenault and Flom (University of Maryland) plainly show that this is the case for thermally consolidated composites. A basis for quantitative evaluation of the contribution of interfaces in strengthening composites is given by the following equation as applied in our model:

$$
\text { Tensile Strength }{ }_{z \text { one }}=4 V_{f}\left(d_{f} t-t^{2}\right)\left(T S_{i}-T S_{m}\right) / d_{m}^{2}
$$


where $d_{f}=$ fiber diameter, $t=$ interfacial zone thickness, $d_{m}=$ diameter of matrix cavity, $\mathrm{V}_{\mathrm{f}}=$ fiber volume fraction, $\mathrm{TS}_{\mathrm{i}}=$ interfacial zone strength, and $\mathrm{TS}_{\mathrm{m}}=$ matrix tensile strength.

Presently measurements are underway in several prototype composites to examine this approach.

\section{Pressure Vessels}

Research is carried out on metallic and composite pressure vessels used in the transportation of high pressure gases. During the present year tests were continued to develop suitable fracture criteria for the safe construction of ultra high strength steel, thin walled cylinders. A publication of these results is in preparation jointly with $M$. Rana of Union Carbide Corp. This project also includes technical assistance to the Office of Hazardous Materials in the Department of Transportation to develop safety standards for the use of such vessels.

Work is continuing to develop a suitable test method for inspecting large, seamless steel cylinders using a combination of acoustic emission and ultrasonics. To date, a large number of cylinders have been tested using several acoustic emission procedures. These studies are being done jointly with Union Carbide Corporation, Linde Division, Tonowanda, NY, and FIBA, Inc., Westborough, MA. Although many defects have been detected with these procedures, the detectability of specific defects has not been clearly established yet: Work is continuing to refine and develop the inspection procedures and to establish a reliable procedure for inspecting cylinders by acoustic emission methods.

Fine, intergranular cracks have been found in the neck/thread area of type $3 \mathrm{~A} 1$ aluminum and composite aluminum seamless cylinders. An investigation is ongoing to determine the extent and significance of these cracks and to develop a reliable inspection technique for finding the cracks. The cracking is believed to be a form of room temperature creep cracking that is enhanced by temperature, stress, and environment; research is continuing to establish the responsible mechanisms.

Metallic Surgical Implants

Subtask 3

\section{A. C. Fraker}

This project maintains a laboratory for the study of metallurgical aspects of surgical implants. Implant problems come to our attention due to failures in service, during the evaluation of selected metals for implant use, and in analyzing the metals used in terms of optimum quality. Studies conducted include microstructural characterization, surface film analysis, corrosion testing, and mechanical property measurements. The laboratory is equipped with computerized corrosion and mechanical testing equipment. The project has, for the past fifteen years, developed literature reference files on the use of metals as surgical implants. Recently, these files have been expanded to include selected references on polymers and ceramics. The files contain 1450 reference papers. 


\section{Electrochemical Measurements}

Studies were continued on the effects of varied surface treatments and the oxidation state of metal ions released during corrosion. Anodic polarization measurements were made on Co-Cr-Mo at $37 \mathrm{C}$ in Hanks' physiological saline solution, $0.9 \%$ saline solution, and serum (NBS SRM 909). There was a significant increase in current in the passive region for tests in the saline solution. The breakdown potential was nearly the same in all three solutions. Chemical analyses after corrosion testing were çarried ușing atomic absorption methods to determine the amounts of $\mathrm{Cr}^{+3}$ and $\mathrm{Cr}^{+6}$ present. The data show both types present in the saline solution but only the $\mathrm{Cr}^{+3}$ in the serum solution. The nature of the $\mathrm{Cr}$ ion release will be studied further since it bears on the biocompatability of metal implants.

Anodic polarization measurements on arc plasma sprayed porous coated Ti-6Al-4V were made in Hanks' physiological solution at $37 \mathrm{C}$. Results showed that grit blasting surface preparation procedure greatly reduces the corrosion resistance and results in a lower breakdown potential of 0.65 volts vs. the saturated calomel electrode (SCE). The breakdown potential for $\mathrm{Ti}-6 \mathrm{~A} 1-4 \mathrm{~V}$ is 2.5 volts vs. SCE. Breakdown potentials for grit blasted and sintered, and for arc plasma spray coated fall intermediate within these two extremes. Energy dispersive $x$-ray analysis showed the presence of iron, silicon, and additional aluminum on the surface of the grit blasted material. These results demonstrate the importance of controlling all parameters to prevent contamination during the plasma spraying process.

\section{Corrosion-Fatigue}

Studies of effects of sintered porous coatings on corrosion fatigue behavior $\mathrm{Co}-\mathrm{Cr}-\mathrm{Mo}$ were investigated. Three types of specimens were prepared; the as cast condition, sintered without the porous coating, and sintered with layers of spheres to produce the porous coating. Specimens were subjected to fully reversible torsion tests with applied shear strain amplitudes ranging from $+/-0.003$ to $+/-0.006$ at a frequency of $1 \mathrm{~Hz}$ in flowing Hanks' physiological saline solution at $37 \mathrm{C}$ and a $\mathrm{pH}$ of 7.2 . The results are shown in figure 4 where the data on porous coated Co-Cr-Mo material is compared with earlier work on hot isostatically pressed, forged and cast Co-Cr-Mo. The materials seem comparable when torsion tested with an applied shear strain amplitude of $+/-0.006$ but the endurance limit for the porous coated material, $(0.003)$ was less than that for the nonporous material, $(0.004)$.

\section{ASTM F-4 Committee on Medical and Surgical Materials and Devices}

The project contributes to standards activities through the Metallurgical Materials Section which develops specifications and standards for metals and alloys to be used as implants. Other $\mathrm{F}-4$ sections of principal interest are the Joint F-4/G-1 Corrosion Section and the Porous Metals Section where we have provided leadership in symposia and standards development. 


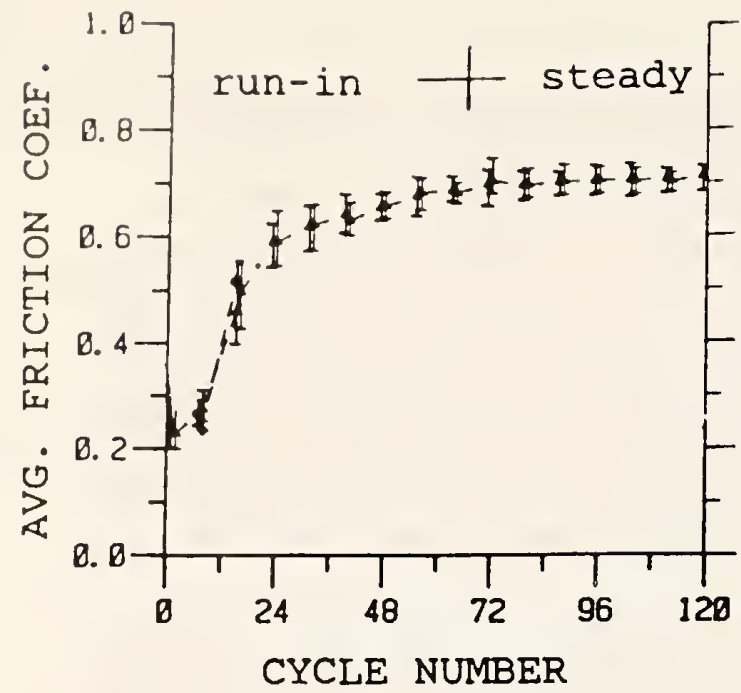

Figure 1. The rise in friction to steady state for reciprocating sliding using a 52100 steel ball on a polished $\mathrm{Cu}-15$ wt\%Ag flat. Load $4.91 \mathrm{~N}$, sliding velocity $5 \mathrm{~cm} / \mathrm{s}$, in argon.

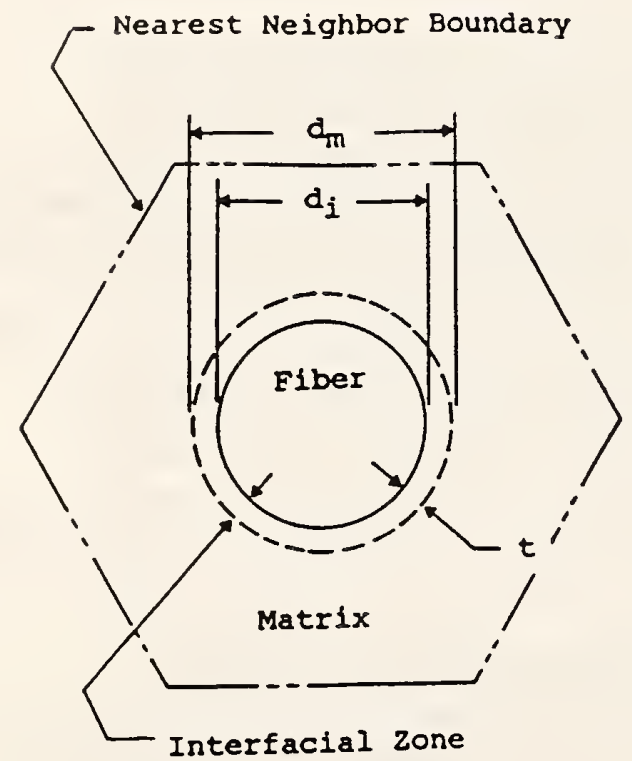

Figure 3. Schematic showing three regions affecting mechanical behavior in a composite.

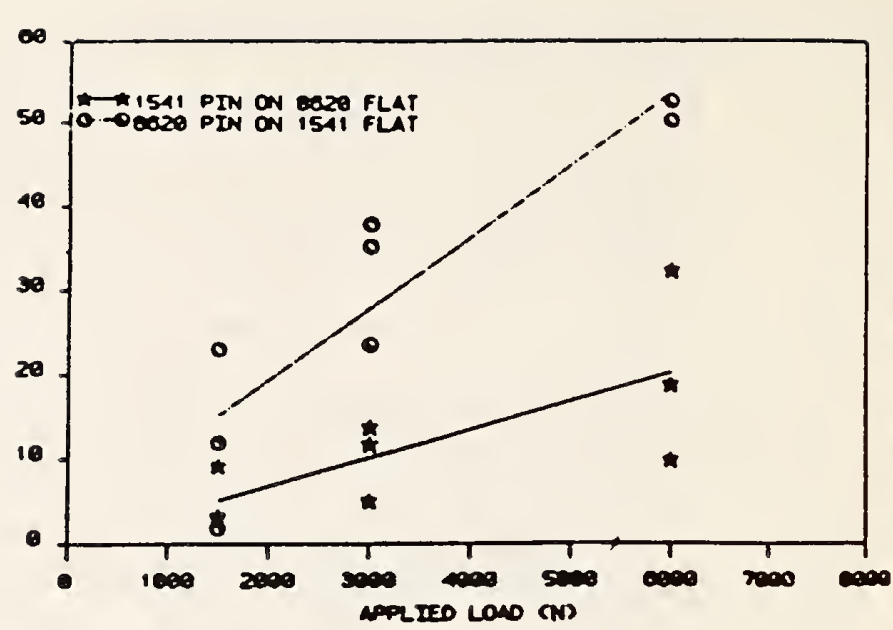

Figure 2. Plot of average roughness (Rt) values versus load for pin-on-flat galling wear tests.

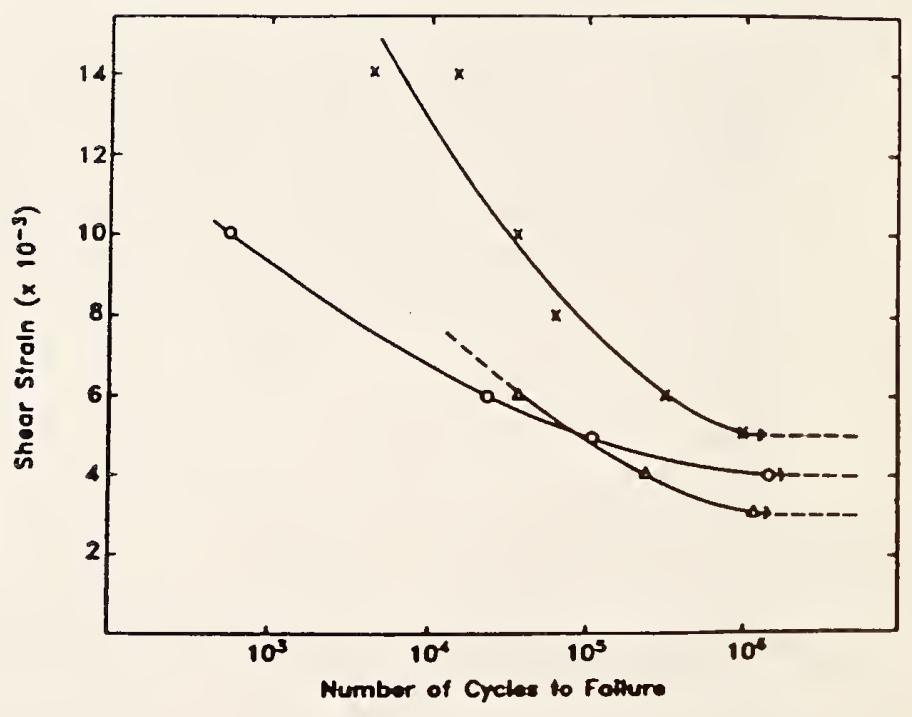

Figure 4. S-N curves for Co-Cr-Mo in the cast $(0)$, forged or hipped $(x)$ and sintered porous coated $(\Delta)$ conditions. Reversible torsion tests conducted in Hanks' solution, $37 \mathrm{C}, \mathrm{pH}$ of 7.2 , frequency $1 \mathrm{~Hz}$. 
The principal activity of this task is the collaborative effort with the American Society for Metals (ASM) in the joint ASM-NBS Alloy Phase Diagram Data Center. This program continues to provide critically evaluated phase diagrams and other constitutional data as well as related bibliographic material. ASM provides overall program guidance, bibliographic support, and dissemination of program outputs. NBS provides overall technical guidance to insure the data reliability and accuracy of the evaluated phase diagrams, development of a model evaluation procedure and style guide by the three binary category editors (titanium, aluminum, and iron) located within the group for use by the other binary category editors, and the development of a prototype database for on-line retrieval of the phase diagram related data. The program has a strong international content through the alloy category editors who are responsible for the selection and evaluation of the data. Currently, there are thirty binary and 20 ternary category editors participating in this program. During the past year, the three NBS category editors completed evaluations on thirteen titanium, seven aluminum, and three iron systems. The titanium binary alloys systems have now been completed and publication of the evaluated titanium phase diagrams as an ASM monograph is in process.

A major effort was initiated in 1985 to digitize 1578 binary phase diagrams for the new ASM compendium updating the compilations of Hansen, Elliott and Shunk. This project has been successfully completed in FY86. Crystal structure and other ancillary data are now being computerized and binary system graphics and numerical data are being loaded into an online database.

The experimental efforts in support of the alloy phase diagram continued with emphasis on binary and ternary Al-based systems. Rapid solidification and stable and metastable phase equilibrium studies have been completed for the Al-Mn system. Studies are being carried out on the $\mathrm{Cu}-\mathrm{Mn}$ system (in relation to the Al-Cu-Mn and Al-transition metal binary systems).

Other activities in this task include an experimental program to improve standards for magnetic particle inspection and dye penetrant testing, and to evaluate the need for standards and specifications in the field of Barkhausen Noise NDE. These efforts involve substantial interactions with standards writing organizations such as ASTM.

\section{FY 86 Significant Accomplishments}

- Theoretical and experimental results in the area of magnetic particle inspection led to the incorporation into a new military standard of a new methods for using Hall-effect probes to determine proper magnetization levels for effective inspection.

- A program of evaluation of $\mathrm{Al}$-based ( $\mathrm{Al}-\mathrm{Cu}-\mathrm{X}$ ) systems has been initiated. 
- Thermodynamics optimization programs have been extended to make use of new Gibbs energy models and optimization algorithms and a userfriendly interaction thermodynamics optimization program has been implemented for ternary systems.

- A workshop on the phase diagram database was held to introduce the database to potential users.

\section{Alloy Phase Stability}

L. K. Charlton*, D. J. Kahan, R. M. Hayes, L. F. Lilly*, A. J. McAlister, J. L. Murray, C. E. Sirofchuck*, H. E. Rubin, L. J. Swartzendruber, C. L. Qualey*, L. B. Wilkinson, D. L. Moffat, and U. R. Kattner

*American Society for Metals Research Associate

We are pursuing a program of four interconnected parts: critical evaluation, compilation and thermodynamic modeling of binary phase diagram data; designing and setting up a prototype database for on-line retrieval of the graphical and numeric phase diagram and ancillary data of the (crystal structure, lattice parameters); experimental work on phase stability of alloy systems, selected with a view a complement the evaluation program; and the theory of phase stability.

\section{Alloy Phase Diagram Data Center Activities}

All activities revolve about a collaborative data evaluation program for alloy phase diagrams with the American Society for Metals. At NBS, the scope of the phase diagram program has been greatly extended. During the last year, the Alloy Phase Diagram Data Center has continued to be the focal point for the entire ASM/NBS Phase Diagram Program.

Phase diagram evaluation projects are being carried out by three category editors at NBS, Joanne L. Murray for Titanium alloys, Archie J. McAlister and Joanne L. Murray for Aluminum alloys, and Lydon J. Swartzendruber for Iron alloys. Coverage of the systems includes crystal structure, metastable and constrained equilibria, and high temperature thermodynamic properties as well as the stable equilibrium diagrams. Calculations of the phase diagram form thermodynamic data are carried out using a number of computer programs available at NBS.

In addition, the data center staff are responsible for technical editing and graphics digitization for the Bulletin of Alloy Phase Diagrams, and for prototype database project, the editing and computer graphics for a book, the Binary Alloy Phase Diagrams, which is to update the compilations of Hansen, Elliott, and Shunk.

The Bulletin of Alloy Phase Diagrams continues to be published at the rate of six issues per year. Technical editing of manuscripts is done by the editor, J. L. Murray; C. E. Sirofchuck supervises the entry computer of graphical and crystal structure data.

In preparation for making the phase diagram database commercially available, a workshop was held to familiarize potential users with the 
database. Attendees of the workshop were from major U.S. corporations, IBM, General Electric, Allied Corp., etc. A manual for the use of the database was written by Jim Sims and Joanne Murray to facilitate the user's application of the database. The attendees operated the database with the assistance of J. S. Sims, J. L. Murray and J. B. Clark. The database was well received. Final changes in the database were made at the suggestion of the participants. A typical search is shown on the last page of the Chemical Metallurgy Group report.

\section{Experimental Phase Diagrams and Related Thermodynamic Calculations}

A major fraction of the past year's effort was devoted to the completion study of the complex, recrystallization and quasicrystalline icosahedral and $T$ phases formed on rapid quenching of $A l$ rich Al-Mn alloys. Heats of transformation and activation energies have been determined by differential thermal analysis (DTA), and the phases occurring during the process by $x$-ray diffraction and transmission electron microscopy. Apart from their inherent interest, these results have proved most useful in the evaluation of the Al-Mn phase diagram. Metastability of the $\mathrm{Al}_{10} \mathrm{Mn}_{3}$ phase was confirmed and that of ' $\mathrm{A} 1_{4} \mathrm{Mn}$ ' established. Certain other features of recent experimental studies of the system were confirmed. The measured heats of transformation facilitate modeling of the non-equilibrium phases and permit estimates of the true liquidus in this region of the diagram to be made. Thermodynamic calculations of Al-Mn have produced a complete catalog of metastable invariant reactions that may occur during cooling from the melt. A peritectoid reaction was predicted by the thermodynamic calculations and confirmed by thermal analysis experiments.

The topological similarity of the Al-rich Al-Cr and Al-Pd systems, in which the icosahedral phase is known to occur, as well as Al-Mo, $\mathrm{Al}-\mathrm{V}$ and Al-W strongly suggest that these systems too may contain long lived metastable phases, and that their presently accepted equilibrium diagrams are incorrect. A systematic study of metastable equilibria in Aluminumtransition metal systems has been completed and a data evaluation of $\mathrm{Al}-\mathrm{Cr}$ is in progress. The extension of metastable equilibria into ternary systems is also of current interest. Thermodynamic calculations have been made of the $\mathrm{Cu}-\mathrm{Mn}$ and $\mathrm{Al}-\mathrm{Cu}-\mathrm{Mn}$ and experiments on the $\mathrm{Cu}-\mathrm{Mn}$ binary systems are underway to resolve discrepancies found by means of the model

calculations. No evidence of the reported $\mathrm{Cu}_{3} \mathrm{Mn}$ or $\mathrm{Cu}_{5} \mathrm{Mn}$ phases have been observed using DTA; interpretation of the reactions that are seen in DTA is in progress. The Al-Cu-Li system is extremely difficult to study experimentally, because of reactivity of the alloys and the high vapor pressure of Li. Strategies for overcoming these difficulties are now being planned.

Expansion of our DTA capability is underway. Equipment is being acquired which will raise the maximum achievable temperature from $1200^{\circ} \mathrm{C}$ to $2000^{\circ} \mathrm{C}$. Moreover, the equipment is being tailored to permit use of the Dils blackbody temperature sensor in lieu of the traditional thermocouples. This will enable more precise determination of transformation temperatures in the $600^{\circ} \mathrm{C}$ to $2000^{\circ} \mathrm{C}$ range, and offer improved accuracy in the heats of transformation there, as well as expanding the scope of our work. 
Several items have been acquired to enable us to melt and heat treat high purity alloys. An arc melter was salvaged, cleaned and refurbished, and tested by melting a titanium ingot. Three furnaces capable of achieving $800^{\circ} \mathrm{C}$ were refurbished and the temperature gradient profiled. New programable controllers were purchased for the furnaces.

A substantial effort has been made this year to improve and update the computer programs for thermodynamic calculations and graphical display. For binary systems, more sophisticated models for compound free energies have been implemented and an improved user-friendly interface was written. For the first time, a program of similar power is available for ternary calculations. A variety of unit transformations and graphical representations of ternary sections and projections can be made using software that interfaces to the two dimensional phase diagram graphics program.

\section{Magnetic NDE}

A variety of magnetic methods are available for nondestructive evaluation, both of defects and of material properties. A number of these, such as magnetic flux leakage, magnetic particle inspection, and eddy-current testing, are widely used in industry, primarily for detection of defects. Some other methods have been used on a limited scale but still require development to make them more reliable and more widely applicable. These include: Barkhausen noise, magnetoacoustic emission, magnetomechanical damping, and ac magnetometry. Finally, magnetic property measurements, including saturation magnetization, coercivity, and initial permeability, contain a wealth of information concerning material properties that has barely begun to be exploited.

To date, this project has been primarily focused on magnetic leakage field methods, especially the magnetic particle methods, and on Barkhausen noise measurements. However, further progress in the use of magnetic methods, especially as applied to the measurement of material properties, will depend on improving our understanding of how the measurement of magnetic properties correlates to material parameters such as alloy composition, heat treatment, stress, states, etc. It is clear that a multivariate approach will be required. That is, two or more magnetic properties can be expected to yield useful information, such as grain size, where a single property measurement would give such information only under very restricted conditions. To this end, the Metallurgy Division has been expanding its ability to perform magnetic measurements, both nondestructive evaluation and for other purposes. During the present year, a vibrating sample magnetometer has been put into operation and is in the process of being computerized. Also, a unique automated ac susceptibility apparatus has been developed. The latter instrument allows the measurement of initial magnetic susceptibility over a frequency range of $20 \mathrm{~Hz}$ to $100 \mathrm{kHz}$. A unique feature is the ability to measure both the real and the imaginary parts of the susceptibility over a wide temperature range. Initial studies are expected to center on the correlation of ac susceptibility, coercive force, and Barkhausen noise with the microstructure of iron-carbon alloys. 
In cooperation with Sandia National Laboratories, a report has been prepared on the NDE of large castings by surface methods. Surface methods include visual inspection, magnetic particle inspection, dye penetrant inspection, eddy-current inspection, leakage field measurement, hardness measurements, and Barkhausen noise measurements. Primary emphasis was on the magnetic particle method because this is the most used method for the inspection of large castings. This report will be combined with two others, one on ultrasonic methods and another on radiographic methods to be used as a resource document for the inspection of large storage casks for the nuclear industry. A talk was given on this report at a Cask Material Technology Seminar held at NBS in December, 1985.

Work has continued in cooperation with ASTM committee E7 and the Standards Subgroup of the JTCG-NDI an improvement of magnetic particle inspection standards. A major problem with both the ASTM standard (ASTM E-709) and with the new military standard (MIL-SID-1949) is the tool steel test ring currently used to verify magnetic particle performance of such rings. An attempt is being made to select a steel and a heat treatment which will reduce the variability in performance of the test rings. Further, even when such variability is reduced to acceptable levels, the currently specified test ring does not do an adequate job of testing the ability of particles to detect narrow cracks. The design of a new test device is being planned. 
Using the "Phases" relation of the database, the search is made for all phases that fulfill the following conditions:

(a) The phase is a congruent melting phase

(b) The phase is Cubic - all faces centered (Pearson symbol contains $\mathrm{cF}$ )

(c) The prototype is not $\mathrm{Cu}$

The selected data is sorted by Prototype.

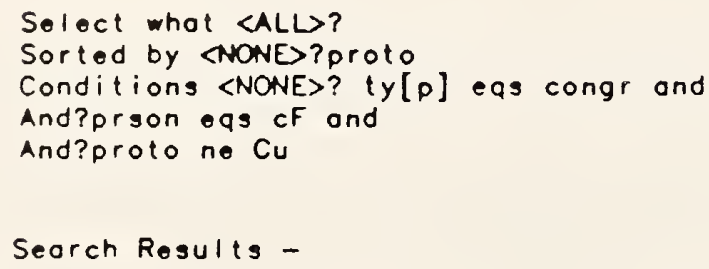

\begin{tabular}{|c|c|c|}
\hline ASYST & $\mathrm{PH}$ & STRK \\
\hline $\mathrm{Mg}-\mathrm{Ge}$ & $\mathrm{Mg} 2 \mathrm{Ge}$ & $\mathrm{C} 1$ \\
\hline $\mathrm{Cu}-\mathrm{S}$ & Cu<2-delta>S & C1 \\
\hline $\mathrm{Cu}-\mathrm{Se}$ & be toCu<2-x>Se & C1 \\
\hline $\mathrm{Mg}-\mathrm{Sn}$ & $M g 2 S n$ & $C_{1}$ \\
\hline$M g-S i$ & $\operatorname{Mg} 2 \mathrm{Si}$ & $\mathrm{Cl}$ \\
\hline $\mathrm{Mg}-\mathrm{Pb}$ & $\mathrm{Mg} 2 \mathrm{~Pb}$ & C1 \\
\hline Al-Ho & AI $2 \mathrm{Ho}$ & C15 \\
\hline$A \mid-L O$ & A I 2 Lo & $\mathrm{C} 15$ \\
\hline$A \mid-G d$ & $A \mid 2 G d$ & C15 \\
\hline $\mathrm{Mg}-\mathrm{Cu}$ & $\mathrm{MgCu} 2$ & C15 \\
\hline$A 1-S c$ & AI2Sc & C15 \\
\hline $\mathrm{Ni}-\mathrm{O}$ & beto & 81 \\
\hline $\mathrm{Ca}-\mathrm{O}$ & $\mathrm{CoO}$ & 81 \\
\hline$v-c$ & $\begin{array}{l}\text { VC } \\
\text { SbU }\end{array}$ & 81 \\
\hline $\mathrm{Sb}-\mathrm{U}$ & SbU & 81 \\
\hline$A I-L i$ & AlLi & 832 \\
\hline$A \mid-A_{S}$ & AlAs & 83 \\
\hline$A \mid D$ & AIP & 83 \\
\hline$A 1-S b$ & AISb & 83 \\
\hline
\end{tabular}

\begin{tabular}{ll}
\multicolumn{1}{c}{ PROTO } & PRSON \\
\cline { 2 - 2 } CoF2 & cF12 \\
CoF2 & cF12 \\
CoF2 & cF12 \\
CoF2 & cF12 \\
CoF2 & cF12 \\
CoF2 & cF12 \\
Cu2Mg & cF24 \\
Cu2Mg & cF24 \\
Cu2Mg & cF24 \\
Cu2Mg & cF24 \\
Cu2Mg & cF24 \\
NoC1 & cF8 \\
NoC1 & cF8 \\
NoC1 & cF8 \\
NoC1 & cF8 \\
NoT1 & cF16 \\
ZnS(sphalerite) & cF8 \\
ZnS(spholerite) & cF8 \\
ZnS(spholerite) & cF8
\end{tabular}

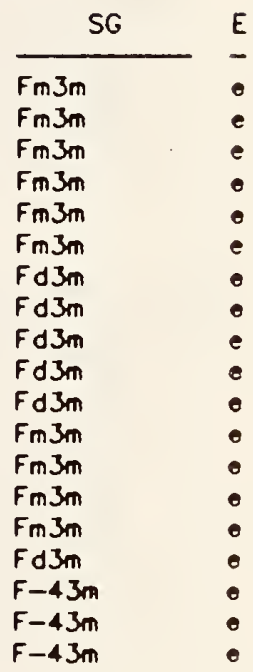

At the time of the search (Jan. 26, 1986) the "Phases" relation contained data on 1267 phases, as shown above, nineteen phases fulfill the above conditions. 
The purpose of this task is to investigate the effects of metallic corrosion, one of the major causes of the shortening of service life of all metallic structures from ships to bridges to pipelines, and whose cost to the US economy is estimated in the $10^{11}$ \$/year range. Corrosion is often a contributing factor in catastrophic failures, whether of chemical plants or prosthetic devices, with consequent loss of life and property.

The work done under this task in FY 1986 has continued to be directed to four main areas: 1) basic research on the mechanism of the major forms of corrosion, 2) development of measurement techniques 3) dissemination of literature data on corrosion and 4) studies of corrosion problems arising from the disposal of high level nuclear waste.

Stress corrosion cracking (SCC) has been the major subject of fundamental research during FY86. The cause of SCC is very poorly understood and there is still debate whether there is only one or several different mechanisms for it. In practice it limits the use and degrades the performance of many engineering materials, ranging from copper and aluminum alloys to stainless steels.

Based on the extensive experience of the Corrosion Group on measurement techniques both in the laboratory and in the field, our efforts in the area of measurement have resulted in the construction of a device for the in-situ corrosion testing of steel in concrete structures. Its performance has been assessed in the laboratory by comparing it with other measurement methods, and it is undergoing field testing. In the area of localized corrosion, electrochemical noise techniques applied to pit initiation are being tested by developing software for statistical analysis.

The joint NACE-NBS program for the institution of a Corrosion Data Center has seen further development in FY 86. This program was initiated in response to a clear need for a central source of reliable corrosion data and for the employment of computer-based media for their dissemination. The activity of the Corrosion Data program has been strengthened by the addition of new staff and by increasing cooperation with industry and other organizations.

Our activity in assisting the Nuclear Regulatory Commission with corrosion problems associated with the development of geological repositories for high level nuclear waste has grown considerably during FY86. This has entailed an expansion of the personnel involved in this effort. This activity concerns a critical national problem with timetables set by congressional order: metallic containers of highly radioactive materials have to be buried at several geologic sites and are expected to withstand corrosion for times well in excess of present industrial experience. The assessment of the problems involved and the estimation of the chances of successful isolation of the radioactive waste pose a very challenging task. 


\section{FY 86 Significant Accomplishments}

- Mechanistic studies of SCC of $\alpha$-brass and Al alloys have continued. Fractographic and electrochemical measurements have indicated that certain proposed mechanisms for brittle fracture may not be valid.

- A system for the simultaneous measurement and analysis of $\mathrm{AE}$ signal during SCC tests has been assembled and successfully tested. Preliminary experiments on stainless steel specimens have been carried out.

- Computer-encoding of NACE Corrosion Data Survey completed.

- Selection of hardware and development of software of DBM of high level nuclear waste completed.

\section{Environmentally Induced Cracking}

\section{Subtask 1}

\section{Stress Corrosion Cracking}

E. N. Pugh, U. Bertocci, T. Cassagne ${ }^{1}$, J. Fink, M. Kaufman, H. Lai ${ }^{2}$, R. Ricker, R. Rotheal, M. Stoudt, A. Van Orden, S. Ventura.

1 Guest Scientists from France

2 Guest Scientist from Taiwan

Our stress corrosion cracking (SCC) studies in FY86 have resulted in some potentially significant findings. First of all, it has been shown that cracking of $\alpha$-brass in aqueous ammonia solutions does not occur in the absence of anodic dissolution of copper. In these conditions the fractures appear ductile indicating that dezincifications is not sufficient for cracking. Furthermore, when a very slight amount of dissolution of $\mathrm{Cu}$ is allowed, the cracking, though localized, appears very different from the "cleavage-like" fractures typical of $\alpha$-brass in cupric ammonia solutions. This result casts serious doubts on the brittle "microcleavage" mechanism for cracking. Finally, TEM observations of regions adjacent to the fracture surfaces of samples tested in cupric solutions at low stresses revealed that very little deformation accompanied the cracking process in contrast to that expected for either the microcleavage or the slip dissolution mechanisms.

Our work on high strength $\mathrm{Al}-\mathrm{Zn}-\mathrm{Mg}$ alloys correlate directly with the $\alpha$ - brass/ammonia results. For example, it has been found that cracking in these alloys occurs for a wide range of microstructural conditions. However, the "cleavage-like" fractures are observed only in those conditions where the slip is coplanar, as shown by TEM analysis, due to the precipitate distribution and, for those conditions, is most prevalent at the largest precipitate sizes. In severely overaged material where the slip is no longer planar, the fractures are not cleavage-like but take on a very complex geometry. In addition, TEM analysis of the material 
adjacent to the cleavage-like fracture surfaces revealed that, again, very little deformation appeared to accompany the cracking process.

According to some mechanisms for T-SCC in ductile metals recently proposed, a surface layer differing in mechanical properties from the bulk metal is necessary for crack initiation. Dealloying may be one way to generate the surface layer. However, pure $\mathrm{Cu}$ also undergoes T-SCC, as it has been shown in nitrite solution. Cracking in this case is associated with the formation of a thick cuprous oxide film. It was therefore interesting to see if T-SCC could be induced in pure $\mathrm{Cu}$ in the absence of the film, possibly in a nitrite solution of suitable acidity. Since the electrochemical behavior of $\mathrm{Cu}$ in nitrite solutions is not well known, it was necessary to carry out polarization studies in various conditions. Extensive data have been collected and some of the electrode reactions identified. However, these studies have shown that it is impossible to prevent film formation without destroying the nitrite in solution. Therefore, SCC tests on $\mathrm{Cu}$ single crystals are now being carried out in sulfate and acetate solutions, where oxide film formation can be prevented. Preliminary results show that T-SCC can be produced in these solutions, with average velocities of the order of $10^{-10} \mathrm{~m} / \mathrm{s}$. More tests are underway to improve control of the cracking process so as to accelerate crack propagation and to perform fractographic studies.

The analysis of acoustic emission ( $A E$ ) signals for the monitoring of SCC and for discriminating among different forms of attack is being applied to austenitic stainless steels in $\mathrm{MgCl}_{2}$ solutions, both during slow strain rate and load pulsing tests. Assembling and testing of the instrumentation has been completed and the experimental work initiated. In a closely related project, sensitized stainless steel is being examined by $A E$ and electrochemical measurements to test the usefulness of $\mathrm{AE}$ as a diagnostic tool.

In the past years efforts have been made to model mathematically the electrochemical and transport processes occurring within crack for $\mathrm{Cu}-$ base alloys. The work has been extended to see if calculations could explain the experimentally observed transition from intergranular to transgranular cracking. However, it became soon obvious that the value of the kinetic parameters involved are not known with sufficient certainty to allow confidence in the numerical results. As a consequence, an experimental effort has been initiated to measure the electrode kinetics of copper in aqueous ammonia solutions. The initial results on the anodic dissolution of $\mathrm{Cu}$ to $\mathrm{Cu}\left(\mathrm{NH}_{3}\right)_{2}{ }^{+}$ions have indicated that this part of the process occur with relatively low hindrance for the chargetransfer step.

Hydrogen Embrittlement

C. G. Interrante, S. Harrison, M. Stoudt

The objective of our work on hydrogen embrittlement is to relate the measurable effects of hydrogen, such as crack growth rate for various stress-intensity $(K)$ levels and the threshold value of $K$ for hydrogenassisted cracking, to the driving force (the fugacity of hydrogen 
associated with a given metal/environment system) and to the important metallurgical factors, such as hardness and inclusion size, shape, and orientation. These relationships will be useful in predicting conditions under which cracking is to be expected, as well as in the development of our understanding of the cracking process, which may lead to theoretical models describing the mechanism of hydrogen embrittlement. In our program, the effects of hydrogen are assessed with fracture mechanics specimens of steels used commercially in the petrochemical industry, and with severe hydrogen-charging environments containing hydrogen sulfide, a common contaminant found in that industry.

In cooperation with the Nondestructive Characterization Group, electric resistance measurements of crack length are coupled with acoustic measurements of strain energy released during crack extension. The results indicate that is possible to estimate the magnitude of the crack extension and of the fracture area associated with each acoustic emission from the acoustic emission alone. It is expected that this sensitive measurement of crack extension will help in understanding the cracking process and the mechanism of embrittlement.

A new computer and a servo-hydraulic test system have been installed for conducting fracture mechanics tests that require complex loading, such as the $J$-integral and constant $K$. Last year, computer codes were written and techniques developed and implemented for the measurements of acoustic energy and crack length, and this year tests were conducted to assure the adequacy of these computer codes. These studies of hydrogen embrittlement of steels have been conducted under the guidance of the Subcommittee on Hydrogen Effects of the Pressure Vessel Research Committee (PVRC) of the Welding Research Council (WRC).

Corrosion Rate Measurements for Practical Applications

Subtask 2

E. Escalante

Corrosion of Steel in Concrete

The final phase of this project, which included corrosion measurements of reinforcing bars in concrete bridge decks, has now been completed. A portable, battery operated, corrosion measuring device was assembled and tested in the laboratory, and the data obtained were compared with weight loss measurements. The results indicate that polarization resistance measurements could be used to measure corrosion of steel in concrete. Field measurements although still preliminary, also appear to be successful. The corrosion data gathered in the field correspond very well with the history of the structures and agree with visual inspection of the bridge decks. Thus, where our measurements indicate high corrosion, we can, indeed, see evidence of corrosion. It was interesting to find that a relatively new bridge (12 years old) was corroding at a higher rate than an older bridge ( 54 years old). 
Steel Piling in Soil

This long term program studying the corrosion of steel piling in soil is continuing under the sponsorship of the American Iron and Steel

Institute. The corrosion measurements, made annually, show that the piling in undisturbed soil are corroding at a much lower rate than those piles in backfilled, disturbed soil. For the second year, these

measurements were made using portable computerized equipment in addition to the usual manually controlled methods.

\section{Corrosion Data Center}

\section{Subtask 3}

G. M. Ugiansky, D. B.Anderson, D. E.Clausen ${ }^{1}$, C. D. Flanigan, T. Flax, and E. D. Verink ${ }^{2}$.

1 NACE Research Associate

2 Guest Scientist, University of Florida

The focus of activities this year in the NACE-NBS Corrosion Data Center has been in two primary areas: (1) the completion of the first output of the data center -- a distributed database; and (2) arranging for the acquisition of industrial corrosion databases.

The distributed database has been completed and is being issued by NACE as a floppy disc package for personal computer use. The package, called CORSUR Vol. 1, is a software version of NACE's Corrosion Data Survey Metals. The software allows the user to search and sort the data by specified environment (over 1000 included) with defined concentration and temperature constraints and to call up the more than 25,000 graphs. Substantial progress has also been made on Vol. 2, a companion volume on nonmetals.

In an effort to acquire industrial corrosion databases, arrangements have been for the transfer of digitized field.corrosion data from the LaQue Center for Corrosion Technology, and with Battelle Columbus Laboratories and Cabot Corporation for additional data.

Nuclear Waste Disposal

Subtask 4

C. G. Interrante, U. Bertocci, T. Coyle, E. Escalante, A. Fraker, S. Harrison, M. Kaufman, W. Liggett, M. Linzer, H. Ondik, E. Plante, E. N. Pugh, R. Ricker, R. D. Shu11, M. Stoudt, and G. M. Ugiansky

Two programs on nuclear waste disposal are supported by the Nuclear Regulatory Commission. A program begun in FY85 in support of NRC's High Level Waste (HLW) Management Program, the NBS assists the NRC by evaluating the Department of Energy (DOE) activities on waste packages designed for use in a permanent repository of disposing of radioactive waste from nuclear power plants and other sources. The work involves 
conducting formal reviews of the research and development efforts of the DOE Waste Package Program, as well as rendering informal technical opinions on numerous issues, attendance at meetings, interaction with the international community and, in general, development of a broad understanding of the present and planned DOE activities, such as those on test methods, design of experiments, and theoretical and modelling efforts. The work involves workers from throughout the Bureau. Major problems threatening the integrity of the waste package include pitting, stress corrosion cracking, and hydrogen embrittlement, which are the main thrust of the Corrosion Group. Work in the area of leaching of borosilicate glass is supported in part by members of the Ceramics Division. The program is supported by statisticians and modelling specialists from the Center for Applied Mathematics.

During FY86 formal reviews of over 30 pertinent documents will have been carried out. NBS recommendations for hardware selection and proposals for the management of the database on HLW, together with specific software developed for the purpose have been approved by NRC and are being implemented. Since an important objective is to identify additional data and types of tests needed to demonstrate that the DOE waste package designs will meet NRC performance objectives, proposals for laboratory work to be conducted by NBS in support of this objective have been submitted and are currently under joint NBS/NRC review, with the expectation of initiating this work at the beginning of FY87. Our assistance to NRC has also required participation of NBS staff to several meetings both in the USA and abroad.

The second program sponsored by the NRC Office of Nuclear Regulatory Research concerns the statistics of pitting, a form of localized corrosion of great concern for the performance of the high level waste containers. Studies have continued during FY86 to develop software for the processing of the current fluctuations observed during the period which precedes the formation of active pits. The results of this analysis are being compared with the predictions of a stochastic model for pit initiation, based on the idea that local breaks of the protective film require a certain time to repair, so that a limited memory affects the breakdown probability. Also, measurements of pits formed on large steel sheets, and statistical analysis of their distribution is being pursued in cooperation with the University of Manchester in the United Kingdom. 
ELECTRODEPOSITION

(ELECTROCHEMICAL METALS PROCESSING)

David S. Lashmore

The Electrodeposition Group is responsible for measurements and standards associated with electrodeposited pure metals and alloys. The objectives of the group are: (1) the determination of the critical mechanistic, material, and process variables controlling the structure/property relationships of electrodeposited coatings and the development of approaches that will result in entirely new materials; (2) the provision of standards such as coating thickness standards, microhardness standards, dye penetrant crack standards, and corrosion step test standards; (3) the development of new standards requiring electrodeposition for their fabrication or utilizing the unique properties of electrodeposited alloys; and (4) the provision of expertise to industry, through research associates and standards organizations, and to other government agencies, through appropriate contracts and consulting arrangements.

Following are some of the many areas in which coatings are important to the commerce of the United States: (1) Strategic Materials - It has been shown that coatings can provide a $30 \%$ savings of imported raw chromium. Research on new alloys in progress indicates that in many applications coatings can replace bulk stainless steels. (2) Corrosion - coatings are the most common form of corrosion protection. It has been estimated that the cost of corrosion to the U.S. economy is about 70 billion dollars per year. (3) Wear - The cost of wear to the U.S. economy has been estimated to be from 30 to 50 billion dollars per year. Electrodeposited coatings play an important role in improving wear properties and surface coatings can be optimized for wear. (4) Custom tailored alloys - Provide new kinds of materials with tailored microstructures which cannot easily be produced by other types of materials fabrication technologies, such as artificial superlattice structures designed for improved magnetic, superconductive properties or mechanical properties.

Electrodeposition is one of the few metals processing techniques that virtually provides atomic control over composition and structure. This technology has been exploited for many years without an in-depth understanding of the process or the morphology of the alloys when applying coatings for wear and corrosion protection and to electroform large items. It seems clear that development of such an understanding would provide information leading to very new and unique types of material.

\section{FY 86 Significant Accomplishments}

- Completion of a mathematical model of the deposition of alloys onto fibers. This modeling process implemented an expression for the boundary layer behavior on fibers moving in electrolytes used for alloy deposition and adapted this knowledge to the existing mathematical model of the deposition process. This model is now used to help design a pilot plant to produce small quantities of aluminum alloy coated fibers to hot process into metal matrix composites for subsequent property measurement.

- Artificial superlattice structures of $\mathrm{Cu}-\mathrm{Ni}$ and $\mathrm{Cu}-\mathrm{Co}$ have been pro- 
duced from a single electrolyte. The first evidence of $x$-ray satellites on all principal planes has been presented for $\mathrm{Cu}-\mathrm{Ni}$ indicating perfection of structure on nearly an atomic level. A technique has been developed for tailoring waveforms to produce sharp interfaces on both the leading and the trailing edge of each layer. The first pure metal-metallic glass ( $\mathrm{Ni} / \mathrm{Ni}-\mathrm{P}$ ) composition modulated alloy has been produced from a single electrolyte. Composition modulated alloys of $\mathrm{Cu}-\mathrm{Ni}, \mathrm{Cu}-\mathrm{Co}, \mathrm{Cu}-\mathrm{Fe}, \mathrm{Sn}-\mathrm{Ni}, \mathrm{Cu}-\mathrm{Ni}-\mathrm{P}$, and $\mathrm{Ni}-\mathrm{NiP}$ have been produced to date.

- New techniques for tailoring interface regions have been developed making use of artificially layered structures whose layer spacing is deliberately increased as a function of distance or whose composition is gradually varied according to a predetermined schedule.

- Developed and produced 270 microhardness standards certified at loads of $25 \mathrm{~g}, 50 \mathrm{~g}, 100 \mathrm{~g}, 300 \mathrm{~g}, 500 \mathrm{~g}$, and $1 \mathrm{Kg}$. Hardness ranges were 125 $\mathrm{Kg} / \mathrm{mm} 2$ and $500 \mathrm{Kg} / \mathrm{mm}$.

- Developed new wear resistant chromium and chromium alloy coatings using both direct and pulsed current deposition. Significantly, pulse parameters were determined that yield a "low contraction" chromium produced at the same operating temperature as the ordinary microcracked chromium.

- Developed the technology for electrodepositing aluminum and aluminum alloys ( $\mathrm{Li}, \mathrm{Mn}$ ) and characterized some of the electrochemistry operative in this electrolyte.

- Three patents or patent disclosures were filed.

1. Room temperature technique for production of composition modulated alloys using a cold rolling process. (disclosure)

2. Patent on automated microhardness measuring system. (application)

3. Patent filed on trivalent chromium deposition. (application)

Mathematical Modeling of Alloy Deposition on Moving Fibers

Subtask 1

C.R. Beauchamp, D.S. Lashmore

The algorithm of the mathematical model previously developed for the electrodeposition of alloys on rotating disk electrodes has been modified to accommodate a new geometry and electrolyte flow. The new system of interest is that of a thin wire or fiber moving along its axial direction through the electrolyte as shown schematically in figure 1 . The treatment of the new system was divided into three stages. First, the treatment of the flow of the solution was modified to accommodate the different convection mass transport and a new boundary profile predicted. Second, the model was extended to a two dimensional analysis since it is required for the prediction of the current distribution due to the IR drop caused by high resistivity of the fibers and due to the changing boundary layer thickness. Last, an attempt to significantly reduce computation time by means of an upgraded finite element method for the solution of the partial differential equations using the Crank Nicolson method. As part of this 
project, a thin flow cell that enables the visual inspection and video recording of film formation and crystal growth has been designed and constructed. The cell enables the study of the effects of addition agents on the mechanisms of film formation and crystal growth on a real time basis during the process of electrodeposition. The cell consists of a plating chamber with a channeled thin flow of electrolyte (about 25 microns thick) placed under a microscope equipped with a video camera that enables specimen inspection during the experiment. The image of the specimen can be displayed on a television screen or recorded using a video cassette.

\section{Wear Resistant Coatings for the Engraving Industry}

Subtask 2

C.E. Johnson, D.R. Kelley, D.S. Lashmore, J.L. Mullen

A study of the electrodeposition of engraved currency printing plates for the Bureau of Engraving and Printing (BEP) has been underway for two years in collaboration with the wear group. The initial portion of this program focused on developing an understanding of the process and process variables along with measurement of properties of the electroformed printing plates. Subsequent investigation focused on the characterization of abrasive wear of various chromium electrodeposits and other metallic coatings under a simulated printing environment and in situ wear tests at BEP. Some of the results of this portion of the program on wear of various chromium deposits are shown in figure 2. The coatings were obtained by direct current (DC) plating, galvanostatic pulse plating, varying operating parameters. The lowest wear rate from the abrasive wear instrument used to rank coatings was recorded for "transition zone" chromium deposits. Recent literature has stated that the lowest coefficient of friction is also obtained for the "transition" zone chromium. The "transition" zone chromium lies between the bright, hard, microcracked chromium and "milky" chromium. A new duplex chromium deposit shows promise in the simulated environment. Galvanostatically controlled pulse plated deposits resulted in similar wear as the BEP chromium. The majority of other metallic coatings investigated for wear in the simulated environment have shown much greater wear than the BEP chromium with the exception of a composite coating of electroless nickel containing 3 micron sized particles of silicon carbide. The coating showed negligible wear (within the range of detection).

Standard Reference Materials

Subtask 3

R.J. Brown, H.B. Nottingham, S.S. Wedemeyer, P. N. Sharpless, and J.L. Mullen

Approximately 5000 coating thickness standards were produced this year. A new computer program was written to use the raw data produced by the Beta Back Scatter instrument for measuring the thick gold standards. Another program was written to calculate the data obtained from the analysis of the gold samples. These programs significantly improved our precious metal measuring ability.

Implementation of a new set of stepping motors for the automation of the 
coating thickness standards has been completed. The time required for this phase of certification of the standards is reduced by a factor of $65 \%$ due to the increased speed of operation of the new motors and to major revisions to the software.

Microhardness standards of electrodeposited bright copper and nickel have been in production for three years. Three new standards have been added this year bringing the total available to seven. Nickel Knoop standards are now certified for loads from $0.245 \mathrm{~N}(25 \mathrm{gf})$ to $9.8 \mathrm{~N}(1000 \mathrm{gf})$. A patent application has been filed on the technique developed at NBS for automating the microhardness measuring procedures. This same instrumentation shows promise of yielding micromechanical properties data (modulus and yield strength) on very small volumes of material. The instrumentation has been developed to the point that it is capable of being used to certify NBS microhardness standard reference material.

Metal Matrix Composites and Interface Properties

Subtask 4

D.S. Lashmore, C.R. Beauchamp, M.P. Darie1*, C.E. Johnson, G.R. Stafford, S.A. Wright-Claggett, J. Yahalom**, R. Polvani***, C. Handwerker $* * * * *$

Currently used technology for the production of metal matrix composite materials (MMC) is not only expensive but has associated with it various inherent problems included among which are reactions between the material of the fiber and the matrix, low packing fraction of the matrix material and the need to process the composite at high temperatures to consolidate the fibers into a three dimensional structure. The technology addressed by the study of MMC in this group is summarized in figure 3 . In principle, a fiber or tow (large bundle) of fibers is coated with sufficient material to supply the matrix when the fiber is hot pressed or otherwise consolidated into a three dimensional structure. The technology provides several very important advantages over powder metallurgy, casting, or other coating techniques such as (1) very high packing fractions because the coatings can be made optimally thin, (2) diffusion barriers or adhesion promoting layers can be applied in a continuous process as can low melting point eutectic coatings to promote consolidation, and ( 3 ) the coating can be applied very rapidly to keep the cost low.

This comprehensive study of MMC's $^{\prime}$ is divided into 5 main areas: (1) the investigation of the properties of aluminum alloys electrodeposited from eutectic salt electrolytes; (2) a study of nucleation and growth; (3) mathematically modeling the alloy deposition process on moving fibers (discussed above); (4) investigation of the properties of alloys with graded properties produced using electrodeposition techniques; and

(5) production of model composites for NDE characterization. Other areas of activity under this program but described under other groups are a micromechanical properties measurement instrument (tribology) and thermodynamic modeling of interfaces (metals processing).

*Guest Scientist, **Research Associate, ***Wear and Mechanical Properties Group, ****Metallurgical Processing Group 


\section{G.R. Stafford and D.S. Lashmore}

Aluminum and its alloys have been deposited from organic and fused salt electrolytes. To date, there has been no successful process for deposition of aluminum from aqueous electrolytes. The processes using the organic systems are reported to have poor throwing power at low deposition rates. In addition, they usually contain toxic components and in some cases, explosive components. Accordingly, this study focused on the development of a complete understanding of the properties of aluminum alloys and their correlation with the deposition parameters from fused salt electrolytes. Successful processes for the electrodeposition of these alloys at near $100 \%$ current efficiency and moderate deposition rates have been reported in the literature.

These systems generally operate at the relatively low temperature of about $150^{\circ} \mathrm{C}$. These processes contain no toxic chemicals and are not explosive or pyrophoric. However, HCL vapor can be released in nonviolent fashion under some circumstances. It was shown that in $\mathrm{AlCl}_{3} / \mathrm{NaCl}$ melts, the deposition process is limited by mass transport of $\mathrm{Al}_{2} \mathrm{Cl}_{7}^{-}$to the cathode. The chronoaperograms of figure 4 show that at low overpotentials, the current, and therefore the electrochemically-active surface area, does not change with time. The deposits obtained under these conditions generally have a low nucleation density. As the overpotential is increased, the nucleation density improves significantly and finer grain deposits can be obtained, figure 5. A further increase in the overpotential, however, causes dendrite formation as seen by an increase in current as shown in figure 4. Good deposits can be obtained from direct current plating at moderate overpotentials where nucleation is favored, but limited mass transport of $\mathrm{Al}_{2} \mathrm{Cl}_{7}{ }^{-}$and therefore dendrite formation does not yet occur. Unfortunately, the highest current density obtained under such conditions from the pure metal is only $20 \mathrm{~mA} / \mathrm{cm}^{2}$. One method of promoting nucleation without introducing diffusion problems is pulse plating. Very high current pulses on the order of milliseconds duration yield very dense, nondendritic deposits. Though the overall current density is still limited to that of the direct current case, deposition occurs under conditions of enhanced nucleation which gives rise to much denser deposits. It has also been shown that small additions of foreign metals or certain organics can have a dramatic effect on the morphology of the coating changing the tendency to form dendrites to a tendency to promote laterial growth, thereby dramatically increasing overall current density (plating rate). In this investigation, organics are avoided and the effort is focused on the addition of manganese chloride to accomplish this. Very bright deposits containing 25-35 w/o Mn have been obtained at $75 \mathrm{~mA} / \mathrm{cm}^{2}$. The microstructure and mechanical properties of these deposits are presently being investigated.

Nucleation of Nickel and Copper on Graphite Tows

J. Yahalom and D.S. Lashmore

Metals are electrodeposited on carbon fibers for use in metal-matrix composites and for electrical applications due to the enhanced surface elec- 
trical conductivity of the carbon-metal composite.

Nickel-deposited carbon fibers are commercially available. However, such fibers may be objectionable for composite applications due to the formation of brittle carbide layers at the metal/fiber interface during sintering. Copper would therefore be more suitable for such applications. There are a number of well established methods for the deposition of copper. It was found, however, that copper does not nucleate well on carbon fibers and the resulting deposit is coarse-grained and non-uniform. We have studied the nature and kinetics of the deposition of copper in comparison to nickel and found that the initial applied potential has a decisive effect on the initial nucleation and subsequent growth of the deposits. It was found that by initially applying either a highly anodic or cathodic pulse, full coverage of the fibers is attainable. The mechanisms for the two cases are different and we are presently investigating the details of the nucleation process in relation to the fiber surface structure and properties and the effects of oxidation and reduction on these properties.

\section{Electrodeposition of Artificial Superlattices}

D.S. Lashmore, M.P. Dariel, and S. Wright-Claggett

Electrodeposition of artificial superlattices or microlayered alloys has been under intensive investigation for the last two years and techniques have been worked to electrodeposit $\mathrm{Cu}-\mathrm{Ni}, \mathrm{Cu}-\mathrm{Co}, \mathrm{Cu}-\mathrm{Fe}, \mathrm{Sn}-\mathrm{Ni}$ and $\mathrm{Ni}-\mathrm{NiP}$ alloys, each from a single aqueous electrolyte. It was found that by carrying out the deposition with a tailored galvanostatic waveform that it is possible to produce materials with sharp interfaces on both the leading and trailing edges of the layer and still maintain precise control of the thickness of the layer. Studies of the morphology of coatings produced on single crystals have shown that the coatings are epitaxial on all the principle orientations $\{100\},\{110\}$, and $\{111\}$. However, only on $\{111\}$ do the coatings maintain their epitaxy for any appreciable thickness (at least $5 \mathrm{~nm}$ ). Because electrodeposition is essentially a room temperature technology, there is reason to believe that the perfection and sharpness of the interfaces between layers created by this technique is much greater than that created by sputtering or vapor deposition for which it is necessary to raise the temperature of the substrate to at least $250^{\circ} \mathrm{C}$. One indication of perfection of the layers is the existence of satellite peaks around the main Bragg peaks. These have been observed for the first time on all principle planes of $\mathrm{Cu}-\mathrm{Ni}$. Examples of $\mathrm{x}$-ray data for $\mathrm{Cu}-\mathrm{Ni}$ produced by tailored waveforms is shown in figure 6 and a typical TEM micrograph with $\lambda=10 \mathrm{~nm}$ in figure 7 . Techniques to measure the elastic constants of $\mathrm{Cu}-\mathrm{Ni}$ foils using ultrasonic techniques have been developed in cooperation with Prof. M. Rosen of Johns Hopkins University, but to date, there has been no evidence of supermodulus effects in the as-deposited alloys, even though the layer spacing was comparable to samples produced by vapor deposition which have demonstrated supermodulus effects. These materials have potential for creating a region between fibers and matrix whose mechanical properties can be graded at will, particularly the yield strength. Studies are also under way to measure the magnetic properties, and the electrical and thermal resistivity. 


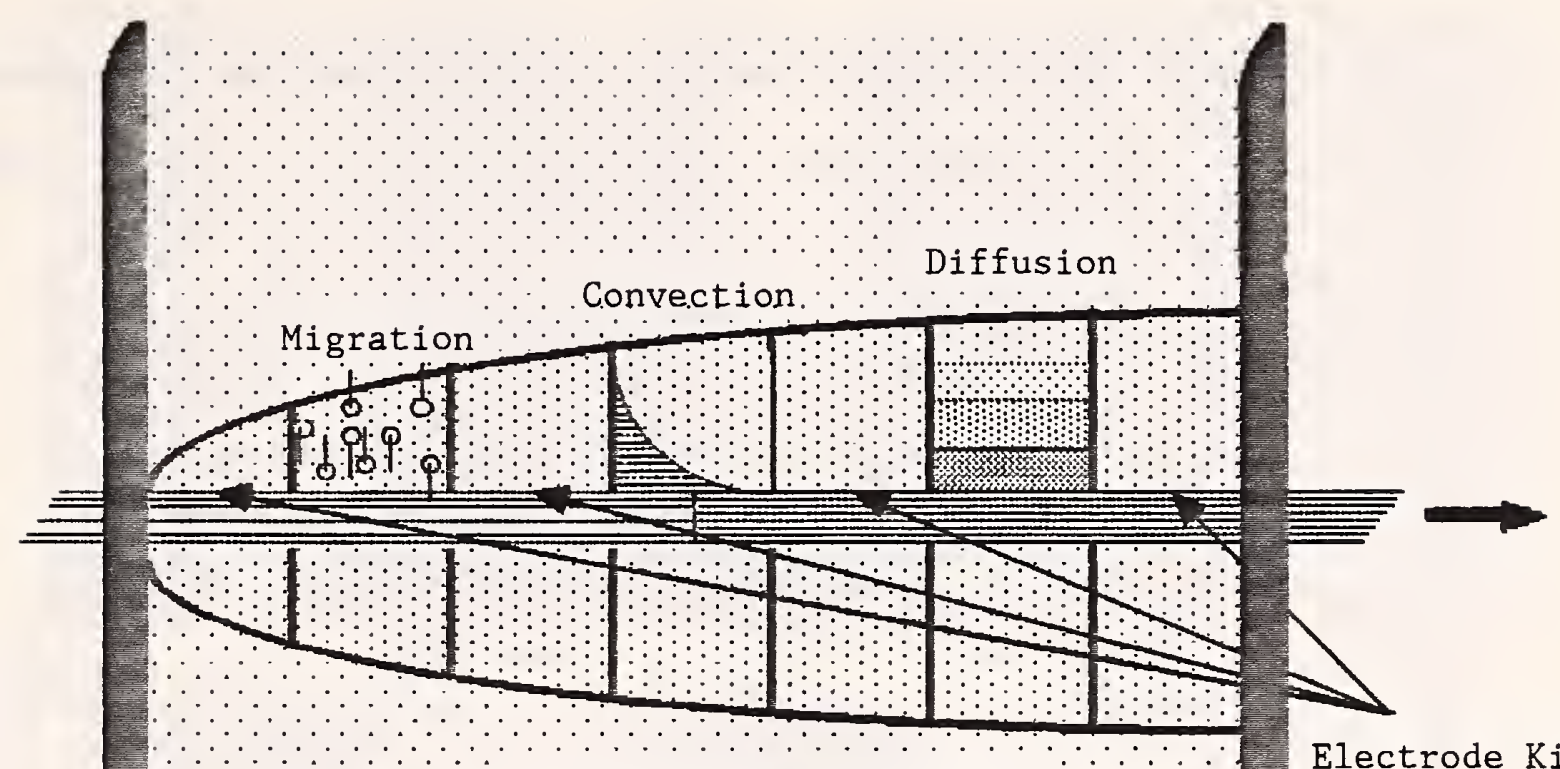

Boundary Layer Thickness

Electrode Kinetics

Figure 1. A Schematic diagram of the geometry used for modeling the deposition process on moving fibers.

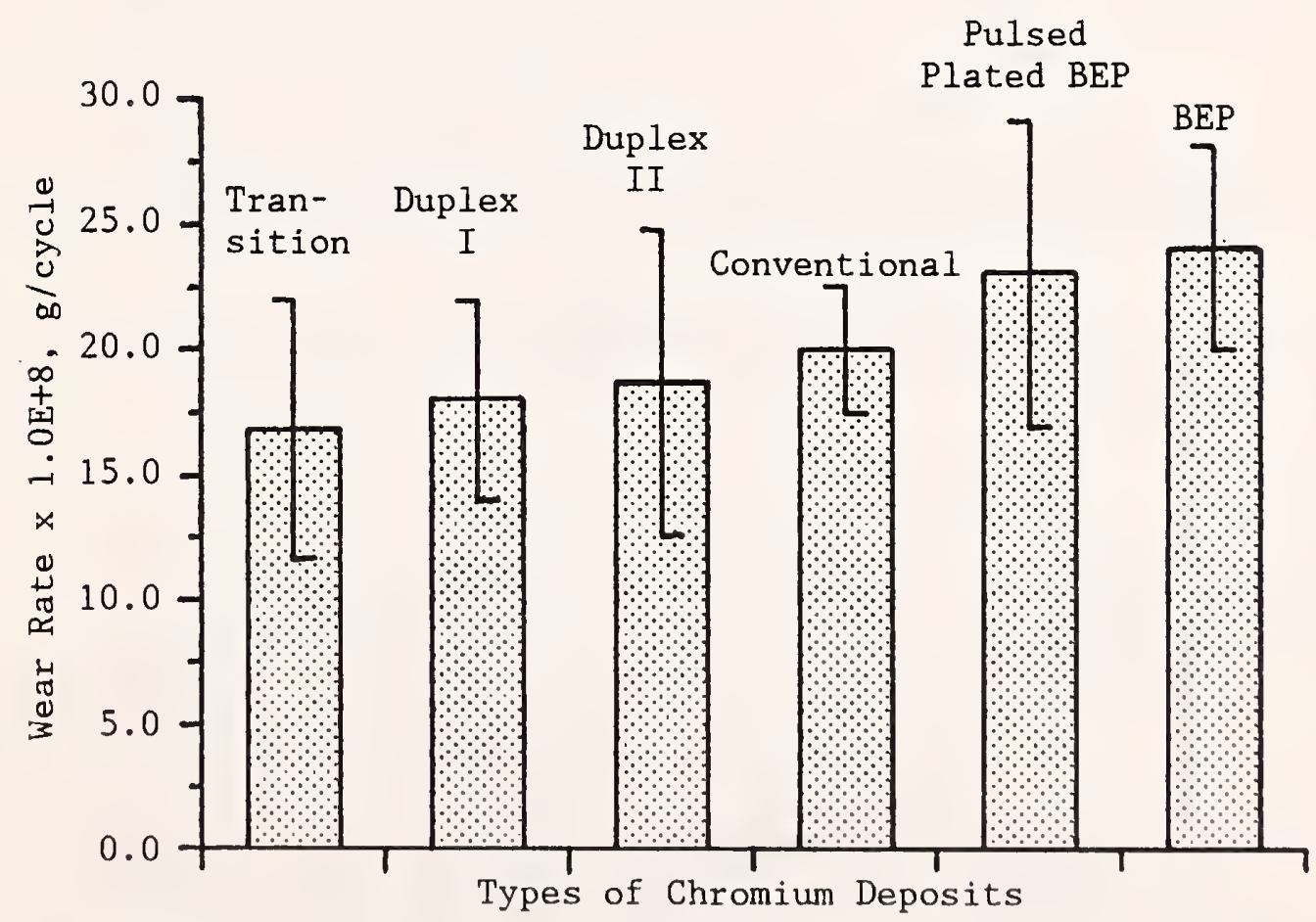

Figure 2. Ranking of different chromium coatings using a simulated abrasive wear testing instrument. 


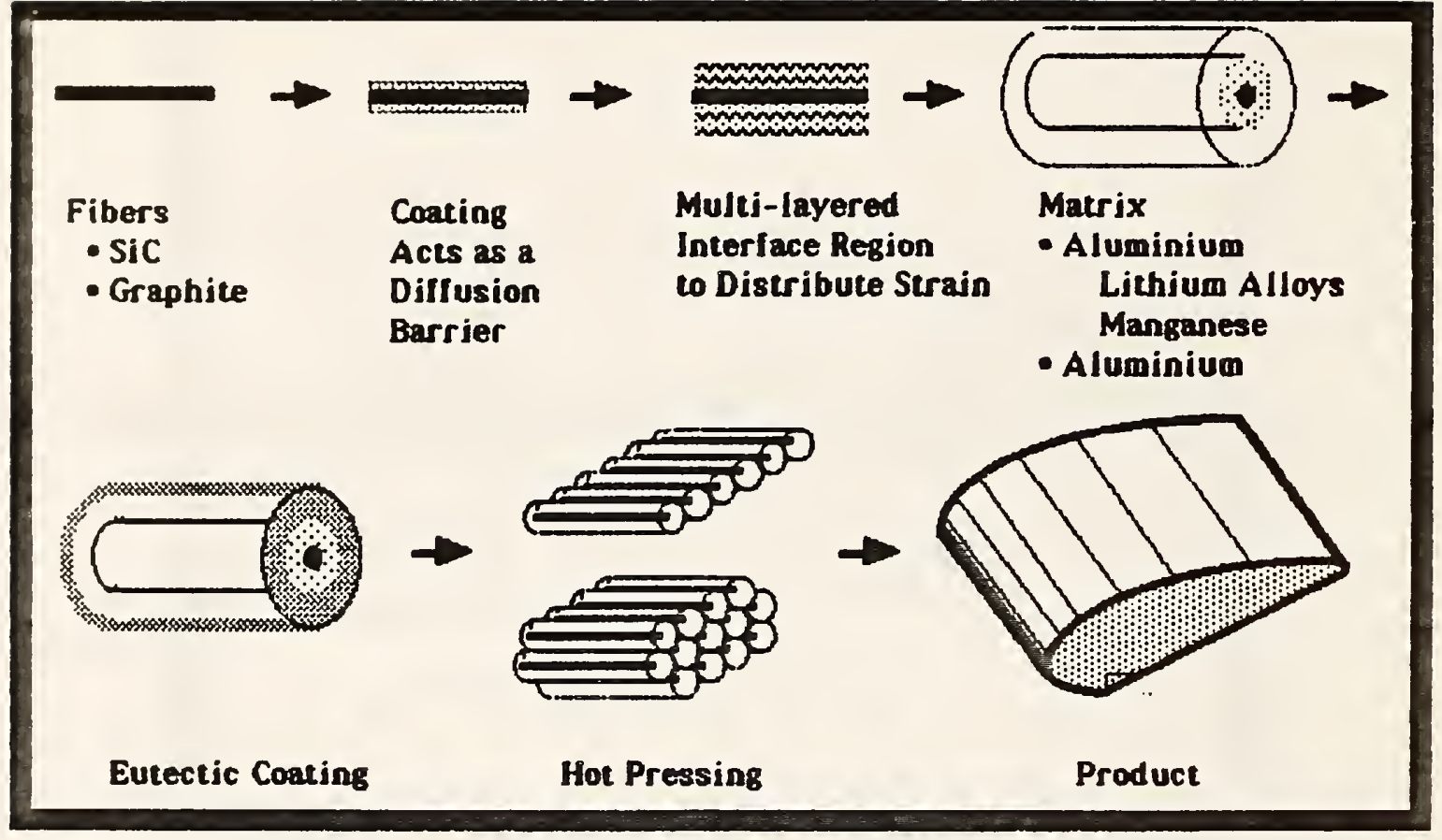

Figure 3. Coating technology addressed in the investigation of metal matrix composits and interfaces.

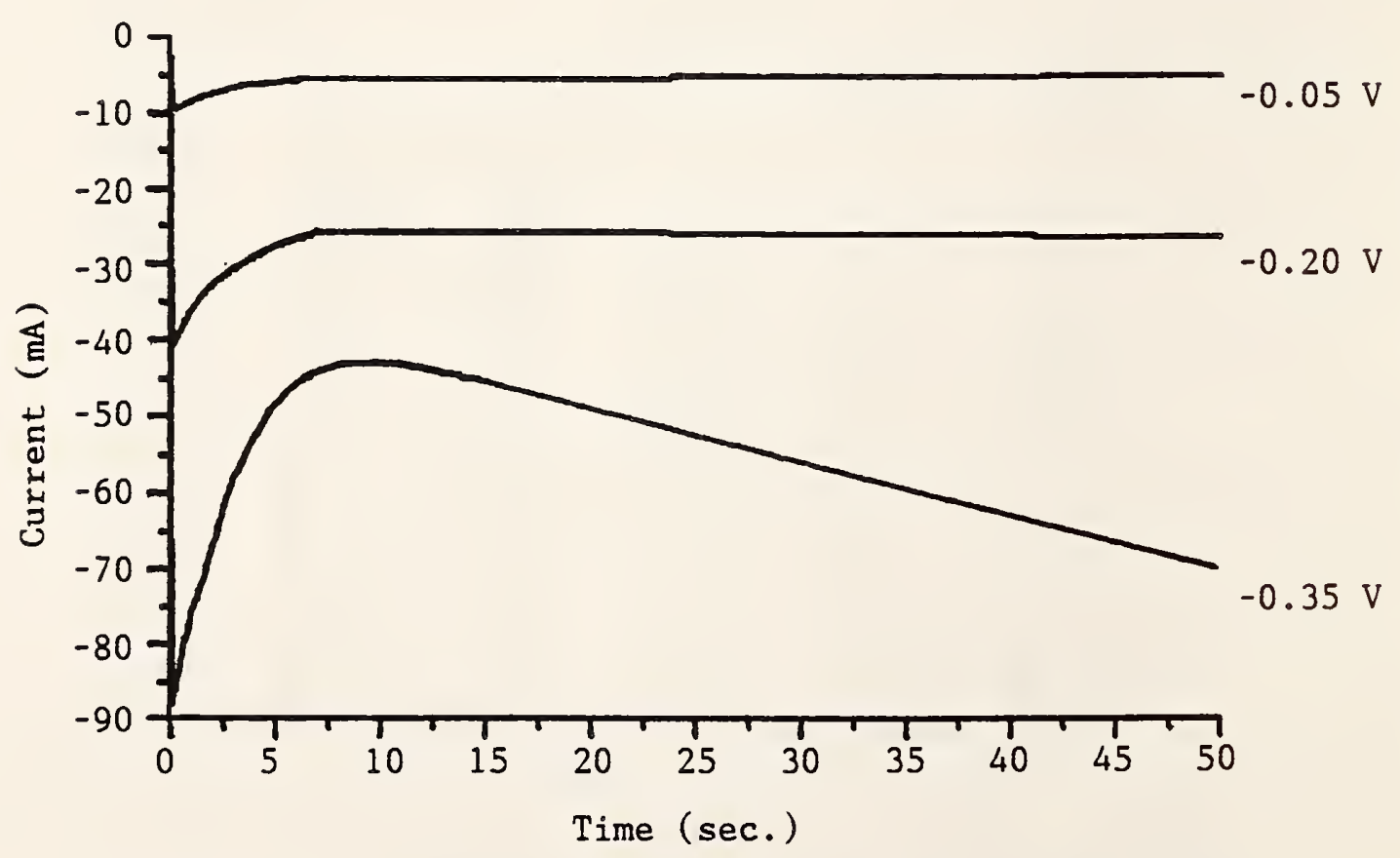

Figure 4. Chronoamperometry curves for single pulse potentiostatic deposition on tungsten. Melt is a $2: 1$ mole ratio of $\mathrm{AlCl}_{3}: \mathrm{NaCl}$ 


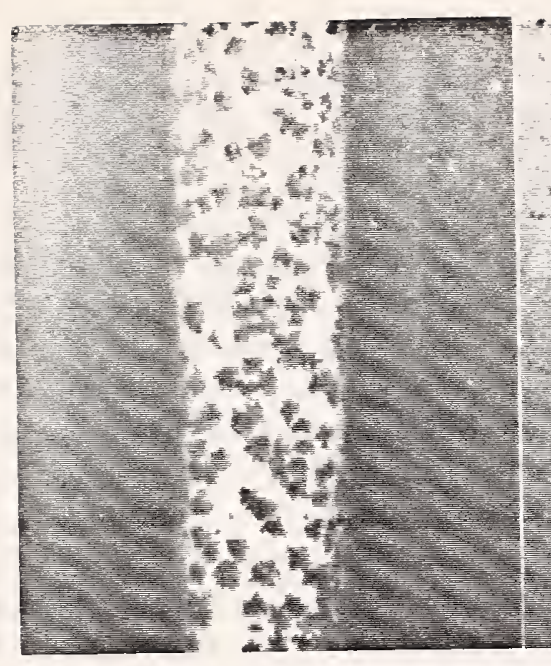

(a)

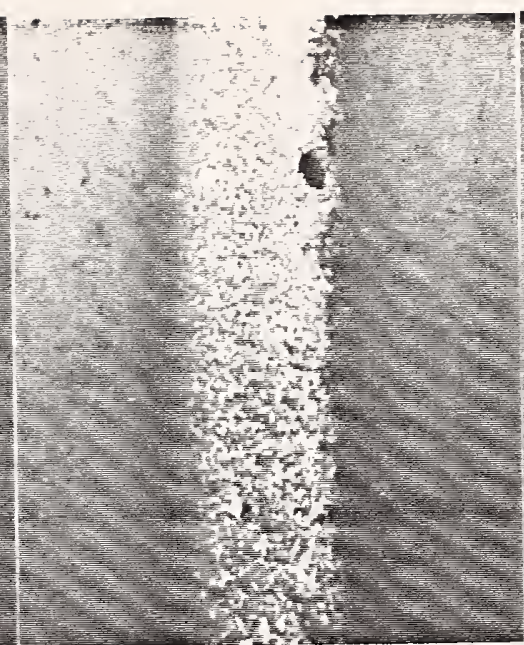

(b)

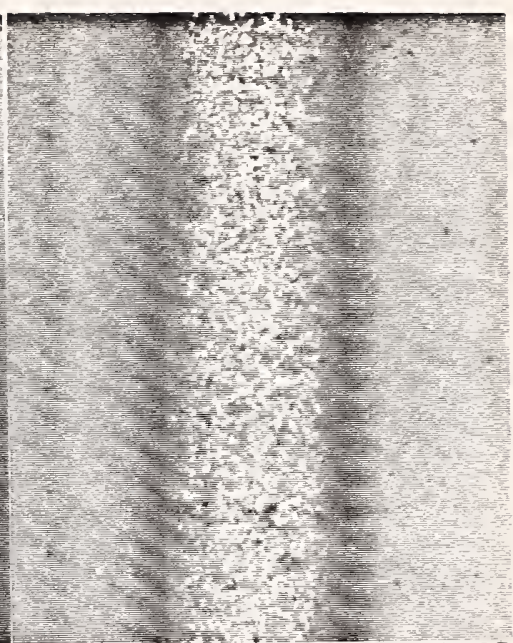

(c)

Figure 5. Backscattered image (SEM, 36x) of aluminum electroplated onto copper wire from $\mathrm{AlCl}_{3} / \mathrm{NaCl}$ melt. Six coulombs were passed at each of the current densities: (a) 1.6 , (b) 3.3 , (c) $5.0 \mathrm{~mA} / \mathrm{cm}^{2}$.

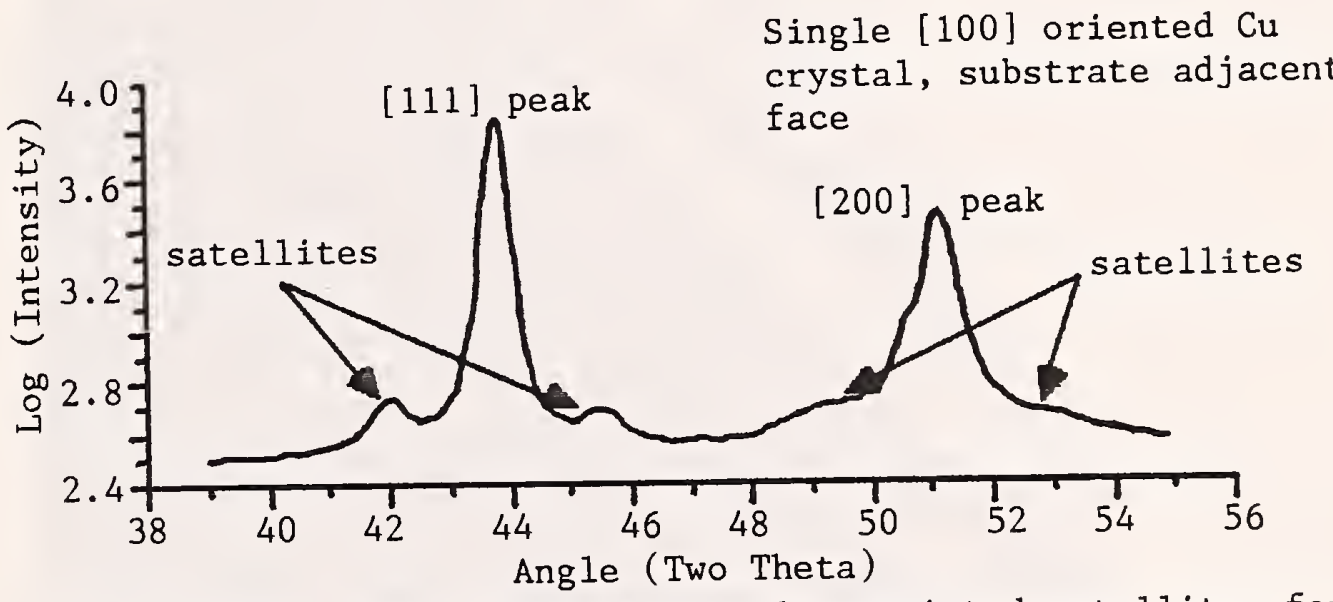

Figure 6(a). Main Bragg peaks and associated satellites for a $3 \mathrm{~nm}$ wavelength CMA. Substrate ia a [100] single crystal.

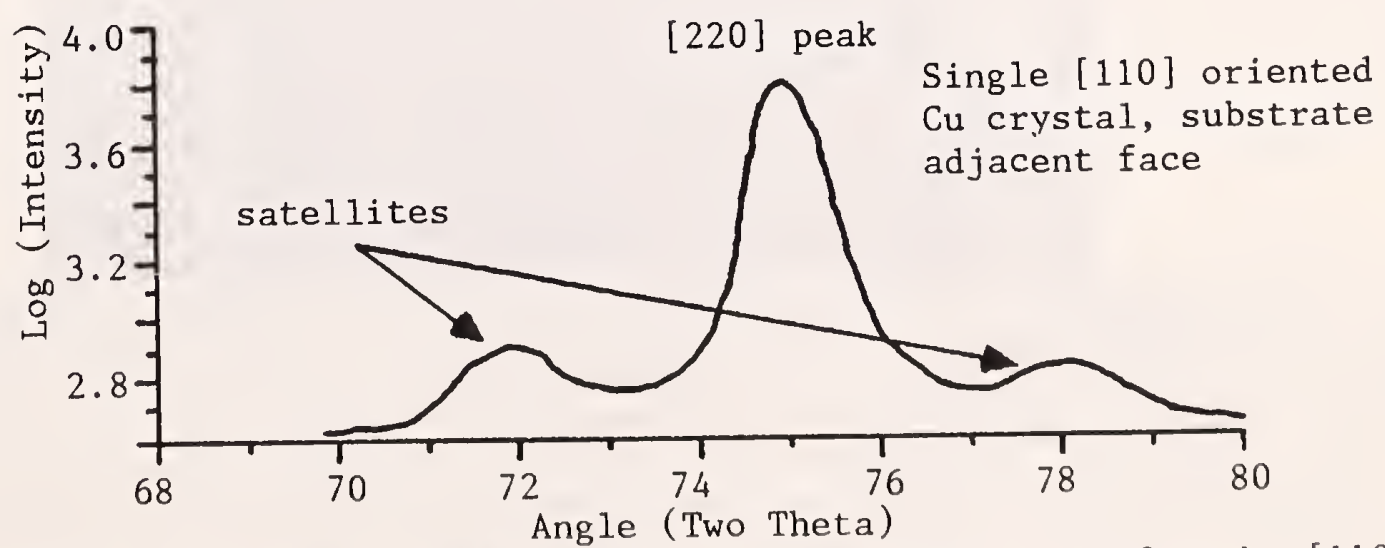

Figure 6(b). Main Bragg peaks with $x$-ray satellites for the [110] single crystal substrate. As on the [100] there is some [111] texture. 


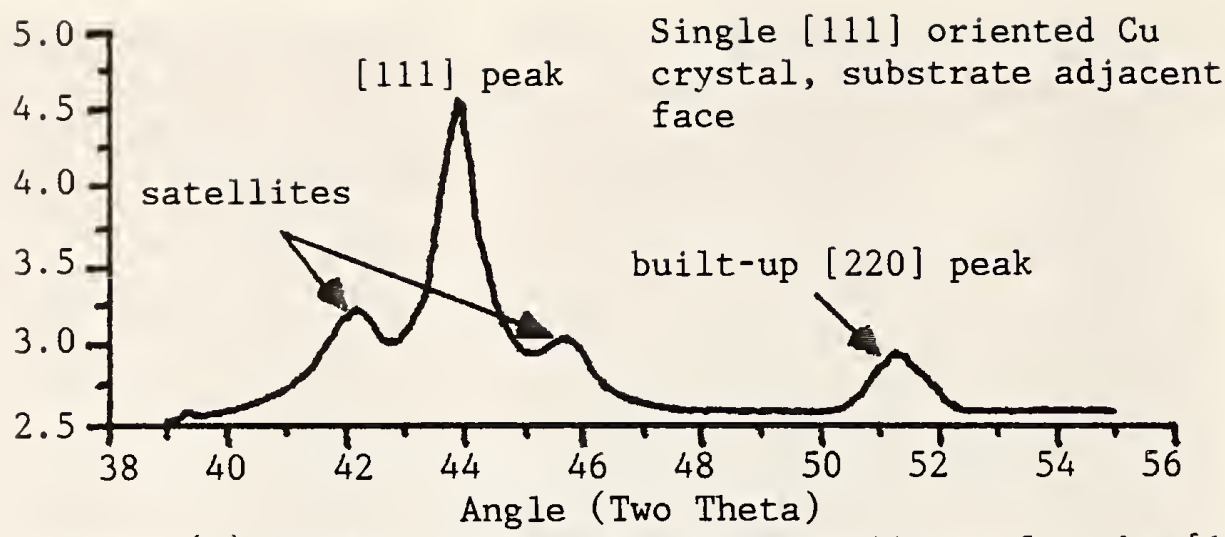

Figure 6(c). Main Bragg peaks with satellites for the [111] single crystal substrate. The [100] and [110] texture is small on this orientation.

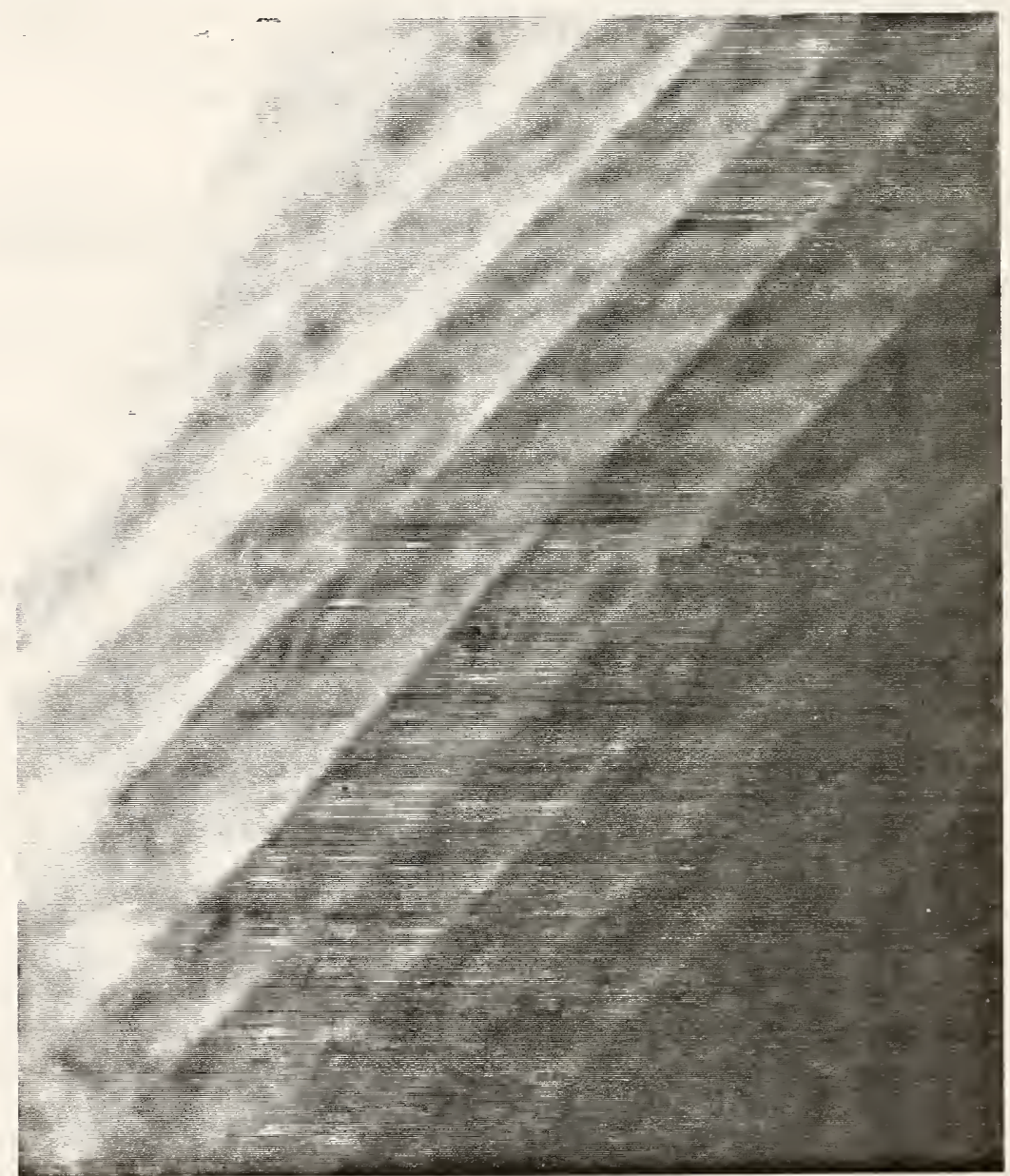

Figure 7. A typical TEM bright field micrograph ( $300 \mathrm{Kev}$ ). The substrate is polycrystalline and the wavelength $10 \mathrm{~nm}$.

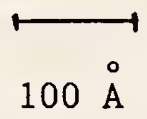


This task is concerned with the development of basic nondestructive measurement methodologies and their application to the characterization needs of materials science. The "pull" for this research area stems from the emerging needs for (1) sensors for implementing new process control scenarios, and (2) insitu measurement techniques for fundamental study of transformation and damage mechanisms. The "push" comes from the recent advances made in the measurement science of noninvasive techniques such as ultrasonics, eddy currents and acoustic emission.

The insatiable demand from designers for ever more advanced materials combined with an increasing awareness of the poor posture of our basic materials in the international marketplace has resulted in an unparalleled interest in the development of a new generation of materials processing sensors. The fortuitous juncture of expertise in nondestructive characterization methods and advanced materials processing has created a unique window of opportunity for this group to make positive contributions to one of the nations most important technological problems. The American Iron and Steel Institute and National Bureau of Standards (AISI/NBS) collaborative research program on sensors for the steel industry has rapidly progressed. An ultrasonic sensor for detecting and locating internal porosity/pipe in hot steel ingots has been developed in cooperation with Magnaflux Corporation and successfully evaluated in full-scale trials at the Argonne National Laboratory (ANL). Our involvement in this activity is now completed. A second sensor for determining internal temperature distributions has also progressed we11, and is now to the stage where a prototype is to be developed by AISI/Pacific Northwest Laboratory (PNL) and evaluated at a steel industry casting facility. Our involvement in this effort is to continue, for we have devised an innovative approach that potentially could revolutionize temperature measurement. There also remains a strong need for better modeling of sensor-microstructure interactions and reference data to support industrial uses of either sensor approach.

A new sensor program was initiated in May 1986 with the signing of a memorandum of Agreement with the Aluminum Association (AA) for cooperative research and development of a temperature sensor for control of aluminum alloy extrusion. For this sensor need, a multifrequency eddy approach has been chosen as the preferred sensing method. It can potentially yield surface and internal temperature information through the "skin depth effect."

A new area in Metal Matrix Composite (MMC) interface characterization was initiated in FY 1985 and has now begun to yield important results. The intent of the SDI/SDIO cofunded program is to develop methods for insitu measurement of local mechanical properties at the ceramic-metal interface in metal matrix composites. Theoretical studies have predicted, and experiments have confirmed, the existence of guided interface waves at the cylindrical interfaces of SiC-A1 fibrous composites. These ultrasonic 
experiments have confirmed, the existence of guided interface waves at the cylindrical interfaces of SiC-Al fibrous composites. These ultrasonic waves promise to reveal the local elastic constants of the interface region. Acoustic emission studies, on the other hand, have begun to reveal the micromechanisms of interface and fiber failure and allow measurement of key quantities such as interface adhesive strength.

As the group's research programs mature, we are beginning to look to future activities. For example, a steel industry workshop was convened at NBS in July 1986 to identify sensor needs for detection of internal discontinuities. The imminent arrival of Ward Johnson from the University of Illinois provides us with the additional ultrasonic expertise to explore the use of acoustic microscopy for characterization of the microelastic state. Melvin Linzer has formulated an approach for imaging the nonlinear elastic properties of media; a possible major contribution to nondestructive measurement methods. The coming year may see one or more of these areas become new subtasks in our group.

During FY 1986 collaborations and interactions with both industry and academia have been extended. Cooperative research with the AISI and with researchers from Johns Hopkins University (JHU) have continued. Four overseas guest scientists, Yoram Berlinsky, Zvi Katz, Paul Horng, and Uri Admon have made valuable contributions to our research program. New interactions have commenced with the AA and MIT, the latter in which we are playing a role in the SDI's Advanced Composites Consortium.

\section{FY 86 Significant Accomplishments}

o A prototype sensor, for detecting internal pipe/porosity in hot steel bodies, has been successfully evaluated at ANL. NBS involvement in this sensor activity has come to a successful conclusion.

o A high resolution computer based ultrasonic sensor for internal temperature measurements in solidifying bodies has been constructed and is undergoing evaluation.

- An eddy current approach to internal temperature measurement during the extrusion of aluminum has been formulated and a prototype system constructed for cylindrical geometries in cooperation with the AA.

o We have confirmed the existence of previously only suspected interface waves at the cylindrical interfaces of fibrous SiC/Al metal matrix composites. These waves show promise for characterizing the local elastic state.

- Using specially prepared single crystal composite samples we have been able to use acoustic emission techniques to observe fiber fracture and interface decohesion during deformation of $\mathrm{MMC}^{\prime} \mathrm{s}$. This is enabling determination of key quantities such as interface cohesive strength and fiber fracture stress. 
Eddy Current Temperature Profiling

Subtask 1

A. H. Kahn, M. L. Mester, and H. N. G. Wadley

The objective of this project is development of electromagnetic methods of sensing temperature and temperature profiles of metals. The electrical conductivity of a metallic material depends on temperature. If this conductivity can be measured, it provides a method of obtaining the temperature. If the conductivity profile can be determined, then so can the profile of temperature, provided the conductivity-temperature dependence of the alloy under test is already known. The depth of penetration of ac magnetic fields and the associated eddy currents depend on the frequency, and this allows the possibility of constructing the profile of conductivity versus depth through the interpretation of impedance measurements at varying frequencies.

During the past year, an agreement was reached with the AA, a consortium of aluminum manufacturing and processing companies, to undertake a joint project with NBS to develop sensors for the measurement of temperature and temperature profiles in aluminum during extrusion processing. Michael L. Mester, a consultant to the AA, has begun work on this project in collaboration with NBS personnel through the NBS Research Associateship Program. Visits were made to several processing plants to determine process constraints upon physical designs for the proposed sensors.

To perform the impedance measurements necessary for research on conductivity profile determination and the design of sensors for field use, we have acquired an impedance analyzer and set up a computer control system which allows the rapid collection of measured data. Measurements of impedance and phase at 400 frequencies are automatically performed in a matter of minutes and the results transferred to disk for analysis with inversion programs for reconstructing the profiles. Programs have been prepared for carrying out this process. The instrumentation is also being used in testing designs for the water-cooled coils to be used in the extrusion sensor.

An alternate approach to eddy current determination of temperature profiles depends upon the measurement of conductivity and conductivity gradient at the surface of the material under test. This determines the temperature and temperature gradient at the surface of the material. With this information it is possible to obtain solutions of the heat flow equations and to obtain the temperature profile. This method depends on high frequency measurements which are readily obtained with the newly acquired instrumentation. A theoretical approach has been developed for obtaining the surface conductivity and the conductivity gradient at the surface from multifrequency data. This approach is based on the Wentzel, Kramers, Brillouin (WKB) method of approximate solution of wave equations of nonuniform media in the limit of short wavelengths. 
Pipe/Porosity Sensor

Subtask 2

M. Linzer and C. D. Rogers

An ultrasonic technique for detecting pipe and porosity in hot steel has been successfully demonstrated. The method employs liquid glass (molten Borax) to couple two buffer rods, in a pitch-catch arrangement, to the hot steel surface. The other ends of the buffer rods are coupled to piezoelectric transducers by conventional room temperature couplants. Borax and stainless steel were shown to be the best liquid glass couplant and buffer rod material among several tested. Subsequent evaluation at the ANL of NBS technology has confirmed the choice of Borax as the optimum couplant material. Based upon these accomplishments, this sensor is now considered suitably developed for implementation in steel mills, and our direct involvement has come to a conclusion.

\section{Ultrasonic Temperature Sensor}

Subtask 3

F. A. Mauer, S. J. Norton, J. Cook, R. Heinrich, and H. N. G. Wadley

In 1982, a workshop sponsored jointly by NBS and AISI identified a need for four types of sensors for use during automated process control in the steel industry. One of these sensors was for the measurement of the internal temperature distribution in hot steel bodies. During FY 86, scientists from NBS and AISI continued their collaboration in order to develop a method based on ultrasonic time-of-flight (TOF) tomography. Theoretical and practical considerations governing formulation of the temperature-profile reconstruction (tomography) problem were described in Technical Activities-1985, and temperature profile reconstructions based on manual first-arrival TOF measurements were shown for hot solid bodies. The reconstructed profiles agreed within $10 \mathrm{C}$ with readings from embedded thermocouples, which is adequate for most practical purposes.

During FY 86 attention has been directed toward automation of the measurement and reconstruction procedure in order to increase the speed and accuracy and to make it more suitable for use on solidifying bodies. One of the steps taken to increase the speed of the automated system is the replacement of a single, bulky EMAT receiver with two arrays, each containing five piezoelectric receivers equipped with water cooled buffer cones to isolate them from the hot steel block. This change permits us to digitally record waveforms for all necessary propagation paths by simply moving the beam steering mirrors under computer control. The new, automated system is shown schematically in Figure 1. At first, mirror 1 is in the position shown and directs the laser beam along the axis of the $X$ positioner. The computer positions mirror 2 and fires the laser at each of five points aligned with the five $X$ receivers. Each time the laser is fired, five transient recorders in a CAMAC crate record waveforms from the five $X$ receivers, Figure 2. Mirror 2 then moves far enough to push mirror 1 out of the beam, allowing it to reach mirror 3 . The 
computer then scans the second face of the block by moving mirror 3 and recording waveforms from the five $Y$ receivers. In all, fifty waveforms are recorded, from which the computer extracts TOF data and reconstructs a two-dimensional image. The 2-D temperature profile will be presented in a variety of formats (e.g., color coded, contour, and pseudo 3-D plots).

With the automated system we expect initially to be able to complete a scan in about fifteen seconds and to display a profile about fifteen seconds later. A further order of magnitude improvement in speed is anticipated. The rapid availability of a larger data set, free from problems of temperature drift and ready for machine processing will permit us to apply this promising new method to measurement of temperature and the characterization of the solid/liquid interface in solidifying bodies.

Temperature Profiling from Rayleigh-Wave Velocity Dispersion Measurements Subtask 4

S. J. Norton, and H. N. G. Wadley

An investigation has begun into the feasibility of measuring the depthdependent temperature profile in the near surface of a body, or its surface temperature gradient, from Rayleigh-wave velocity dispersion measurements. For the case of an elastically-isotropic medium, characterized by a depth-dependent density and two depth-dependent Lame constants, an integral equation has been derived which relates the dispersion measurements to the variations in these three material parameters. Since changes in the material parameters are induced by changes in temperature, the dispersion measurements can be used to compute the temperature variation in the near surface region provided the temperature dependence of the material parameters can be calibrated in advance. The resulting integral equation is nonlinear since the dispersion is also a function of the wave field as well as the material parameters. Using first-order perturbation theory, the equation can be linearized by substituting the unperturbed wave field into the integral equation, providing a linear relation between the measurements (surface wave dispersion) and the unknown (the temperature profile). If a finite weighted sum of suitable basis functions is used to approximate the one-dimensional temperature profile (e.g., piece-wise linear functions), the integral equation can be evaluated analytically. Analytical integration can also be performed if the unknown is the surface temperature gradient only. The resulting integration yields a system of linear equations which can be inverted to obtain a least-squares estimate of the basis-function coefficients using standard linear inversion methods (e.g., singular value decomposition).

Progress to date includes the derivation of the linearized integral equation and its analytical evaluation for the case of a linear surface gradient. Future work will include an evaluation of the integral equation for the case of piece-wise linear basis functions, and a study of the ill-conditioning of the resulting linear system of equations. This will determine the maximum number of basis functions that can be feasibly employed and, as a result, the best spatial resolution in the 
reconstructed temperature profile that can be expected. Our interest in this approach stems from its possibility of directly measuring the heat transfer coefficient of a surface. With this information, thermal models for casting and reheating are sufficiently powerful to predict accurately the temperature everywhere within.

Acoustic Emission Study of Interface Adhesion in Metal Matrix Composites Subtask 5

R. B. Clough, F. Biancaniello, and H. N. G. Wadley

The cohesive strength of composite interfaces (matrix-reinforcement interface) in metal matrix composites is one of the least understood but most important of variables, since it critically affects both strength and fracture toughness. The principal reason for this lack of understanding is an absence of experimental approaches for direct measurement of this quantity. Such measurements provide a basis for understanding the metallurgy of interfacial bonding and thus a way toward improving mechanical properties.

When interfacial decohesion occurs, elastic waves are emitted. Thus, detection of acoustic emission can be used to determine the load at failure and the local fracture stress of the event. Transducers attached at both ends of the sample monitor the arrival of fracture-initiated stress waves, and by comparison of arrival times, the location of the microfracture can be determined. The location can be determined by comparison of signal waveforms using cross-correlation. Having identified the site of the fracture, post-test metallography has been used to identify the size and geometry of the fracture.

An advanced acoustic emission system has been constructed and interfaced with a 32-bit minicomputer to permit continuous monitoring during tensile testing of load, strain, and acoustic emission as well as automated capture of the large acoustic emission transients associated with microfracture. A unique feature of the system is the use of a highspeed wideband rms-to-dc converter to calculate signal energy prior to capture so that orders of magnitude fewer data points need to be stored.

Preliminary tensile tests of composites were made using the continuous monitoring system. Load elongation curves of monofilament SiC in single crystal aluminum show pronounced load drops which are simultaneously accompanied by acoustic emission, Fig. 3a. Post-test metallography reveals these fibers to be broken transversely in accordance with composite fracture mechanics models. These fractures cause load drops and associated bursts of emission. In addition, smaller acoustic signal which do not produce load drops occur and are thought to be due to interfacial decohesion. In addition there is a background of continuous emission produced by general plasticity in the matrix. By deforming single crystals of pure aluminum this plasticity generated emission has been independently measured, Fig. $3 \mathrm{~b}$. The fiber fracture strength is $0.3 \mathrm{GPa}$ (only $10 \%$ of that of a virgin fiber) while the interface shear strength is $9 \mathrm{MPa}$ consistent with failure by matrix slip. 
Ultrasonic Techniques for Interface Characterization in Metal Matrix Composites

Subtask 6

J. A. Simmons, E. Krasicka, M. Rosen, T. Hsieh, E. Lindgren, K. Hirshman and H. N. G. Wadley

The performance of advanced metal matrix composites is critically dependent upon the mechanical properties of the interface between the metal matrix and the ceramic reinforcement. The interface can be considered as a surface or as a region of coupling/transmitting displacements and surface tractions between the reinforcing material and the metal matrix. The goal of this subtask is to develop methods for measuring the local elastic properties of the interface by utilizing ultrasonic scattering and guided interface waves.

When ultrasonic waves encounter the discontinuity associated with an interface, they are both reflected and refracted. The character of these scattered waves is dependent on the elastic properties of the interface. In some cases a part of the energy travels as a wave in the direction of the interface and is concentrated near the interface. We refer to such waves as guided interface waves (GIW). The simplest example of a GIW is the Stoneley wave which travels unattenuated and nondispersively between two elastic half spaces when sufficiently restrictive conditions are obeyed by the elastic constants of both regions. In other cases and other geometries, such as the cylindrical geometry of a fiber reinforced material, GIW's still exist, but the velocity is dispersive and energy leaks away from the interface region as the wave travels, resulting in an attenuating or 'leaky' GIW. The velocities and leakage of such waves are even more sensitively dependent upon the interface mechanical properties and extent of the interface than in the case of scattered waves.

Wave propagation theory has been worked out in the cylindrical geometry for radially symmetric GIW's traveling in a medium consisting of an isotropic rod and an enclosing isotropic matrix. Leaky GIW's have been theoretically predicted and experimentally measured in the model composite case of silicon carbide reinforced aluminum, Figure 4. The wave was generated by sending a surface wave along a free SiC cylinder extending out from the end of an aluminum encasement. The wave partially converts to a leaky GIW upon entering the aluminum and is detected along the cylinder at the other end of the encasement at a length along the cylindrical axis of approximately eight rod diameters, Figure 5. Measurement of the predicted attenuation is in progress. Detection of leakage displacement profiles has been carried out in a stainless-steel reinforced aluminum system using a sensitive water-bath measurement apparatus, Figure 6 . This type of experiment has not yet been correlated with theory.

In the planar geometry, a propagator matrix theory has been developed for scattering and GIW in an elastic A-B-C sandwich of materials on which the $B$ layer corresponds to the interface. For modeling we have tried to keep this layer as general as possible. So far we consider it a homogeneous 
thin anisotropic region with possible anelasticity (dislocation motion) and viscoelasticity. The theory for both the cylindrical and planar geometries can be further generalized to an inhomogeneous interface region in which the composition and properties can vary from the matrix over to the reinforcements. Because ultrasonic scattering is strongly dependent upon inhomogeneities, this structural difference should be measurable at high frequencies.

Experiments in the propagation of Stoneley waves in the planar geometry have been carried out in conjunction with Moshe Rosen and graduate students $\mathrm{K}$. Hirshman and $\mathrm{E}$. Lindgren from JHU.

Three major issues were considered:

1. The effect of surface smoothness.

2. The effect of microstructure near the interface.

3. The effect of wavelength on probing non-uniform structure on either side of the interface.

It was found that the velocity of propagation of GIW at a titanium-steel interface is strongly affected by the surface smoothness at the interface. The two materials were subjected to pressure normal to the interface and the GIW velocity measured as a function of pressure and surface smoothness. For a fixed surface finish the velocity increased with increasing pressure to that of the theoretically predicted Stoneley wave. Increasing the smoothness of the surface finish decreased the amount of pressure needed to achieve the Stoneley velocity.

The microstructure of the materials forming a planar interface have been found to have a substantial effect on the measured Stoneley wave velocities of the titanium-steel couple. Microstructural variations could be achieved by subjecting steel plates to controlled heat treatments to yield microstructures of coarse pearlite, fine pearlite, martensite, and tempered martensite. It was found that the maximal values of the Stoneley wave velocities, for the different titanium-steel couples, were sensitive not only to the general microstructure but to the particular heat treatments of the steel. Measurements are underway to determine whether this effect is due solely to the change in elastic constants of the steel produced by the changes in microstructure.

The velocity of Stoneley interface waves is nondispersive, i.e., frequency independent. However, the penetration depth of these waves has an approximate linear dependence on wavelength. Thus, the material layer through which the Stoneley wave propagates, at the interface between two planar samples, will depend on the frequency of the propagating wave and changes in the elastic properties will affect the Stoneley velocity.. This property may enable one to nondestructively characterize not only the interface itself but also the elastic properties and integrity of the material adjoining the interface. Measurements are currently being conducted over a $1-15 \mathrm{MHz}$ frequency range to determine the feasibility of this approach. 


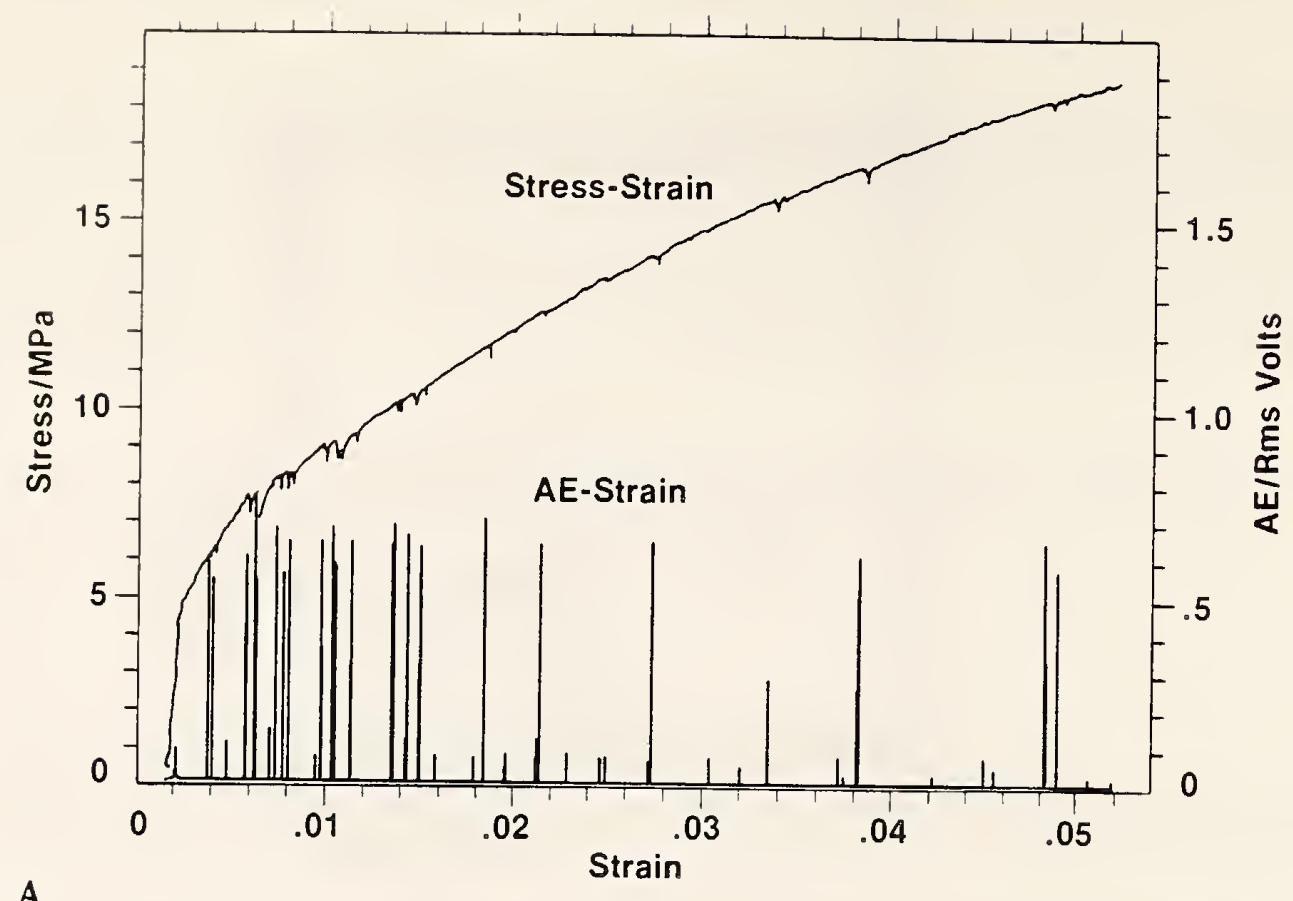

A

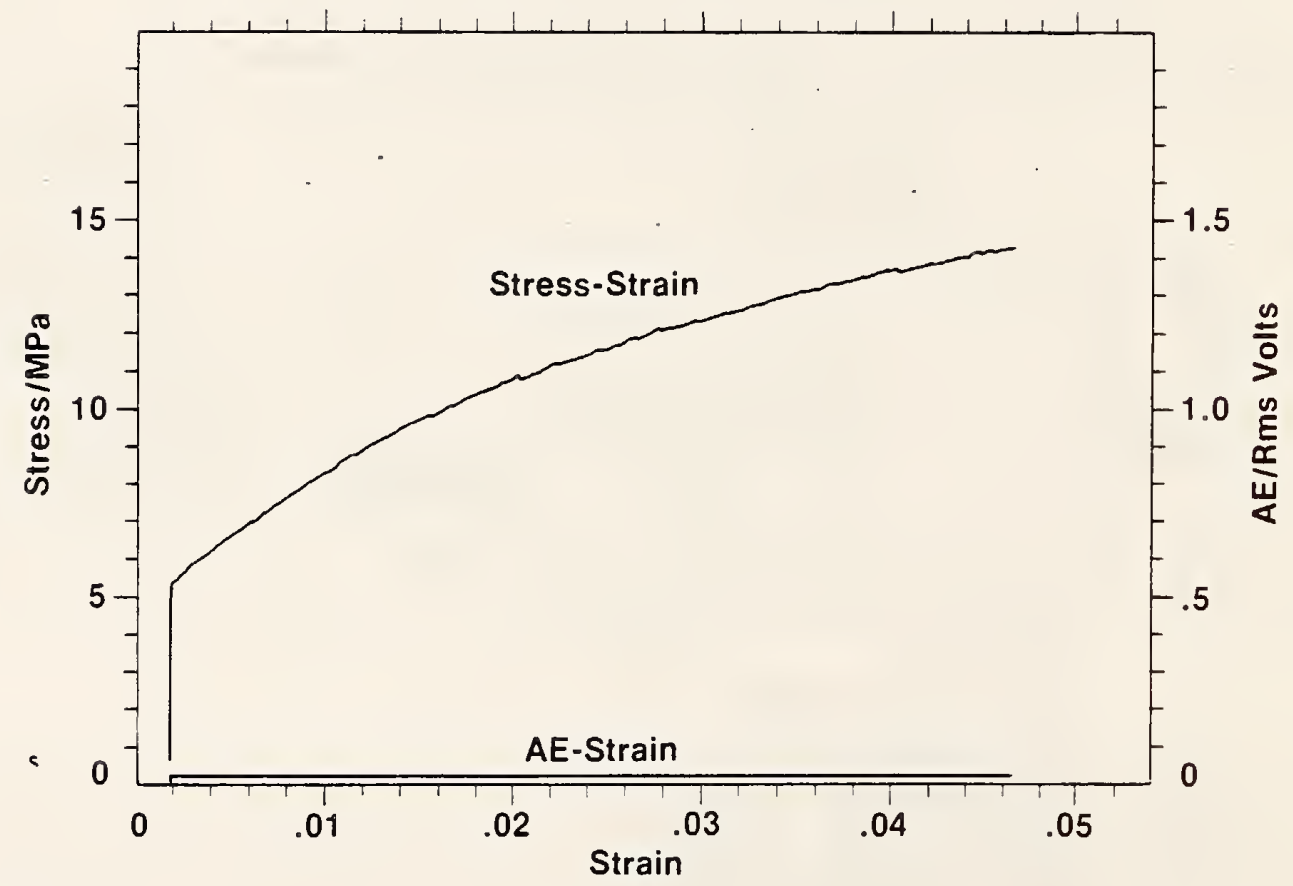

B

Fig. 3(a) Stress-strain and acoustic emission strain relations for a single crystal of aluminum containing a $140_{\mu} \mathrm{m}$ diameter SiC fiber along the tensile axis.

Fig. 3(b) Shows the corresponding data for a single crystal containing no fiber. 


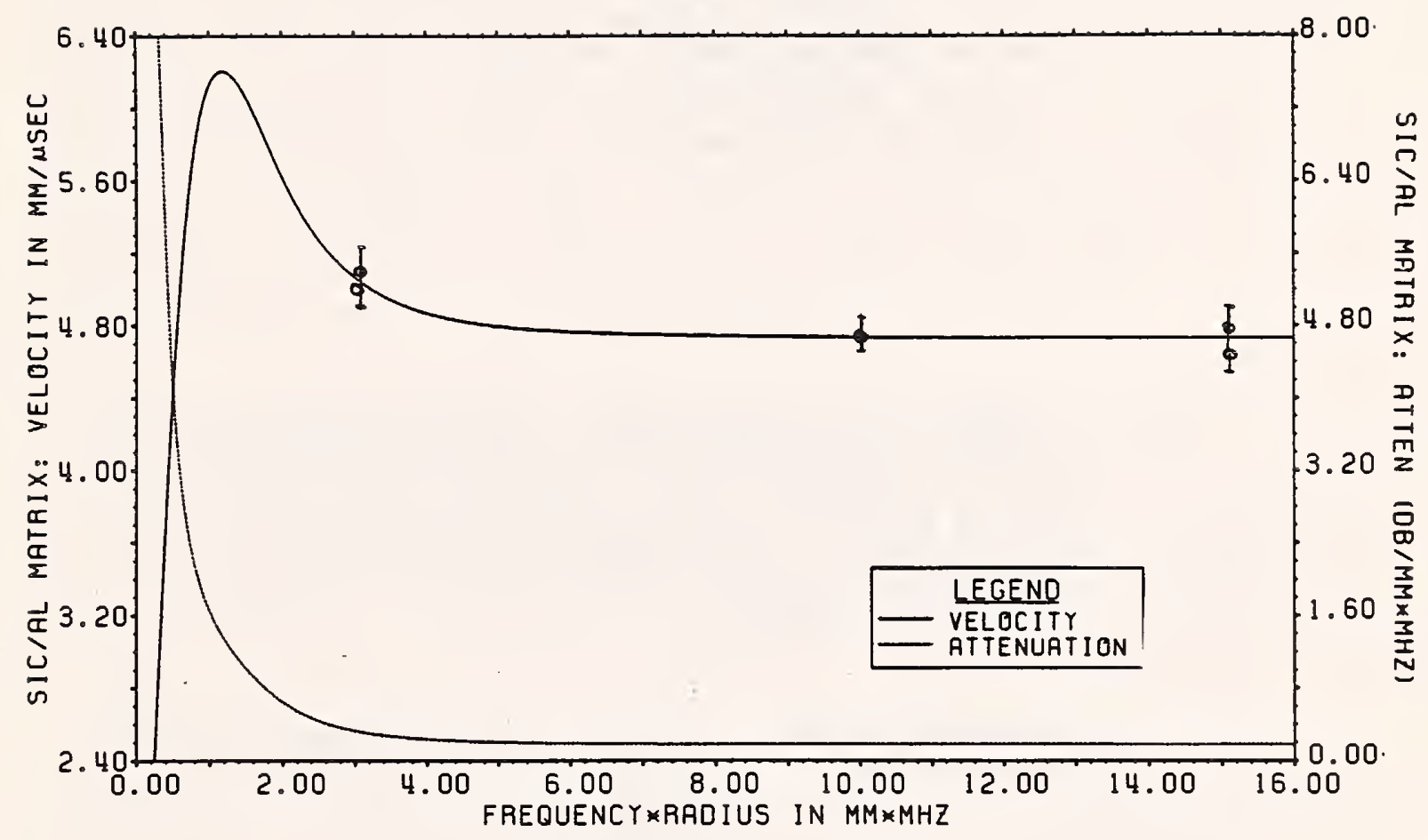

Fig. 4 Comparison of theoreticaliy predicted (curve) and experimentally measured (points) dispersion behavior of a guided interface wave propagating along the cylindrical surface of Sic rod buried in an aluminum matrix. 


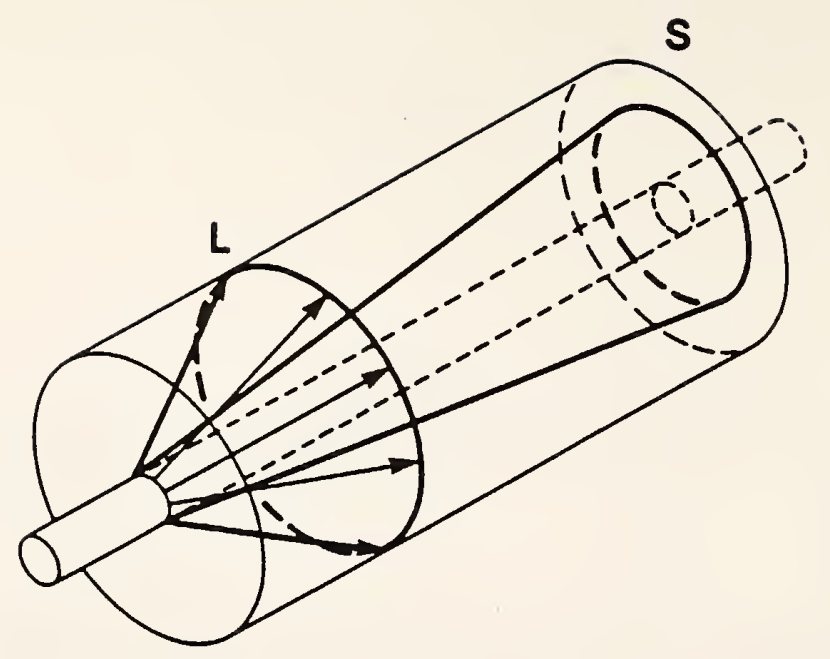

Fig. 5 Schematic diagram on model composite sample. A surface wave propagating to the right undergoes mode conversion at the interface to a "leaky" guided interface wave. Radiation of both longitudinal ( $L$ ) and shear (S) waves occurs as the GIW propagates.

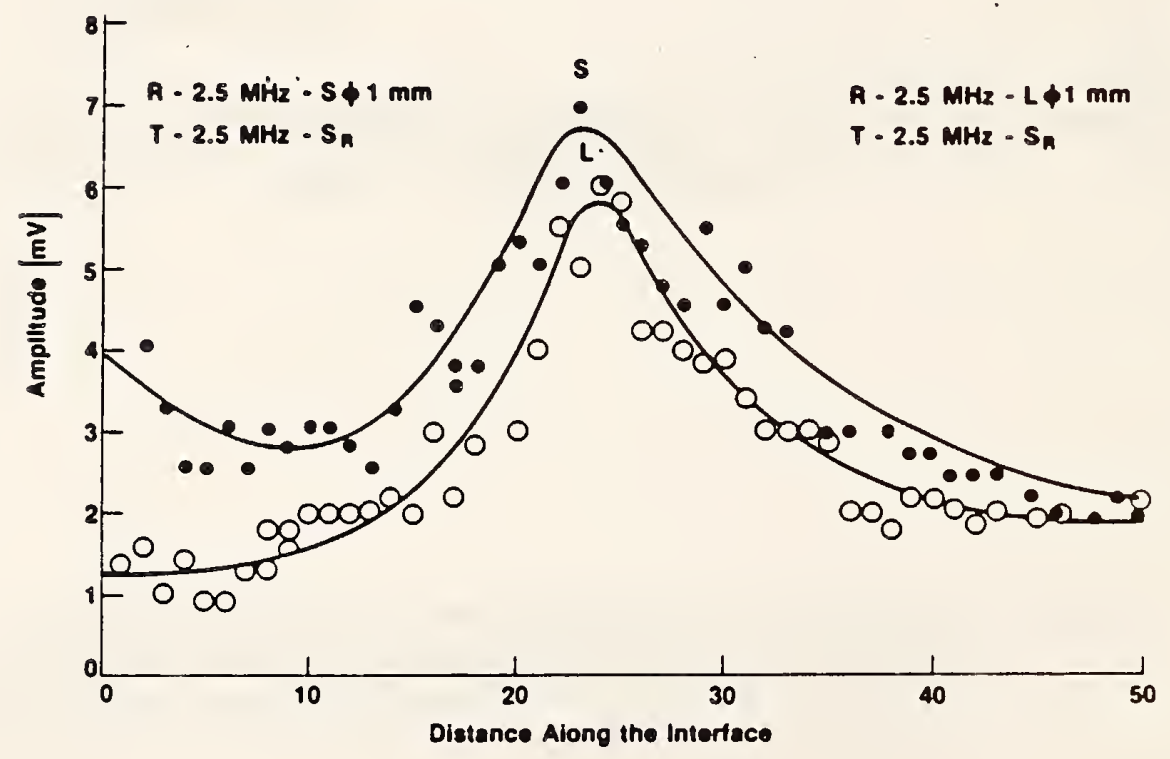

Fig. 6 The variation of transducer voltage with distance along the outer aluminum surface when a guided interface wave is propagating along a cylindrical steel rod - aluminum matrix interface. The curves $S$ and $L$ correspond to "leaky" radiation detected with shear and longitudinal transducers. 
Pulsed potentiostatic deposition has been developed for the production of composition modulated alloys (CMA) by the Electrodeposition Group. A cooperative effort has been established between NBS and scientists from the Naval Research Laboratory to study the magnetic properties of electrodeposited CMA. Magnetization and ferromagnetic resonance studies have now been completed in $\mathrm{Cu}-\mathrm{Ni}$ and $\mathrm{Cu}-\mathrm{Co}$ alloys. Transmission electron micrography shows the existence of sharp interfaces and $x$-ray diffraction shows satellite lines. The magnetic results on the two alloy systems contrast strongly. In the $\mathrm{Ni}-\mathrm{Cu}$, the room temperature magnetic moment reduced rapidly with layer thickness, for $\mathrm{Ni}$ thicknesses less than about $6 \mathrm{~nm}$. (This is the same behavior reported for vapor-deposited $\mathrm{Ni}-\mathrm{Cu}$ CMA.) No such systematic trends were seen in the $\mathrm{Co}-\mathrm{Cu}$. We conclude that the reduced moment of $\mathrm{Ni}$ in $\mathrm{Ni}-\mathrm{Cu}$ multilayered structures may be the result of greater interdiffusion of $\mathrm{Ni}$ into $\mathrm{Cu}$, as compared to Co into $\mathrm{Cu}$.

We are continuing the study of the local topology of atoms in crystals, in collaboration with Dr. R. E. Watson of Brookhaven National

Laboratory. The method used is a Wigner-Seitz (or Voronoi) analysis, with provision for accounting for the different radii of the atoms. We have proposed a connection between the occurrence of strong magnetism and "disclination" paths inferred from our computations. These ideas are being applied to suggestions for new hard magnetic materials, and to aid in the analysis of site occupancies in magnetic materials.

We have carried out nuclear magnetic resonance experiments in the aperiodic Al-Mn Shechtmanite crystals, as well as in normal Al-Mn crystalline structures. We conclude that there is a broad distribution of Al and of Mn site environments in Shechtmanite, and that the electronic and magnetic structure of the Shechtmanite is similar to the periodic crystals. We have also used the Wigner-Seitz analysis to investigate site symmetries and local environments in two different descriptions of Shechtmanite.

In collaboration with colleagues at the Naval Surface Weapons Laboratory and a visiting Israeli, Dr. M. Melamud, we have used the Mossbauer effect to measure the distribution of magnetization in metallic glasses having large magnetomechanical couplings.

We have measured the temperature dependence of the ac susceptibility for melt-spun monel (see Figure). The tail above the steep drop ("Hopkinson effect") from 320 to $355 \mathrm{~K}$ in the melt-spun alloy is due to a distribution of Curie temperatures which may arise from microscopic compositional in homogeneity. The fine granular structure obtained in the rapid solidification process reduces the effective magnetocrystalline anisotropy as evidenced by the enhanced low temperature ac susceptibility. 


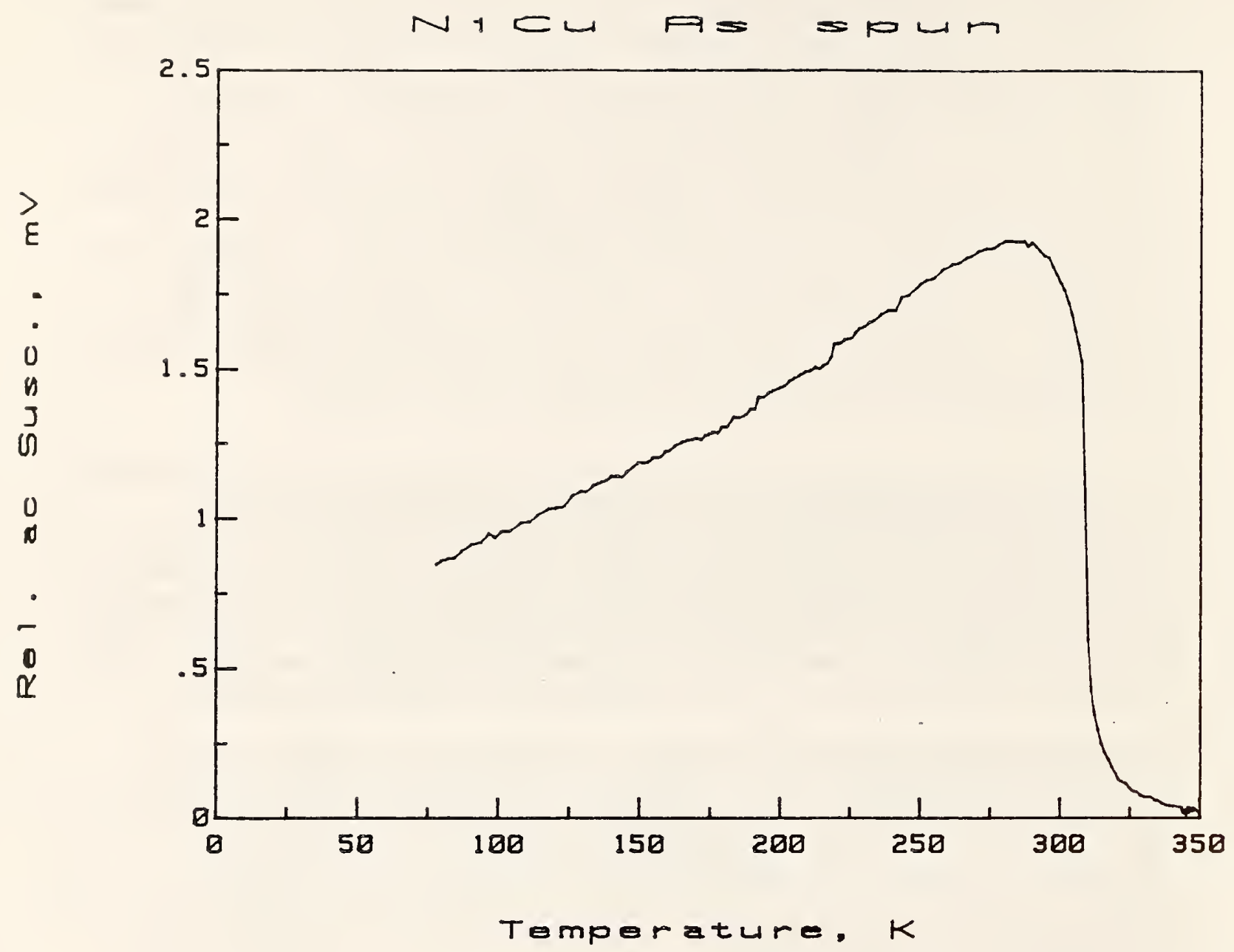

Figure 1. The ac susceptibility of a melt-spun ribbon of a Ni-Cu alloy of the monel composition. The microstructure is columnar, with a grain width of about $\mu \mathrm{m}$. 


\section{PUBLICATIONS}

\section{Structure Characterization Group}

Black, D. R.; Bechtoldt, C. J.; Placious, R. C.; Kuriyama, M.; Three-dimensional strain measurements with $\mathrm{X}$-ray energy dispersive spectroscopy. J. of Nondestructive Evaluation 5 (1); 21-25; 1985.

Black, D. R.; Burdette, H. E.; Early, J. G.; Diffusion bonding of ductile single crystals for strain free mounting. J. of Appl. Crystallography $19 ; 1986$.

Black, D. R.; Spain, I. L.; Energy dispersive X-ray diffraction in the diamond anvil high pressure apparatus: Comparison of synchrotron and conventional X-ray sources. Rev. Sci. Inst. 56 (7); 1461-1463; 1985.

Dobbyn, R. C.; Boettinger, W. J.; Voorhees, P. W.; Burdette, H. E.; A study of the coarsening of liquid-solid mixtures using synchrotron radiation microradiography. Met. Trans. A; 1986; in press.

Dobbyn, R. C.; Glinka, C. I.; Fields, R. J.; Microstructural characterization by small angle neutron scattering. NDE of Microstructure for Process Control. ASM; Metals Park, OH; 1985.

Kuriyama, M.; Long, G. G.; Single crystal structure of rapidly cooled alloys with icosahedral symmetry: II Theoretical analysis--Internal modulations. Acta Cryst. A 42; 164-172; 1986.

Kuriyama, M.; Long, G. G.; Bendersky, L.; Unit-cell structure of rapidly cooled Al-Mn alloys with icosahedral symmetry. Phy. Rev. Lett. 55 ; $849-851 ; 1985$.

Long, G. G.; Kruger, J.; EXAFS as a technique for studying the effects of alloying elements on the nature of the oxide films on steels proc. USA-Japan Seminar; Critical Issues in Reducing the Corrosion of Steels, Nikko, Japan, NACE; 1985; in press.

Long, G. G.; Kuriyama, M.; Single crystal structure of rapidly cooled alloys with icosahedral symmetry: I Experimental analysis. Acta Cryst. A 42; 156-164; 1986.

Long, G. G.; Kuriyama, M.; Theory of extinction in dynamical X-ray diffraction by real crystals. Acta Cryst. A; in press.

Long, G. G.; Revesz, A. G.; Kuriyama, M.; X-ray absorption study of tantalum oxide films on silicon. J. Noncrystalline Solids 70; 271-278; 1985.

Spal, R.; Interpenetrating incommensurately modulated lattices with icosahedral symmetry. Phy. Rev. Lett. 56: 1823; 1986. 


\section{Metallurgical Processing Group}

Bendersky, L.; Decagonal phase. Proc. of Workshop on Aperiodic Crystals; Les Houches; 1986; in press.

Bendersky, L.; Quasicrystals with 1-D translational periodicity and a ten-fold rotation axis. MRS Proceedings; Boston; 1986; in press.

Bendersky, L. A.; Biancaniello, F. S.; Boettinger, W. J.;

Perepezko, J. H.; Microstructure of rapidly solidified Nb-Si alloys. Mats. Sci. and Eng.; 1986; in press.

Bendersky, L.; Kaufman, M. J.; Determination of the point group of the icosahedral phase in an Al-Mn-Si alloy using convergent beam electron diffraction. Phil. Mag. B 53; 3; L15; 1986.

Bendersky, L. A.; Ridder, S. D.; Nucleation behavior of Al-Mn icosahedral phase. J. Mats. Res. 1; 3; 405; 1986.

Bendersky, L.; Schaefer, R. J.; Biancaniello, F. S.; Boettinger, W. J.; Kaufman, M. J.; Shechtman, D.; Icosahedral Al-Mn and related phases: Resemblance in structure. Scripta Met. 19; 909; 1985.

Bendersky, L.; Schaefer, R. J.; Biancaniello, F. S.; Shechtman, D.; Rapidly solidified Al-Cr alloys: structure and decomposition behavior. J. of Mats. Sci. 21; 1889; 1986.

Blendell, J. E.; Handwerker, C. A.; Effect of chemical composition on sintering of ceramics. J. Cryst. Growth 75 (1); 138; 1986.

Boettinger, W. J.; Bendersky, L. A.; Early, J. G.; An analysis of the microstructure of Al-8 wt\% Fe rapidly solidified powders. Met. Trans. A $17 \mathrm{~A} ; 781 ; 1986$.

Boettinger, W. J.; Coriell, S. R.; Microstructure formation in rapidly solidified alloys. Proc. of NATO Advanced Research Workshop on Rapid Solidification Technologies; 1985; in press.

Boettinger, W. J.; Perepezko, J. H.; Fundamentals of rapid solidification. Rapidly Solidified Crystalline Alloys; S. K. Das, B. H. Kear, and C. M. Adam, eds.; TMS-AIME; 21 ; 1985.

Glicksman, M. E.; Coriell, S. R.; McFadden, G. B.; Interaction of flows with the crystal-melt interface. Ann. Rev. Fluid Mech. 18; 307; 1986.

Hackney, S. A.; Biancaniello, F. S.; Directional invariance of grain boundary migration in the $\mathrm{Pb}-\mathrm{Sn}$ cellular transformation and the Tu-Turnbull hysteresis. Scripta Met.; 1986; in press.

Hackney, S. A.; Biancaniello, F. S.; Yoon, D. N.; Handwerker, C. A.; Observations on crystal defects associated with diffusion induced grain boundary migration in $\mathrm{Cu}-\mathrm{Zn}$. Scripta Met. 20; 937; 1986. 
Hackney, S. A.; Shiflet, G. J.; Anisotropic interfacial energy at pearlite lamellar boundaries in a high purity $\mathrm{Fe}-0.80 \% \mathrm{C}$ alloy. Scripta Met. 20; 389; 1986.

Handwerker, C. A.; Diffusion induced grain boundary migration in thin films. Diffusion in Thin Films; D. Gupta and P. Ho, eds. Noyes Publications; 1986; in press.

Hardy, S. C.; The surface tension of liquid gallium. J. Cryst. Growth $71 ; 602 ; 1985$.

Low, S. R.; Early, J. G.; Drop-weight testing of non-standard specimen geometries. ASTM Spec. Tech. Pub. 919; 1986.

McFadden, G. B.; Coriell, S. R.; The effect of fluid flow due to the crystal-melt density change on the growth of a parobolic isothermal dendrite. J. Cryst. Growth 74; 507; 1986.

McFadden, G. B.; Coriell, S. R.; Boisvert, R. F.; Double-diffusive convection with sidewalls. Phys. Fluids 28 (9); 2716; 1985.

Parker, R. L.; Manning, J. R.; Application of pulse-echo ultrasonics to locate the solid/liquid interface during solidification and melting. Proc. of 8th International Conference on Crystal Growth; North-Holland Publishing; Amsterdam; 1986.

Parker, R. L.; Manning, J. R.; Peterson, N. C.; Application of pulse-echo ultrasonics to locate the solid/liquid interface during solidification and melting of steel and other metals. J. Appl. Phys. $58 ; 4150 ; 1985$.

Perepezko, J. H.; Boettinger, W. J.; Kinetics of resolidification. Surface alloying by ion electron and laser beams. ASM; in press.

Rottman, C.; Thermal fluctuations in interfaces: From fluid-fluid interfaces to small-angle grain boundaries. Conference volume for International Conference on Low-Energy Dislocation Structures. Mats. Sci. and Eng. 81; 553; 1986.

Rottman, C.; Thermal fluctuations in low-angle grain boundaries, Acta Met.; 1986; in press.

Schaefer, R. J.; The metallurgy of quasicrystals. Scripta Met.; 1986; in press.

Schaefer, R. J.; Bendersky, L.; Formation of quasicrystals in rapidly solidified Al alloys. Materials Research Society Symposium Series; 1986; in press.

Schaefer, R. J.; Bendersky, L.; Replacement of icosahedral Al-Mn by T phase. Scripta Met. 20; 745; 1986. 
Schaefer, R. J.; Bendersky, L.; Biancanie1lo, F. S.; Nucleation and growth of aperiodic crystals in aluminum alloys. Proc. of International Workshop on Aperiodic Crystals. Journal de Physique; 1986; in press.

Schaefer, R. J.; Bendersky, L. A.; Shechtman, D.; Boettinger, W. J.; Biancaniello, F. S.; Icosahedral and decagonal phase formation in Al-Mn alloys. Met. Trans. A; in press.

Schaefer, R. J.; Biancaniello, F. S.; Cahn, J. W.; Formation and stability range of $G$ phase in the Al-Mn System. Scripta Met.; in press.

Voorhees, P. W.; Glicksman, M. E.; Thermal measurement of Ostwald ripening kinetics in partially crystallized mixtures. J. Cryst. Growth $72 ; 599 ; 1985$.

Voorhees, P. W.; Johnson, W. C.; Interfacial equilibrium during a first order phase transformation in solids. J. Chem. Phys. 84; 5108; 1986.

Voorhees, P. W.; Johnson, W. C.; Laraia, V. J.; Elastic effects during late stage phase transformations. Solute-Defect Interaction: Theory and Experiment. Pergamon Press; 409; 1985.

Voorhees, P. W.; Schaefer, R. J.; In situ observation of particle motion and diffusional interactions during coarsening. Acta Met.; 1986; in press.

Yoon, D. N.; Cahn, J. W.; Handwerker, C. A.; Blende11, J. E.; Baik, Y. J.; Coherency strain induced migration of liquid films through solids; in Interface Migration and Control of Microstructure. ASM Press; 1986.

\section{Wear and Mechanical Properties Group}

Blau, P. J.; A model for run-in and other transitions in sliding friction. J. of Tribology; 1986; accepted for publication.

Blau, P. J.; Applications of microindentation methods in tribology research. ASTM STP 889, P. J. Blau and B. R. Lawn, eds; Philadelphia, PA; 209; 1986.

Blau, P. J.; Measurements and interpretations of sliding wear damage in metals. J. of Tribology $107 ; 483 ; 1985$.

Blau, P. J.; Methods and applications of microindentation hardness testing. Chapter in Handbook of Applied Metallography, G. Vander Voort, ed.; Van Nostrand Co.; NY; 1986; in press.

Blau, P. J.; Microindentation hardness testing of coatings. Chapter in Proc. Amer. Vac. Society Symposium on Physics and Chemistry of Protective Coatings; 1985; in press. 
Blau, P. J.; Wear testing methods and standardization. ASTM Standardization News; 34; 1985.

Blau, P. J.; Lawn, B. R., eds.; Microindentation techniques in materials science and engineering. ASTM Spec. Tech. Pub. 889;

Philadelphia, PA; 1986.

Fraker, A. C.; Corrosion of ammunition. Proc. of 34th Dept. of Defense Conference on Nondestructive Testing; S. 0. McMillan, ed.; Charleston, $\mathrm{SC}$; in press.

Kanakia, M. D.; Owens, E. C.; Peterson, M. B.; High temperature lubrication systems for ring/liner applications in advanced heat engines. Report to Department of Energy, A1641955; 1986.

Polvani, R. S.; Effects of vacancy silicon clusters on the creep of NiAl. J. Mat. Sci.; 1986; in press.

Polvani, R. S.; Ruff, A. W.; Whitenton, E. P.; A dynamic microindentation apparatus for materials characterization. ASTM J. Testing and Evaluation; 1986; in press.

Rigney, D. A.; Naylor, M. G. S.; Divakar, R.; Ives, L. K.; Low energy dislocation structures caused by sliding and particle impact. Proc. of International Conference on Low-Energy Dislocation Structures, University of Virginia; Charlottesville, VA; August 1986.

Ruff, A. W.; Analysis of interlaboratory test results of solid particle impingement erosion. Wear; $108 ; 323$; 1986.

Ruff, A. W.; Ludema, K. C.; Wear. Encycl. of Mat. Sci. and Eng.; M. B. Bever, ed. Pergamon Press; 5273; 1986.

Ruff, A. W.; Polvani, R. S.; Characterization of surface properties of materials including wear. Proc. of the SURTEC International Conference on Surface Technology; Berlin, West Germany; October 1985.

Ruff, A. W.; Schmitt, G. F.; Erosion. Encycl. of Mat. Sci. and Eng.; M. B. Bever, ed. Pergamon Press; 1573; 1986.

\section{Chemical Metallurgy Group}

Massalski, T. B.; Murray, J. L.; Burton, B. P.; Bennett, L. H., tech. eds.; Constitution of binary alloys. Bull. Alloy Phase Diagrams; in press.

McAlister, A. J.; Kahan, D. J.; The Al-Pt (aluminium-platium) system. Bull. Alloy Phase Diagrams 7(1); 47; 1986.

McAlister, A. J.; Murray, J. L.; The Al-Mn (aluminium-manganese) system. Alloy Phase Diagrams; in press. 
Murray, J. L.; Assesment and calculation of the Ti-Cu phase diagram. Noble Metal Alloys; T. B. Massalski, et al., eds. Proc. of TMS Alloy Phase Committee at the Metallurgical Society AIME Annual Meeting;

February 1985; 289-304.

Murray, J. L.; Constitution of binary titanium alloys. American Society for Metals; in press.

Murray, J. L.; The Al-Cu (aluminium-copper) system. Int. Met. Rev. $30(5) ; 211-233 ; 1985$.

Murray, J. L.; The Ga-Ti (gallium-titanium) system. Bull. Alloy Phase Diagrams 6(4); 327-330; 1985.

Murray, J. L.; The Pb-Ti (lead-titanium) system. Bull. Alloy Phase Diagrams 5(6); 613-615; 1985.

Murray, J. L.; The Se-Ti (selenium-titanium) system. Bull. Alloy Phase Diagrams $7(2)$; 1986 ; in press.

Murray, J. L.; The S-Ti (sulfer-titanium) system. Bull. Alloy Phase Diagrams 7(2); 1986; in press.

Nash, P.; Murray, J. L.; The Al-Ni (aluminium-nickel) system. Bull. Alloy Phase Diagrams; in press.

Schechtman, D.; Swartzendruber, L. J.; Metastable phases in rapidly solidified Al-rich Al-Fe alloys. Transactions; AIME; 1986.

Spear, K.; Murray, J. L.; The B-Ti (boron-titanium) system. Bull. Alloy Phase Diagrams 7(2); 1986; in press.

Swartzendruber, L. J.; The Fe-Cr (iron-chronium) System. Bull. Alloy Phase Diagrams; 1986.

Swartzendruber, L. J.; The Fe-Cu (iron-copper) System. Bull. Alloy Phase Diagrams; 1986.

Swartzendruber, L. J.; Alcock, C. B.; Itkin, V. P.; The Fe-Ni (iron-nickel) system. Bull. Alloy Phase Diagrams; 1986.

Swartzendruber, L. J.; Bennett, L. H.; Nuclear magnetic resonance. Metals Handbook, Vol. 3. ASM; 277; 1986.

Swartzendruber, L. J.; Massalski, T. B.; Pearson, W. B.; Bennett, L. H.; Chang, Y. A.; Thermodynamic assessment of the iron noble-metal equilibrium diagrams. AIME; $1986 ; 305$.

\section{Corrosion Group}

Bertocci, U.; Electrochemical principles of corrosion. Encycl. of Mat. Sci. and Eng. Pergamon Press; 1403; 1986. 
Bertocci, U.; Random noise in passivity. 5th Brasilian Symposium of Electrochemistry; 1986; in press.

Bertocci, U.; Pugh, E. N.; Modeling of the potential at the tip of a transgranular stress-corrosion crack in the alpha-brass-ammonia system. Proc. of Conference on Corrosion Chemistry Within Pits, Crevices, and Cracks; London; 1984; in press.

Escalante, E.; Patterson, D. E.; Husar, R. B.; Bronze, zinc, aluminum and galvanized steel: corrosion rates as a funciton of space and time over the United States. ACS Symposium Series 318, Materials Degradation Caused by Acid Rain; 152; 1986.

Escalante, E.; Underground corrosion. Encycl. of Mat. Sci. and Eng. Pergamon Press; 1986.

Interrante, C. G.; Standard terminology related to fracture testing. ASTM designation E616-82 2, revised in April 1986; ASTM 03.01; Annual Book of ASTM Standards; 1986.

Kaufman, M. J.; Cunningham, J. E.; Fraser, H. L.; Metastable phase production and transformation in $\mathrm{Al}-\mathrm{Ge}$ alloy films by rapid crystallization and annealing treatments. Acta Met.; in press.

Kaufman, M. J.; Ellner, M.; Fraser, H. L.; Constitution of an Al-37.5 Ge splat quenched foil: Implication on nucleation kinetics. Scripta Met. 20; 103; 1986.

Kaufman, M. J.; Forty, A. J.; A detailed fractographic analysis of cleavage steps in Si. J. Mat. Sci.; in press.

Kaufman, M. J.; Fraser, H. L.; Undercooling and microstructural evolution in glass forming alloys. Proc. of the Hume-Rothery Symposium on Undercooling; C. C. Koch, E. W. Collings, eds.; in press.

Kaufman, M. J.; Konitzer, D. G.; Shull, R. D.; Fraser, H. L.; An analytical electron-microscopy study of the recently reported $\mathrm{Ti}_{2} \mathrm{Al}$ phase in -TiAl alloys. Scripta Met. 20; 125; 1986.

Kaufman, M. J.; Pearson, D. D.; Fraser, H. L.; The use of convergent beam electron diffraction to determine local lattice distortions in Ni-base superalloys. Phil. Mag.; in press.

Kaufman, M. J.; Pugh, E. N.; Thomson, R. M.; Forty, A. J.; A mechanism for cleavage crack arrest by ligament formation in transgranular stress corrosion cracking. Scripta Met.; in press.

Kaufman, M. J.; Shull, R. D.; Nature of large $\mathrm{Ti}_{4} \mathrm{Cu}_{2} \mathrm{O}$ particles formed during annealing of $\mathrm{Cu}_{55} \mathrm{Ti}_{45}$ metallic glass ribbons. Metall. Trans. $17 \mathrm{~A} ; 575 ; 1986$.

Pugh, E. N.; Corrosion: Metallurgical aspects. Encycl. of Mat. Sci. and Eng. Pergamon Press; 889; 1986. 
Pugh, E. N.; Corrosion cracking. Encycl. of Mat. Sci. and Eng.

Pergamon Press; 4669; 1986.

Pugh, E. N.; Kaufman, M. J.; Cleavage step formation and resistance to transgranular stress corrosion cracking. Proc. 1986 Materials

Technology Congress; Adelaide, Australia; May 1986; in press.

Ricker, R. E.; Baumert, B.A.; Effect of heat treatment on corrosion resistance of Al-Li alloys. Aluminum Lithium Alloys III; C. Baker; P. J. Gregson; S. J. Harris; C. J. Peel, eds. The Institute of Metals; London, England; 282-286; 1986.

Ricker, R. E., contributor to book; Failure analysis and prevention. Metals Handbook, Vol. 11, 9th Ed. ASM; Metals Park, OH; 1986.

Ricker, R. E., contributor to book; Fractography and atlas of fractographs. Metals Handbook, Vol. 10, 9th Ed. ASM; Metals Park, OH; 1986.

Ricker, R. E.; The influence of environment on the fatigue properties of Aluminum alloys. Modeling Environmetally Effects on Crack Initiation and Propagation; R. Jones, ed. American Institute of Mining, Metallurgical and Petroleum Engineers; New York; 1986.

Ugiansky, G. M.; Clausen, D. C.; The NACE-NBS corrosion data program: An answer to the high cost of corrosion. Proc. of Corrosion Prevention and Control Conference "Major Initiatives in Corrosion Prevention and Control" sponsored by U.S. Army Material Command; Williamsburg, VA; April 1986.

Ugiansky, G. M.; Payer, J. H.; Impact of the NBS-Battelle cost of corrosion study of the USA. Proc. of Corrosion ' 86 Symposium on International Approaches to Reducing Corrosion Costs sponsored by NACE; Houston, TX; March 1986.

Ugiansky, G. M.; Van Orden, A. C.; Clausen, D. C.; The NACE-NBS corrosion data program. The International Corrosion Forum: Corrosion '86, sponsored by NACE; Houston, TX; March 1986.

\section{Electrodeposition Group}

Lashmore, D. S.; Brown, H. J.; Kelley, D. R.; The production of a duplex nickel standard reference material. J. Plating and Surface Finishing 73; 10; 1986.

Lashmore, D. S.; Oberle, R.; Dariel, M. P.; Electrodeposition of artificially layered material. Proc. of 1986 International Pulse Plating Symposium; Washington, DC.

Lashmore, D. S.; Weisshaus, I.; Pratt, K. W.; Electrodeposition of nickel-chromium alloys. J. Plating and Surface Finishings $73(3)$; 48; 1986. 
Ratzker, M.; Lashmore, D. S.; Pratt, K. W.; The corrosion performance of electrodeposited nickel-phosphorus amorphous alloys. J. Plating and Surface Finishing 9; 73; 1986.

VanVechten, T. C.; Lashmore, D. S.; Johnson, C. E.; Puippe, J. C. ; Electrochemical measurement of surface area. J. Plating and Surface Finishing $73 ; 9 ; 1986$.

\section{Nondestructive Characterization Group}

Alers, G.; Wadley, H. N. G.; Development of easily scanned transducers for the ultrasonic testing of hot steel. Proc. of Review of Quantitative NDE; San Diego; August 1986.

Berlinsky, Y.; Rosen, M.; Simmons, J. A.; Wadley, H. N. G.; A calibration approach to acoustic emission energy measurement. NDE Communications; 1986.

Berlinsky, Y.; Rosen, M.; Simmons, J. A.; Wadley, H. N. G.; Acoustic emission: A technique for characterizing the martensitic transformation in Fe-30 wt\%Ni. Proc. of Review of Quantitative NDE; Williamsburg, VA; June 1985 .

Berlinsky, Y.; Rosen, M.; Simmons, J. A.; Wadley, H. N. G.; Acoustic emission: An NDE technique for characterizing the martensitic transformation. Review of Progress of Quantitative NDE 5; D. O. Thompson and D. E. Chimenti, eds; Plenum Press; 1986.

Clough, R. B.; Schaefer, R.; Wadley, H. N. G.; Acoustic emission monitoring of laser drilling in NDE of microstructure for process control; H. N. G. Wadley, ed. ASM; Metals Park, OH; 1985; 133-142.

Droney, B. E.; Wadley, H. N. G.; Norton, S. J.; Mauer, F. A.; Experiments with ultrasonic sensors to measure internal temperature distributions. Proc. of Review of Quantitative NDE; Williamsburg, VA; June 1985.

Elkind, B. J.; Rosen, M.; Wadley, H. N. G.; Ultrasonic characterization of surface modified layers. Met. Trans. A; 1986; in press.

Elkind, B. J.; Rosen, M.; Wadley, H. N. G.; Ultrasonic characterization of microstructurally modified surfaces of steel subjected to electron beam irradiation. World Conference on NDT 3; 1985; Las Vegas, NV; $1633-1640$.

Gvishi, M.; Rosen, M.; Wadley, H. N. G.; Nondestructive characterization of the martensitic phase transformation in NiTi by means of acoustic emission and electrical resistivity. Review of the Progress in Quantitative NDE 4B; D. Thompson and D. Chimenti, eds. Plenum Press; 1985. 
Kahn, A. H.; Long, K. R.; Ryckebusch, S.; Hsieh, T.; Testardi, L. R.; Determination of electrical conductivity profiles from frequency-sweep eddy current measurement. Review of Progress in Quantitative NDE 5; $1383 ; 1986$.

Kahn, A. H.; Wadley, H. N. G.; Application of eddy current methods to the in-process measurement of temperature distributions. Proc. of the Aluminum Association Workshop on Sensors; Atlanta, GA; May 1986; in press.

Krasicka, E. D.; Simmons, J. A.; Wadley, H. N. G.; Guided interface waves. Proc. of Review of Quantitative NDE; San Diego, CA; August 1986.

Linzer, M.; Sato, T.; Ikeda, O.; Hatsuzawa, T.; Real-time evaluation of wear particles using electro-magnetic forced rotation and laser scattering. Wear; in press.

Mauer, F. A.; Droney, B. E.; Norton, S. J.; Wadley, H. N. G.; Ultrasonic sensors to measure internal temperature distribution. Review of Progress in Quantitative NDE; D. O. Thompson and D. E. Chimenti, eds.; 5A; 643-650; Plenum Press; 1986.

Norton, S. J.; Testardi, L. R.; Reconstruction of one-dimensional inhomogeneities in elastic modulus and density using acoustic dimensional resonances. J. Acoust. Soc. Amer. 79; 932-941; 1986.

Rosen, M.; Ives, L.; Ridder, S.; Biancaniello, F.; Mehrabian, R.; Correlation between ultrasonic and hardness measurements in aged aluminum alloy 2024. Materials Science and Engineering 74; 1; 1985.

Simmons, J. A.; Deconvolution for acoustic emission. Review of Progress in Quantitative NDE; D. O. Thompson, ed.; 5; Plenum Press; 1986.

Smith, J. J.; Rosen, M.; Wadley, H. N. G.; Laser/ultrasonic NDE of melt spun ribbons. World Conference on NDT; 2; Las Vegas, NV; 902-909.

Testardi, L. R.; Norton, S. J.; Hsieh, T.; Acoustical dimensional resonance tomography: Some examples in one-dimensional systems. J. App1. Phys. 59; 55-58; 1986.

Wadley, H. N. G.; Acoustic emission: A quantitative NDE technique for the study of fracture. Solid Mechanics Research for Quantitative NDE; J. O. Achenbach and Y. Rajapakse, eds.; 1986.

Wadley, H. N. G.; Acoustic emission: Nature's ultrasound. Proc. of Review of Quantitative NDE; Williamsburg, VA; June 1985.

Wadley, H. N. G.; New sensors will save steel industry $\$ 400$ million. CME; February 1985. 
Wadley, H. N. G.; Process control sensors: Status of AISI

collaborative programs. Proc. of Vacuum Metallurgy Conference on Specialty Melting and Processing; Pittsburgh, PA; June 1986.

Wadley, H. N. G.; Norton, S. J.; Mauer, F. A.; Droney, B. E.; An ultrasonic method for measuring internal temperature distributions in steel and aluminum. Proc. of the Aluminum Association Workshop on Sensors; Washington, DC; 1986; in press.

Wadley, H. N. G.; Norton, S. J.; Mauer, F. A.; Droney, B.; Ultrasonic measurement of internal temperature distribution. Proc. of the Royal Society of London; 1986; in press.

Wadley, H. N. G.; Norton, S. J.; Droney, B. E.; An ultrasonic method for measuring internal temperature distribution in steel and aluminum. Proc. of the Aluminum Association Workshop on Sensors; Washington, DC; May 1986.

\section{Magnetic Properties}

Bennett, L. H., ed.; Computer modeling of phase diagrams. Met. Soc. of AIME; Warrendale, PA; 1986.

Bennett, L. H.; McAlister, A. J.; Vegard's law. Encycl. of Mat. Sci. and Eng. Pergamon Press; 5241; 1986.

Bennett, L. H.; Mossbauer techniques in nondestructive evaluation. Encycl. of Mat. Sci. and Eng.; 3121; 1986.

Bennett, L. H., ed.; Resonance techniques. Metals Handbook, Vol. 10. ASM; Metals Park, OH; 1986.

Bennett, L. H.; Long, G. C.; Kuriyama, M.; Goldman, A. I.; Local atomic structure in transition metal/metalloid glasses: Ni-P. Structure and Bonding in Noncrystalline Solids; G. E. Walrafen, ed.; Plenum Press; in press.

Bennett, L. H.; Swartzendruber, L. J.; Nuclear magnetic resonance. Metals Handbook, Vol. 10 (Materials Characterization), 9th Ed.; 277; ASM; Metals Park, OH; 1986.

Bennett, L. H.; Watson, R. E.; Systematics of the alloying behavior of the noble metals. Noble Metal Alloys; T. B. Massalski, W. B. Pearson, L. H. Bennett, and Y. A. Chang, eds. Met. Soc. of AIME; Warrendale, PA; 1986.

Bennett, L. H.; Watson, R. E.; Pearson, W. B.; Topology of local atomic environments: Implications for magnetism and superconductivity. J. Mag. and Mag. Mat. 54; 1537; 1986.

Dariel, M.; Bennett, L. H.; Lashmore, D. S.; Lubitz, P.; Rubinstein, M.; Harford, M. Z.; Lechter, W. L.; Properties of electro-deposited Co-Cu multilayers. J. Appl. Phys.; in press. 
Massalski, T. B.; Pearson, W. B.; Bennett, L. H.; Chang, Y. A., eds.; Noble metal alloys. Met. Soc. of AIME; 3; Warrendale, PA; 1986.

Melamud, M.; Bennett, L. H.; Cullen, J.; Wun-Fogel, M.; Moment distribution in amorphous magnetic ribbons. J. Appl. Phys.; in press.

Melamud, M.; Bennett, L. H.; Watson, R. E.; Where are the iron atoms

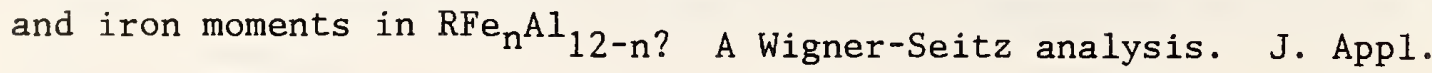

Phys.; in press.

Rubinstein, M.; Bennett, L. H.; Chien, C. L.; Magnetism and the observation of NMR lines in hexagonal $\mathrm{Al}_{4} \mathrm{Mn}$ and icosahedral $\mathrm{Al}-\mathrm{Mn}$ alloys. J. Appl. Phys.; in press.

Rubinstein, M.; Stauss, G. H.; Phillips, T. E.; Moorjani, K.;

Bennett, L. H.; Nuclear magnetic resonance in Al-rich quasiperiodic crystals. J. Mater. Res. 1; 243; 1986.

Swartzendruber, L. J.; Bennett, L. H.; Mossbauer spectroscopy. Metals Handbook, Vol. 10 (Materials Characterization), 9th Ed.; 287; ASM, Metals Park, OH; 1986.

Swartzendruber, L. J.; Bennett, L. H.; Ettedgui, H.; Initial susceptibility studies of rapidly solidified monel. J. Appl. Phys.; in press.

Watson, R. E.; Bennett, L. H.; Alpha manganese and the Frank-Kasper phases. Scripta Met. 19; 535; 1985.

Watson, R. E.; Bennett, L. H.; The noble metals as incipient transition elements. Noble Metal Alloys; T. B. Massalski, W. B. Pearson, L. H. Bennett, and Y. A. Chang, eds. Met. Soc. of AIME; 3; Warrendale, $\mathrm{PA} ; 1986$.

Watson, R. E.; Bennett, L. H.; The quasicrystalline structures of transition metal/metalloid glasses. J. Mag. and Mag. Mat. 54-57; 295; 1986.

Watson, R. E.; Bennett, L. H.; Davenport, J. W.; Weinert, M.; Electron band theory and the construction of phase diagrams. Computer Modeling of Phase Diagrams, L. H. Bennett, ed. Met. Soc. of AIME; 1; Warrendale, PA; 1986.

Watson, R. E.; Melamud, M.; Bennett, L. H.; Disclinations and magnetism in rare earth-transition metal hard magnets. J. App1. Phys.; in press. 


\section{INDUSTRIAL AND ACADEMIC INTERACTIONS}

The research programs of the Metallurgy Division are designed and carried out in support of industrial and scientific needs. Specialized facilities within the Division, including metals processing and nondestructive evaluation, attract scientists from both academic and industrial organizations for cooperative research efforts. Interactions with industry, universities, and professional organizations are viewed as an important element of our work with collaborative programs, consulting and general involvement with outside groups being a long standing practice. For example, the Metallurgy Division has been working for more than 70 years with the steel industry to improve the durability and performance of alloys.

In 1986, the Division performed collaborative research with many private organizations through its Industrial Research and Guest Worker programs and other arrangements. Representative examples of such interactions include:

\section{INDUSTRY}

1. Aluminum Association

A memorandum of understanding and agreement was signed with the Aluminum Association in May 1986. The agreement is for the cooperative research and development of a sensor for determining the internal temperature of aluminum alloys undergoing high-speed extrusion: Under the agreement Aluminum Association Research Associate M. Mester is collaborating with NBS scientists in the Nondestructive Characterization Group in evaluating nove1 multifrequency eddy current approaches to internal temperature measurement.

\section{American Iron and Steel Institute}

The American Iron and Steel Institute (AISI) is sponsoring a program in the Corrosion Group directed at identifying the effect of landfill conditions on the corrosion of steel piling underground.

\section{American Iron and Steel Institute}

The Nondestructive Characterization Group has continued a strong collaboration with the American Iron and Steel Institute (AISI) during FY 86. The interaction began in 1983 with the signing of a memorandum of understanding and agreement to research and develop ultrasonic approaches for internal temperature distribution and pipe/porosity sensors for control of steel processing. The work on the pipe/porosity has essentially been completed with the successful evaluation of a prototype system in FY 86. Research continues with the temperature sensor toward developing full specifications for a prototype sensor. 
The technical activities of the joint NBS/American Society for Metals Data Program for alloy phase diagrams are centered at NBS. The editor and associate editor of the Bulletin of Alloy Phase Diagrams are J. L. Murray and B. Burton (both of NBS). Three category editors of the program are working at NBS: J. L. Murray, L. J. Swartzendruber and A. J. McAlister, for $\mathrm{Ti}_{-}, \mathrm{Al}-$, and $\mathrm{Fe}^{-}$alloys, respectively.

5. Artech Corporation

Henry Hahn, President of Artech Corporation, has worked with the Wear and Mechanical Properties Group (A. C. Fraker) in conducting studies of arc plasma sprayed porous coatings of titanium and Ti-6A1-4V. The strength of the interface, corrosion fatigue behavior and corrosion resistance were determined. Effects of variable parameters in the porous coating application were investigated and best processing methods were determined.

\section{Battelle Columbus Laboratories}

A joint activity is underway to prepare a wear atlas from selected literature and research findings at Battelle Columbus Laboratories and NBS. W. Glaeser of Battelle and A. W. Ruff (NBS) are evaluating 250 publications in wear and friction to select authoritative findings that relate wear and friction with material properties and surface morphology. The findings will be published as an atlas under a cooperative effort that also includes the West German Bundesanstalt fur Materialprufung.

\section{Deere and Company}

A Research Associate Program with Deere and Company (P. A. Swanson) and NBS ( $\mathrm{L}$. K. Ives) is concerned with investigating problems connected with the measurement of galling damage and the development of tests to determine the galling behavior of metals. Tests and measurement methods developed at NBS are currently being employed to evaluate alloys used in agricultural and industrial equipment where galling wear is a serious problem.

8. DePuy Manufacturing Company, Inc.

Todd Smith of DePuy Manufacturing Company, Inc. has cooperated with NBS (A. C. Fraker) in research designed to study the mechanical and electrochemical effects of applying sintered porous coatings of Co-Cr-Mo to Co-Cr-Mo substrates. Specimens involving extensive preparation and modelled after industrially produced prosthetic devices were provided.

9. C. S. Draper Laboratory, Inc.

Studies are underway involving the evaluation of an idea for an improved microstructural design for beryllium. The goal is to reduce "dimensional instability," time dependent shape distortion, by means 
of reduced agglomeration of the dispersed phases. Mechanical properties being considered are: dimensional instability, the Micro Yield Strength ( $1 \times 10^{-6}$ offset value), and the coefficient of linear thermal expansion. All three properties critically determine the navigational precision of "instruments" constructed of beryllium. C. S. Draper Laboratory, Inc. has supplied materials in the form of test samples and funding. NBS continues to provide the necessary measurement capability and interpretation of the data. This is a collaboration between $\mathrm{K}$. Kaplesh and J. McCarthy (both of Draper) and R. Polvani (NBS).

10. FIBA, Inc. and Union Carbide Corporation

A collaborative effort is underway between FIBA, Inc. (P. Horrigan), Union Carbide Corporation (R. Tripolet), and NBS (J. H. Smith) to evaluate use of acoustic emission techniques for use in the periodic inspection of large steel pressure vessels. NBS is in the process of developing specific procedures and test criteria to permit the use of acoustic emission techniques for this application.

11. Howmedica, Inc.

Larry Gustavison of Howmedica, Inc. has cooperated with NBS (A. C. Fraker) and provided sintered porous coated $\mathrm{Co}-\mathrm{Cr}-\mathrm{Mo}$ research materials and devices for use in metallurgical studies. He also provided the Co-Cr-Mo material used for the Standard Reference Material 1891.

\section{Industrial Technology Research Institute}

A corrosion specialist from Materials Research Laboratories, Industrial Technology Research Institute of Taiwan, has spent several months at NBS in the Corrosion Group cooperating in a study of acoustic emission as a diagnostic method for detecting stress corrosion cracking.

\section{International Business Machines}

The International Business Machines Corporation is sponsoring a project at NBS (D. Lashmore and L. Bennett) dealing with the magnetic properties of electrodeposited artificial super lattices.

14. Lockheed Corporation

A collaborative effort is underway between the Lockheed Research Laboratory of Lockheed Corporation (R. Lewis and A. Joshi) and NBS (R. Shull) to prepare metastable magnesium alloys via rapid solidification and to determine their structures and corrosion resistance. Significant enhancement of transition metal solubilities in magnesium have been obtained which may lead to large reductions in the rates of atmospheric attack of these alloys. 
15. Luxfer USA, Inc.

A collaborative effort between NBS (J. H. Smith) and Luxfer USA, Inc. (G. Waite) is ongoing to determine the extent of cracking in seamless aluminum compressed gas cylinders and to develop a reliable test method for inspecting the cylinders in service.

\section{Magnaflux Corporation}

The Nondestructive Characterization Group has continued an interaction with the Magnaflux Corporation advising them on materials selection and high temperature ultrasonic couplant alternatives for emerging steel sensors.

\section{Minnesota Mining and Manufacturing Company}

D. P. Smith of Memory Technologies Laboratory, Minnesota Mining and Manufacturing Company, and R. Polvani (NBS) are collaborating on a means of characterizing the mechanical properties of "floppy" disk coatings. The ability of disks to store information depends on both the recording/reading head maintaining intimate contact with the magnetic coating and using coatings as thin as possible. The pressure needed to maintain contact and thinness of the coating causes a serious durability problem. Dynamic Microindentation Instrument load-depth curves are providing a unique means for understanding the mechanical performance of the coating/disk system.

18. National Association of Corrosion Engineers

The technical activities of the collaborative National Association of Corrosion Engineers-National Bureau of Standards (NACE-NBS) Corrosion Data Program are centered at NBS. This program is providing scientists and engineers with computerized corrosion data. NACE has recently delivered to users the first products of the cooperative program -- a floppy disk corrosion database. The floppy disk package with search capability presents uniform corrosion data for alloys in aqueous environments as graphs and tables showing corrosion rate as a function of concentration and temperature of the environment. A second floppy disk database on non-metals is also near completion. Projects are also underway to acquire large computerized corrosion databases from specific industry sources. The efforts were aided greatly by D. E. Clausen, a full-time Research Associate assigned to the program by NACE.

\section{Parker Hannifin Corporation}

Research on characterizing the weldability of a leaded, resulfurized, rephosphorized carbon steel is being carried out in a cooperative program between Parker Hannifin Corporation (W. Hertel), the U.S. Coast Guard (H. Hime), and NBS (J. G. Early). This research is aimed at establishing welding limits for this steel which is not currently allowed in ship components. The deformation behavior of weld test samples (prepared by Parker Hannifin) is being studied by analysis of test results from semi-guided bond tests and wrap-bend tests. 
20. Union Carbide Corporation and Taylor-Wharton, Inc.

A collaborative effort is underway between the Linde Division of Union Carbide Corporation (M. Rana), Taylor-Wharton, Inc. (K. Miller), and the Wear and Mechanical Properties Group (J. H. Smith) to develop criteria for the safe design and fabrication of high strength steel, seamless pressure vessels. Criteria have been developed, based on fracture mechanics principles, to permit the use of new, higher strength steels for the construction of pressure vessels without reducing the level of safety of these vessels.

\section{INDUSTRY/UNIVERSITY}

1. National Bureau of Standards Metals Processing Laboratory

The National Bureau of Standards Metals Processing Laboratory is one of the special facilities available at NBS to aid researchers from industry and universities in independent or collaborative research and testing of new materials. Such investigators can come to NBS to participate in the preparation of special samples not readily obtainable elsewhere. During the past year, investigators from Lockheed, Martin Marietta, General Electric, Air Force Materials Laboratory, Naval Research Laboratory, Bureau of Mines, Lawrence Livermore Laboratory, Massachusetts Institute of Technology, University of California at Santa Barbara, University of Washington, and University of Wịsconsin have participated in interactions in this program. Collaboration with NBS scientists on metallurgical aspects of the generic technical problems involved is often included in these activities. Particular interest has been shown in rapid solidification technology, where the Metals Processing Laboratory possesses unique capabilities.

2. Rhone Poulenc, Inc./University of Lyon, France

Under the sponsorship of the French company Rhone Poulenc, Inc., and in cooperation with the University of Lyon (Professor Mazille), a French graduate student is spending sixteen months at NBS to study the use of acoustic emission to detect, and possibly identify, different corrosion and stress corrosion processes on stainless steels.

\section{UNIVERSITIES}

\section{Carnegie-Mellon University}

W. Johnson (Carnegie-Mellon University) and P. Voorhees (Metallurgical Processing Group) have been collaborating on a study of stress effects on alloy coarsening. In high-strength alloys designed for use at high temperatures, control of precipitate size and avoidance of excessive coarsening of the alloy microstructure is important in order to maintain high performance. This joint program in which the expertise of $W$. Johnson and his students on elastic interactions in alloys is combined with the expertise of P. Voorhees and co-workers at NBS on kinetic effects has resulted in significant progress toward evaluating the effect of stress on coarsening processes. 
A fruitful collaboration between Johns Hopkins University graduate students (T. Hsieh, K. Hershman, and E. Lindgren) and NBS (M. Rosen) has begun in the area of composite materials interface characterization. The collaboration centers around the use of guided stoneley waves for characterizing the elastic property gradients at interfaces. It extends the approach of an earlier collaboration on Rayliegh wave characterization of surface elastic property gradients.

3. Johns Hopkins University

A cooperative program between Johns Hopkins University (J. Kruger) and NBS (G. Long) for the study of the influence of alloying on the nature of passive films has been in progress for the past year. Considerable progress has been made in applying both ex situ and in situ EXAFS techniques to the study of the passive film on iron, and the research is continuing at the NBS/IMSE $x$-ray beamline at the National Synchrotron Light Source. One senior post-doc (D. Tanaka) and two graduate students from Johns Hopkins are stationed at NBS.

4. Johns Hopkins University

Studies on the mechanism of transgranular stress corrosion cracking are being pursued in cooperation with J. Kruger of Johns Hopkins University. The experimental part is being carried out at NBS by a graduate student ( $T$. Cassagne), and the staff of the Corrosion Group is involved both in the experimental and in the analysis of the results.

5. Johns Hopkins University

A cooperative program between the Johns Hopkins University and NBS for study of rapid solidification processes has been in progress for the past five years. Typically, in this program rapidly solidified alloys are produced in the NBS Metals Processing Laboratory and then characterized by electron microscopy techniques by scientists from Johns Hopkins (D. Shechtman and L. Bendersky). The results are jointly analyzed by the cooperating NBS and Johns Hopkins scientists to determine the effect of rapid solidification processing on alloy microstructure. This collaboration has recently resulted in a major discovery of a new class of materials, quasicrystals, that do not obey previously accepted crystallographic restrictions concerning periodicity.

\section{Massachussetts Institute of Technology}

The Nondestructive Characterization Group has commenced a close collaboration with J. Cornie and his colleagues at the Massachussetts Institute of Technology (MIT) as part of a new SDI/SDIO program on advanced composites. The Nondestructive Characterization Group is responsible for developing innovative methods for determining the mechanical properties of the interfaces between metal matrix and ceramic reinforcement in metal matrix composites. 
7. North Carolina State University

This research is a collaborative effort between North Carolina State University (H. H. Stadelmaier and I. K. Simonsen) and NBS

(A. C. Fraker) to determine the identity and conditions of formation of carbides found in $\mathrm{Co}-\mathrm{Cr}-\mathrm{Mo}-\mathrm{C}$ alloys. The results should be useful in controlling the amounts and distribution of carbide phases in this material.

8. University of Illinois

R. D. Shull and M. J. Kaufman, both of NBS, have been collaborating with $\mathrm{D}$. Konitzer and $\mathrm{H}$. Fraser at the University of Illinois (Urbana-Champaign) to clarify the structures of the intermetallic compounds found in titanium-aluminum alloys. A recent notable finding was that the previously reported $\mathrm{Ti}_{2} \mathrm{Al}$ phase does not exist; but is instead a ternary phase formed on contamination with nitrogen.

9. University of Manchester -- Institute of Science Technology

A long-term study of the statistics of pit distribution and their variations with time is being carried out in the Corrosion Group in cooperation with the University of Manchester -- Institute of Science Technology (UMIST) in the United Kingdom. This program is being sponsored by the Nuclear Regulatory Commission.

10. University of Maryland

R. W. Armstrong (University of Maryland) and R. Polvani (NBS) are collaborating on a study of ignition of energetic materials. Theory can be used to show dislocation motion is a likely cause for "hot spot" formation and subsequent ignition. However, the competition between plasticity and cleavage deformation that occurs in $\mathrm{RDX}$, a typical energetic material, is a major complication for this theory. The NBS Dynamic Microindentation Instrument is a tool uniquely suited for studying the effect of load and rate on the location of the ductile-brittle transition in RDX type materials.

11. University of Virginia

A cooperative program on the electrodeposition of gallium arsenide is being undertaken between the University of Virginia Materials Science Department and the Electrodeposition Group (D. Lashmore).

12. University of Wisconsin -- Madison

J. H. Perepezko (University of Wisconsin) and W. J. Boettinger (Metallurgical Processing Group) have been collaborating on problems related to microstructure formation during rapid solidification.

Extensive experience at the University of Wisconsin on the undercooling and nucleation behavior of liquid metal droplets has been combined with NBS work on alloy growth kinetics to yield results which present a more comprehensive view of how microstructures develop in 
rapidly solidified powders and ribbons. This knowledge can be used to tailor microstructures to meet specific alloy property requirements.

13. Vanderbilt University

A cooperative program on corrosion of amorphous alloys is being undertaken. 
TECHNICAL/PROFESSIONAL COMMITTEE LEADERSHIP ACTIVITIES

American Association for Crystal Growth

S. R. Coriell, Executive Committee

American Electroplaters Society

Alloy Deposition Handbook

D. S. Lashmore, Editor

American Institute of Mining, Metallurgical and Petroleum Engineers

The Metallurgical Society

R. Ricker, Committee on Corrosion and Environmental Effects

American Society for Metals

L. H. Bennett, Editor, "Resonance Techniques," The Metals Handbook: Materials Characterization, Volume 10

NDT Committee

H. N. G. Wadley

Subcommittee on Metallurgical Reactions and Electromigration in Electronic Devices

C. A. Handwerker, Chairman

Washington, DC Chapter

P. J. Blau, Chairman

A. W. Ruff, Chairman, Program Committee

American Society for Testing and Materials

B7: Light Metals and Alloys; Aluminum Alloy Ingots and Castings

B7.07.09: Conversion Coatings on Aluminum

D. S. Lashmore, Chairman

B8: $\quad$ Electrodeposited Coatings

B8.01: Terminology, Editing Public Relations and Metrication

WG.05: D. S. Lashmore, Metrication Chairman

B8.06: Chemical Conversion Coatings

D. S. Lashmore, Subcommittee Chairman

B8.10.03: General Test Methods for Microhardness

C. E. Johnson, Liaison to E04

E3: Chemical Analysis of Metals

E3.07: Acoustic Emission

R. C. Clough

E7: $\quad$ Nondestructive Testing

Joint Task Group on Acoustic Emission; System Calibration

J. A. Simmons, Chairman 


\begin{tabular}{|c|c|}
\hline E24.05: & $\begin{array}{l}\text { Fracture Testing } \\
\text { C. G. Interrante, Member of Executive Committee } \\
\text { Terminology for Fracture Testing } \\
\text { C. G. Interrante, Co-Chairman }\end{array}$ \\
\hline $\begin{array}{l}\text { E38: } \\
\text { E38.02: }\end{array}$ & $\begin{array}{l}\text { Resource Recovery } \\
\text { J. G. Early, Executive Committee } \\
\text { Metals Resource Recovery } \\
\text { J. G. Early, Chairman }\end{array}$ \\
\hline $\begin{array}{l}\text { F4: } \\
\text { F4.G1: }\end{array}$ & $\begin{array}{l}\text { Medical and Surgical Materials and Devices } \\
\text { Joint Section on Corrosion of Implants } \\
\text { A. C. Fraker, Co-Chairperson }\end{array}$ \\
\hline $\begin{array}{l}\text { F7: } \\
\text { F7. } 04:\end{array}$ & $\begin{array}{l}\text { Aerospace Industry Methods } \\
\text { Hydrogen Embrittlement Testing } \\
\text { C. G. Interrante, Chairman, Task Group on Terminology }\end{array}$ \\
\hline $\begin{array}{l}\text { G1: } \\
\text { G1.06: }\end{array}$ & $\begin{array}{l}\text { Corrosion of Metals } \\
\text { SCC and Corrosion Fatigue } \\
\text { R. Ricker }\end{array}$ \\
\hline G1.11: & $\begin{array}{l}\text { Electrochemical Measurements in Corrosion } \\
\text { R. Ricker }\end{array}$ \\
\hline $\begin{array}{l}\text { G2: } \\
\text { G2.2: }\end{array}$ & $\begin{array}{l}\text { Erosion and Wear } \\
\text { Solid Particle Erosion } \\
\text { A. W. Ruff, Task Group Leader }\end{array}$ \\
\hline G2.9: & $\begin{array}{l}\text { Executive Subcommittee Task Group on Operations } \\
\text { A. W. Ruff, Chairman }\end{array}$ \\
\hline G2.91: & $\begin{array}{l}\text { Terminology and Definitions } \\
\text { P. J. Blau, Chairman }\end{array}$ \\
\hline
\end{tabular}

ASTM Committee on Nondestructive Testing

L. J. Swartzendruber, Member

L. H. Bennett, Member

ASTM Coordinating Group on Terminology for Environmental Efforts

C. G. Interrante, Convener

ASTM Standing Committee on Terminology

P. J. Blau, Chairman, Terminology Coordinating Task Group on Tribology

C. G. Interrante, Technical Committee Representative

American Society of Mechanical Engineers

Tribology Division, Executive Committee

A. W. Ruff 
Electrochemical Society

Editorial Committee

U. Bertocci, Division Editor

Electrodeposition Division

D. S. Lashmore, Secretary-Treasurer

Federation of Materials Societies

S. R. Coriell, Trustee

G. M. Ugiansky, Trustee

G. M. Ugiansky, First Vice President/Treasurer

Awards Committee

G. M. Ugiansky, Chairman

Instrument Society of America

S. J. Norton, Session Organizer, 1986 Annual International Meeting

Interagency Strategic Materials Stockpile Advisory Group

J. G. Early, NBS Representative

International Advisory Committee and Program Committee for International Conference on Rapidly Quenched Metals

W. J. Boettinger, Member

International Institute for the Science of Sintering

P.W. Voorhees, Corresponding Member

International Journal of Crystal Growth

R. L. Parker, Associate Editor

International Metallographic Society

P. J. Blau, Member of Technical Committee

International Society of Electrochemistry

TC156: Corrosion of Metals

G. M. Ugiansky, Delegate

2. Stress Corrosion

G. M. Ugiansky, Delegate

TC164: Medical Testing

1. Terminology

C. G. Interrante, Delegate

Committee on Fuel Cell Materials Technology in Vehicular Propulsion U. Bertocci, Liaison Representative 
International Standards Organization

TC107: Metallic and Other Non-Organic Coatings

C. E. Johnson, Delegate

D. S. Lashmore, Delegate

2: Methods of Inspection and Coordination of Test Methods

C. E. Johnson, Delegate

D. S. Lashmore, Delegate

3: Electrodeposited Coatings and Related Finishes

C. E. Johnson, Delegate

D. S. Lashmore, Delegate

Maryland Institute of Metals

W. J. Boettinger, Executive Board Member

Materials Science and Engineering

L. H. Bennett, Associate Editor

Materials Science Division

R. Ricker, Committee on Corrosion and Environment Effects

R. Ricker, Executive Committee, Notre Dame, South Bend, IN, Chapter Student Affairs Coordinator

Mechanical Failures Prevention Group

Committee on Mechanisms of Failure

J. G. Early, Chairman

National Association of Corrosion Engineers (NACE)

E. N. Pugh, Director, ex officio, Board of Directors

E. N. Pugh, Research Committee, Chairman

R. Ricker, Reviewer, Corrosion ' 86 Symposium on New Electrochemical Techniques

R. Ricker, Reviewer for Journal: Corrosion -- The Journal of Science and Engineering

R. Ricker, Review Board for the Journal: "Materials Performance"

T.1 Corrosion Control in Petroleum Production

T.1D Corrosion Control by Chemical Treatment

R. Ricker, Unit Committee

T.1D.26 The Role of Bacteria in Corrosion

R. Ricker, Task Group

T.3 Corrosion Science and Technology Committee

T.3E R. Ricker, Unit Committee on SCC and Corrosion Fatigue

T.3L R. Ricker, Unit Committee on Electrochemical Techniques

T.3.1 Computers in Corrosion

Ann Van Orden, Vice Chairman of Task Group

G. M. Ugiansky, Director, ex officio, Board of Directors 
Government Affairs Committee

G. M. Ugiansky, Chairman

Strategic Planning Committee

G. M. Ugiansky, Chairman

1986 Conference on Magnetism and Magnetic Materials

L. H. Bennett, Member, local committee

L. H. Bennett, Local Treasurer

Office of Energy-Related Inventions, National Bureau of Standards

L. H. Bennett, Reviewer of Invention Disclosures

Read Research Conferences

Organizing Committee

D. S. Lashmore, Member

Society for Automotive Engineers

Committee on Automotive Trim

D. S. Lashmore, Invited Member

Society for Biomaterials Standards

A. C. Fraker, Chairperson, Representative

Society of Automotive Engineers/American Society of Testing and Materials Unified Numbering System for Metals and Alloys

L. H. Bennett, NBS Representative

U.S. Department of Transportation

Technical Safety Standards Committee

J. H. Smith, Secretary

Versailles Advanced Materials and Standards

Subcommittee on Wear

A. W. Ruff, U.S. Representative 



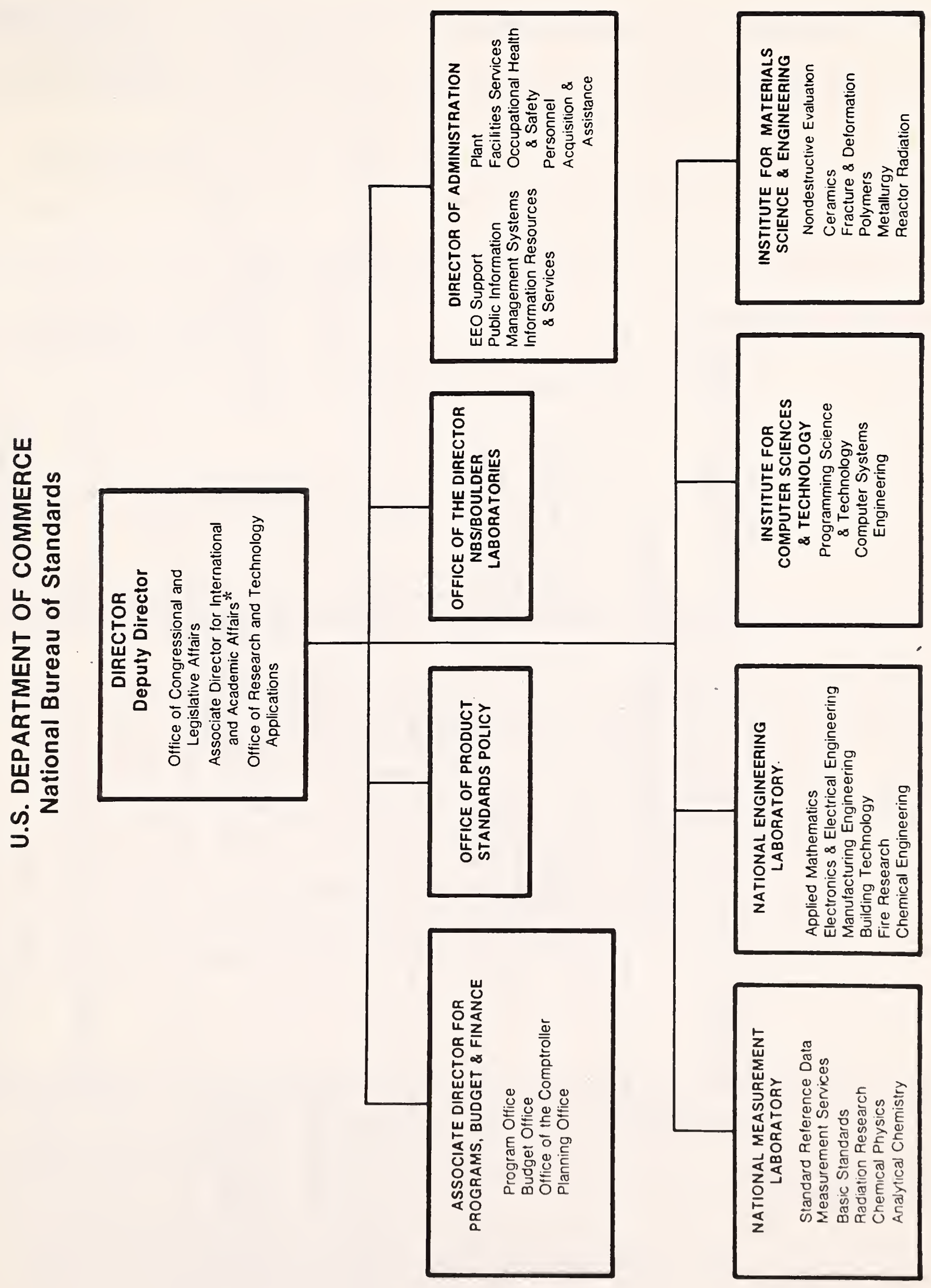




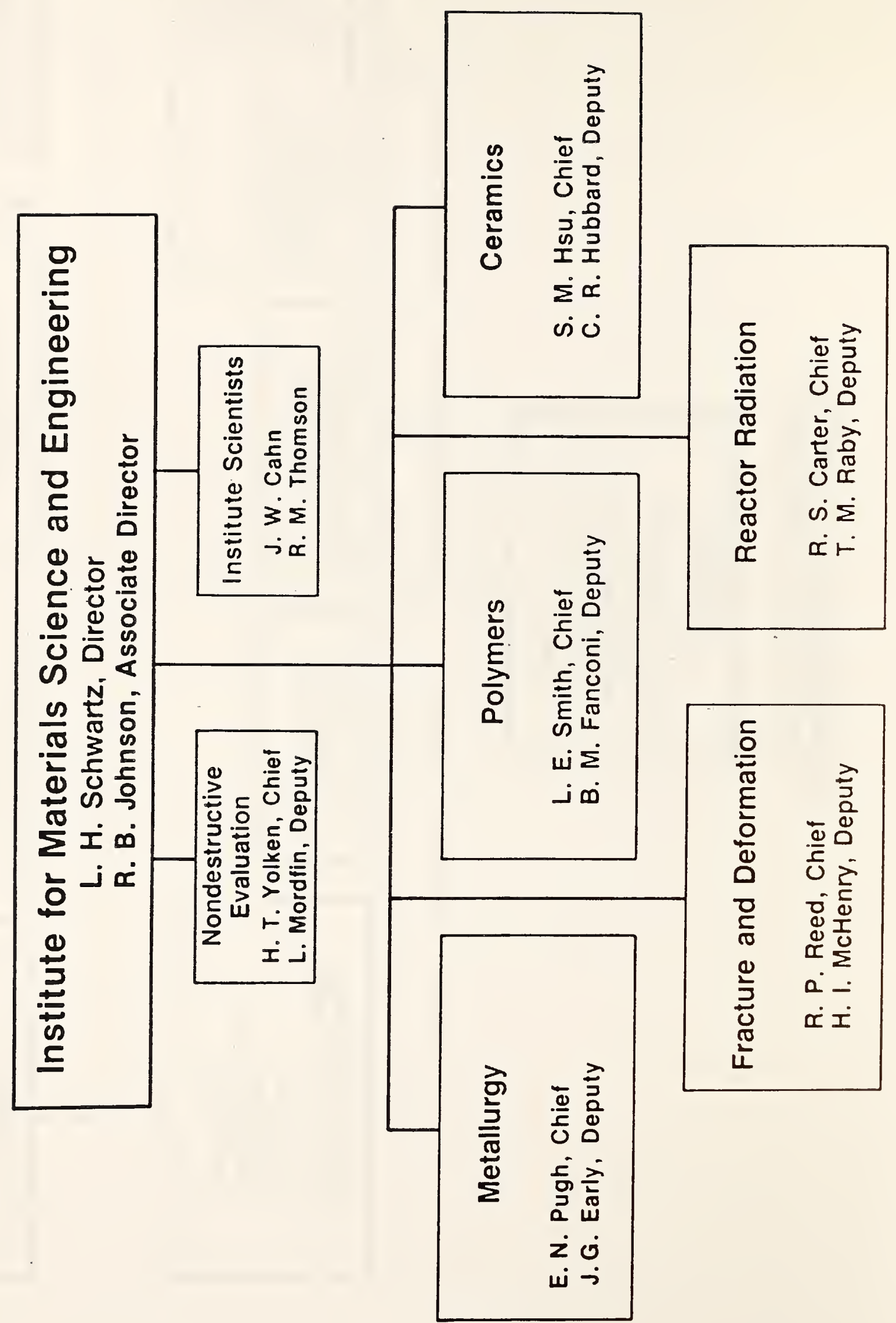


NBS-114A (REV. $2-8 C$ )

U.S. DEPT. OF COMM

BIBLIOGRAPHIC DATA

SHEET (See instructions)

1. PUBLICATION OR REPORT NO.

NBSIR 86-3438

2. Performing Organ. Report Nof 3. Publication Date

OCTOBER 1986

4. TITLE AND SUBTITLE

Metallurgy Division Annual Report 1986

NBSIR 86-3438

5. AUTHOR(S)

6. PERFORMING ORGANIZATION (If joint or other than NBS, see instructions)

7. Contracd Grant No.

NATIONAL BUREAU OF STANDARDS

DEPARTMENT OF COMMERCE

WASHINGTON, D.C. 20234

8. Type of Report \& Period Covered

9. SPONSORING ORGANIZATION NAME AND COMPLETE ADDRESS (Street, City, State, ZIP)

10. SUPPLEMENTARY NOTES

Document describes a computer program; SF-185, FiPS Software Summary, is attached.

11. ABSTRACT (A 200-word or less factual summary of most significant information. If document includes a significant bibliography or literature survey, mention it here)

This report summarizes the FY 1986 activities of the Metallurgy Division of the National Bureau of Standards. The research centers upon the structure-processingproperties relations of metals and alloys, and on the methods of their measurement. Efforts comprise studies of synchrotron radiation research for materials characterization, metallurgical processing, wear and mechanical properties, chemical metallurgy, corrosion and protection of metals, electrodeposition, nondestructive characterization, and magnetic materials. The work herein described includes three cooperative data programs with American professional societies and industry: the American Society for Metals-NBS Alloy Phase Diagram Program, the National Association of Corrosion Engineers-NBS Corrosion Data Program, and the American Iron and Steel Institute-NBS Steel Sensor Program. The scientific publications, committee participation, and other professional interactions of the 86 .full-time and part-time members of the Metallurgy Division and its 70 guest researchers are identified.

12. KEY WORDS (Six to twelve entries: alphabetical order; capitalize only proper names; and separate key words by semicolons) Annual report; industrial interactions; Metallurgy Division; metals; publications; technical activities.

13. AVAILABILITY

$x$ Unlimited

For Official Distribution. Do Not Release to NTIS

Order From Superintendent of Documents, U.S. Government Printing Office, Washington. D.C. 20402.

14. NO. OF

PRINTED PAGES

Order From National Technical information Service (NTIS), Springfield, VA. 2216i

104

15. Price

$\$ 16.95$ 


